Portland State University

PDXScholar

Winter 3-1-2013

\title{
First Bacterial Endosymbionts Found in the Phylum Ascomycota
}

Eileen Elizabeth Fitzpatrick

Portland State University

Follow this and additional works at: https://pdxscholar.library.pdx.edu/open_access_etds

Part of the Biology Commons, and the Other Plant Sciences Commons Let us know how access to this document benefits you.

\section{Recommended Citation}

Fitzpatrick, Eileen Elizabeth, "First Bacterial Endosymbionts Found in the Phylum Ascomycota" (2013). Dissertations and Theses. Paper 675.

https://doi.org/10.15760/etd.675

This Thesis is brought to you for free and open access. It has been accepted for inclusion in Dissertations and Theses by an authorized administrator of PDXScholar. Please contact us if we can make this document more accessible: pdxscholar@pdx.edu. 
First Bacterial Endosymbionts Found in the Phylum Ascomycota.

\author{
by \\ Eileen Elizabeth Fitzpatrick
}

A thesis submitted in partial fulfillment of the requirements for the degree of

Master of Science

in

Biology

Thesis Committee:

Kenneth Stedman, Chair

Martin Fisk

Dirk Iwata-Reuyl

Radu Popa

Portland State University

2013 


\begin{abstract}
Organisms belonging to the Kingdom Fungi are known to occupy a wide variety of ecological niches and are found globally in virtually all environments. Two members of the smallest of the fungal phylum, the Zygomycota, have also been found to harbor intercellular bacteria initially described as being from or closely related to organisms from the Genus Burkholderia. In this study two microaerophilic members of the species Verticilium from the phyla Ascomycota were characterized. Both appear to carry two bacterial endosymbionts. This is the first evidence of bacterial endosymbionts found within a member of the Ascomycota. Through the use of fluorescent stains, isolation of the intercellular bacteria, DNA analysis and fluorescent in situ hybridization (FISH) it appears that the newly isolated Verticilium sp. fungi contain not one but two bacterial endosymbionts from the family Proteobacteria. One putative symbiont is from the genus Bradyrhizobium, a member of the $\alpha$-Proteobacteria, and one from the genus Burkholderia, a member of the $\beta$-Proteobacteria. This is the first evidence of a fungus containing not one, but two distinct endosymbionts from two separate bacterial families. Additionally the fungi were found to grow from spore across a large $\mathrm{pH}$ gradient ( $\mathrm{pH} 1.2$ to $\mathrm{pH} 13.5)$ and in conditions lacking given nutrient. They were tolerant of concentrations of $\mathrm{Fe}$ (II) up to $50 \mathrm{mM}$ and grew better with low oxygen levels (1.6\%) than without.
\end{abstract}




\section{Dedication}

This work is dedicated to my father, Dr. Joseph Ferris Fitzpatrick, Jr., who shared his love of science with me and always encouraged me to ask questions. 


\section{Acknowledgements}

I would like to acknowledge my advisor Dr. Radu Popa whose patience and encouragement was integral to the success of this work. I would also like to give a large thanks to Dr. Kenneth Stedman who stepped up from committee member to committee chair when times got tough and spent untold hours helping to mold this thesis into its final form. I would also like to thank my committee members Dr. Martin Fisk and Dr. Dirk Iwata-Reuyl without whom this work would not have been possible. To all of my lab mates Amy Smith, Manar Alattar, Tara Chestnut and Wen Fang who just listened when it was needed, encouraged when things got rough and helped to keep perspective at all times. All of the undergraduates and volunteers who helped in the lab: Susan Holmes, Burton Parks, Dania Yousef, Krista Cobb, Hung Ma, Carissa Bishop, and Mick Dolsen. And last but not least, my friends and family: Michele Thompson, Samantha Chess, Christina Flinn, Jimmy Radney, Brit Anderson, Joseph Fitzpatrick, Deanna Fitzpatrick, Kathleen Fitzpatrick, Leigh Fitzpatrick, Daniel Fitzpatrick and Twyla Estes who all sat through endless soliloquies about fungus, iron and bacteria without falling asleep and still managing to say "wow" at all the appropriate places. Thank you all. 


\section{TABLE OF CONTENTS}

$\begin{array}{lc}\text { ABSTRACT } & \mathrm{i} \\ \text { DEDICATION } & \mathrm{ii} \\ \text { ACKNOWLEDGEMENTS } & \mathrm{iii} \\ \text { LIST OF TABLES } & \text { vi } \\ \text { LIST OF FIGURES } & \text { vii }\end{array}$

Chapter 1: Introduction

Overview 1

General Approach 2

General Hypotheses $\quad 4$

Chapter 2: Review of Literature

$\mathrm{Fe}(\mathrm{II})$ in the Environment 5

Fe(II) Oxidation 5

Bacterial Oxidation of Fe(II) 6

Microbial Degradation of Glass and Iron Containing Minerals 6

Low Molecular Weight Organic Acids (LMWOA) as Fungal Exudates 8

Endosymbionts 9

Burkholderia 11

Bradyrhizobium 12

Chapter 3: Fungal Isolation and Metabolism Results and Discussion

$\begin{array}{ll}\text { Plating and Microscopy } & 14\end{array}$

$\begin{array}{lr}\text { Sequencing and Phylogeny } & 16\end{array}$

$\begin{array}{ll}\mathrm{pH} \text { Tolerance } & 16\end{array}$

Growth on Borosilicate Glass $\quad 19$

LMWOA Fungal Exudates $\quad 21$

$\mathrm{Fe}(\mathrm{II}) / \mathrm{Fe}(\mathrm{III})$ Utilization $\quad 26$

Chapter 4: Intercellular staining, antibiotic treatment and isolation in culture of putative bacterial endosymbionts

Introduction $\quad 30$

$\begin{array}{ll}\text { Nucleic acid staining } & 31\end{array}$

Antibiotic Treatment 33

$\begin{array}{ll}\text { Bacterial Endosymbiont Isolation } & 37\end{array}$

PCR of Bacterial Isolates and in situ Bacteria from Fungal gDNA 38

Fluorescent in situ Hybridization $\quad 40$

Chapter 5: Characterization of isolated Bradyrhizobium strains 
Chapter 6: Conclusion

Conclusions and Future Work

$\begin{array}{ll}\text { Formulae } & 68\end{array}$

$\begin{array}{ll}\text { References } & 69\end{array}$

Appendix A: Bacterial 16s and Fungal 18s Sequences $\quad 77$

Appendix B: Bacterial Counts After Antibiotic Exposure per Fungal Cell $\quad 80$

Appendix C: HPLC and GC Raw Data and Example Data Plot 84

Appendix D: Phospholipid Phosphate Spectrophotometer Data 90 


\section{List of Tables}

Table 1 Growth at low $\mathrm{pH}$ of fungal isolates and final $\mathrm{pH}$ readings in media amended with varying volumes of concentrated $\mathrm{HCl}$.

Table 2 Fungal growth from spore seen in test tubes incubated with varying volumes of antibiotics.

Table $3 \quad$ Fungal PCR Primers $\quad 59$

$\begin{array}{lll}\text { Table } 4 & \text { Bacterial PCR Primers } & 60\end{array}$

Table 5 v/v deionized formamide used in FISH protocol with corresponding 64 $\mathrm{NaCl}$ concentration used in the washing buffer 


\section{List of Figures}

Figure 1. Species of $\mathrm{Fe}(\mathrm{II})$ present in an aqueous environment, by

concentration, along the $\mathrm{pH}$ gradient in the presence of $\mathrm{CO}_{2}$.

Figure 2. Color image of an Asp01 mycelium grown on a low-nutrient agarose plate.

Figure 3. Color image of Ver01 mycelium grown on low-nutrient agarose plates embedded with olivine sand.

Figure 4. Optical micrograph of Ver01 hyphae grown at $\mathrm{pH} 2.4$ without $\mathrm{Fe}(\mathrm{II})$.

Figure 5. Optical micrograph of Asp01 hyphae grown on a glass slide with acidic liquid media and without Fe(II).

Figure 6. Color image of Ver01 grown in 1/10 diluted Luria broth soft agar stabs.

Figure 7. Molecular Phylogenetic analyses of fungal isolates by Maximum Likelihood.

Figure 8. Trends in the concentration of oxalate and acetate $(\mathrm{mM})$ in nutrient free media containing isolate Ver01as determined by HPLC.

Figure 9 The evolution of organic acids in media inoculated with Ver01 as determined by GC.

Figure 10. Organic acids detected after four days in low nutrient glucose media with Ver01 both with and without tetracycline.

Figure 11. Phospholipid phosphate produced by Ver01 in varying oxygen concentrations both with and without $\mathrm{Fe}(\mathrm{II})$ as $\mathrm{Fe}(\mathrm{II}) \mathrm{SO}_{4}$.

Figure 12. Phospholipid phosphate produced by Ver01 in varying oxygen concentrations both with and without $\mathrm{Fe}(\mathrm{III})$ as $\mathrm{FeCl}_{3}$.

Figure 13. Hyphae of $V$. sp. Ver01 grown in acidic liquid media without Fe(II) stained with Acridine orange.

Figure 14. Ver01 grown in acidic liquid media with $50 \mathrm{mM} \mathrm{Fe(II)} \mathrm{stained} \mathrm{with}$ Invitrogen's BacLight Live Dead bacterial stain. 
Figure 15. Fluorescent micrograph of hyphae of $V$. sp. Ver01 grown in acidic liquid media without $\mathrm{Fe}(\mathrm{II})$ and stained with DAPI.

Figure 16. The percentage of fungal cells with and without putative endosymbionts after treatment with antibiotics.

Figure 17. Mixed bacterial cultures from the Asp01 hyphae.

Figure 18. PCR product from fungal gDNA culture using generic bacterial 16s primers 8F/1391R.

Figure 19. Molecular Phylogenetic analysis by Maximum Likelihood of bacteria Burkholderia sp. and Bradyrhizobium sp..

Figure 20. $\quad V$. spAsp01 hybridized with florescent fungal probe VERT164 and fluorescent generic bacterial probe NON338.

Figure 21. $\quad V$. sp Ver01 hybridized with florescent fungal probe VERT164 and fluorescent generic bacterial probe NON338.

Figure 22. $\quad V$. sp. Ver01 hyphae hybridized with specific bacterial probes BURK8 and BRAD865.

Figure 23. Bradyrhizobium isolate growing in 1/10 diluted LB agar with resazurin redox indicator.

Figure 24. Bradyrhizobium isolate grown in $1.6 \%$ oxygen with varying concentrations of ASP provided as an energy source.

Figure 25. Growth seen in varying $\mathrm{mM}$ concentrations of ASP (30 mM to $1.875 \mathrm{mM}$ ) at $1.6 \% \mathrm{O}_{2}$. 


\section{Chapter 1}

\section{Introduction}

\section{Overview}

Organisms belonging to the Kingdom Fungi are known to occupy a wide variety of ecological niches and are found globally in virtually all environments [1]. Fungi play an important role in the global nutrient cycle where, due to their osmotrophic nutritive style, they act as primary degraders $[1,2]$. It has been estimated that over $90 \%$ of all land plants live in symbiosis with at least one mycorrhizal fungus and it has been demonstrated that the fungi in these symbioses are crucial for both plant growth and development $[1,3]$.

The Kingdom Fungi is composed of seven phyla: Microsporidia, Chytridiomycota, Blastocladiomycota, Neocallimastigomycota, Glomeromycota (Zygomycota), and in the subkingdom Dikarya, Ascomycota, and Basidiomycota [4]. Of these seven phyla the phylum Ascomycota is the largest and is composed of over 64,000 known species. As a phylum, the Ascomycota are known for their involvement in symbiotic relationships. It has been estimated that over $40 \%$ of currently named species within the Ascomycota are lichonized, living in association with a photosynthetic (photobiont) partner which can be either an algae or cyanobacterium $[1,5]$.

The Glomeromycota (Zygomycota) are also known for their formation of symbiotic relationships and it is within this phylum that the arbuscular mycorrhizal fungi are found [6]. Two members of the phyla Zygomycota, Gigaspora margarita and Rhizopus microsporus, have also been found to harbor intercellular bacteria initially described as being from or closely related to the Genus Burkholderia [7, 8]. 
The majority of this thesis is dedicated to possible bacterial endosymbionts in two members of the fungal species Verticilium from the phyla Ascomycota. These would be the first bacterial endosymbionts found within a member of this phylum. Through the use of fluorescent stains, isolation of the intercellular bacteria, DNA identifications and fluorescent in situ hybridization (FISH), I demonstrate that these novel fungal isolates contain two bacterial endosymbionts from the family Proteobacteria. I also show that one symbiont is from the genus Bradyrhizobium, a member of the $\alpha$-Proteobacteria, and one symbiont from the genus Burkholderia, a member of the $\beta$-Proteobacteria. This is the first evidence of a fungus containing two distinct bacterial endosymbionts.

Additional work was performed to demonstrate possible advantages granted by the endosymbionts in regards to fungal growth. Moreover, some of the growth parameters of the fungus were determined.

\section{General Approach}

Two fungal lab isolates were found growing in a low $\mathrm{pH}$ nutrient free liquid being used to clean lab glassware and designated Ver01 and Asp01. Both were found to have small, fast moving bodies that were located within their hyphael cells. These bodies appeared to not only occupy normal fungal hyphael cells but to also occupy what appeared to be specialized percurrent growth (normal fungal hyphael cells surrounded by a second cellular membrane which creates an extracellular but still membrane enclosed space) and vacuoles spaced at intervals along the fungal hyphae [9]. Given the work showing that bacterial endosymbionts are present in the cells of at least two fungi from other phyla and knowing that fungi are directly involved in ectosymbiotic relationships, attempts were undertaken to determine if these intercellular bodies were bacteria $[3,7,8]$. 
Fungal growth and phylogenetic relationships were determined. Classification of the fungi was performed using polymerase chain reactions (PCR) to amplify its $18 \mathrm{~S}$ ribosomal ribonucleic acid (rRNA) gene from genomic deoxyribonucleic acid (gDNA) extracted from fungi grown in liquid media inoculated from isolated colonies. The amplicons where then sequenced and the sequence similarity established by searching the GenBank database. Sequences similar to those of the isolates were then selected from the GenBank database and a phylogenetic tree constructed using those sequences. The tolerance of the fungi to variances in $\mathrm{pH}$ was established, as well as its basic nutritional requirements. The availability of micronutrients, specifically $\mathrm{Fe}(\mathrm{II})$, and their contribution to fungal growth was examined in an attempt to separate fungal metabolic capacities from those of the putative endobacterium. Low molecular weight organic acid (LMWOA) fungal exudates were also characterized in fungus grown with and without antibiotics. This was done to examine how the fungi might be extracting micronutrients from its environment and if the presence of the endobacterium impacted the levels or composition of the exudates.

Isolation and preliminary characterization of the intercellular bodies was attempted and the bacteria obtained from these isolations were classified using PCR to amplify the 16S rRNA gene from the extracted gDNA, sequencing the resultant PCR amplicons and a BLAST search performed to find homology in the GenBank database. PCR was also performed on fungal gDNA using generic bacterial 16S rRNA primers in an attempt to ascertain if other bacteria might also be present within the fungal hyphae. The resultant amplicons were then sequenced, the sequences BLAST searched for homology in the Genbank database and phylogenetic trees constructed from the 
sequences given by the database. Basic nutrient requirements were characterized for the isolated bacteria and growth rates with different organic carbon sources were deternined.

Intracellular location and viability of putative endosymbionts was determined by fluorescent staining. The fungus and the intercellular bodies were stained with Acridine orange $(\mathrm{AO})$, Life technologies LIVE/DEAD ${ }^{\circledR}$ BacLight ${ }^{\mathrm{TM}}$ Bacterial Viability Kit, and 4',6-diamidino-2-phenylindole (DAPI) was used to identify the position and composition of the intercellular bodies in relation to fungal cellular components. The same staining was performed on the bacterial isolate with the addition of Gram staining to identify cell membrane structure. The fungal spores and hyphae were also stained with Trypan blue to identify their structures. FISH was performed using specific fungal 18S rRNA probes and both generic and specific bacterial 16S rRNA probes to demonstrate definitively the location of the two possible bacterial endosymbionts in regards to the fungal hyphael cells.

\section{General hypotheses}

Three major hypotheses were established regarding the isolates Ver01 and Asp01 and the small motile intercellular bodies.

Hypothesis 1 . The small intercellular bodies are bacterial endosymbionts.

Hypothesis 2. The fungi degrade borosilicate lab glassware using low molecular weight organic acids (LMWOA) to extract the mineral micronutrients therein.

Hypothesis 3 . The putative bacterial endosymbionts contribute to the ability of the fungus to survive and grow in nutrient-free and low nutrient media by the metabolizing $\mathrm{Fe}(\mathrm{II})$ extracted by the fungi from the borosilicate lab glass. 


\section{Chapter 2}

\section{Review of Literature}

\section{Fe (II) in the Environment}

$\mathrm{Fe}(\mathrm{II})$ in natural environments is subject to abiotic chemical oxidation by oxygen and $\mathrm{Mn}(\mathrm{IV})$ oxides at circumneutral $\mathrm{pH}$ [10-12]. In silicates rich in $\mathrm{Fe}(\mathrm{II})$, such as olivine, the $\mathrm{Fe}$ (II) is protected from this chemical oxidation by a thin layer of $\mathrm{Fe}(\mathrm{III})$ oxides on the outer surface of the material. But even under optimal conditions all $\mathrm{Fe}(\mathrm{II})$ exposed to atmosphere will eventually become Fe(III) oxides [11, 13-15] (Fig. 1).

\section{Fe (II) Oxidation}

Fe(II) oxidation yields little

energy for growth

thermodynamically when compared

to other lithotrophic energy sources,

hence chemolithoautotrophic iron

oxidizers generally have a slow

growth rate when compared to other

lithotrophic bacteria [16]. While iron

oxidation is favorable at both neutral

and acidic conditions, more energy is

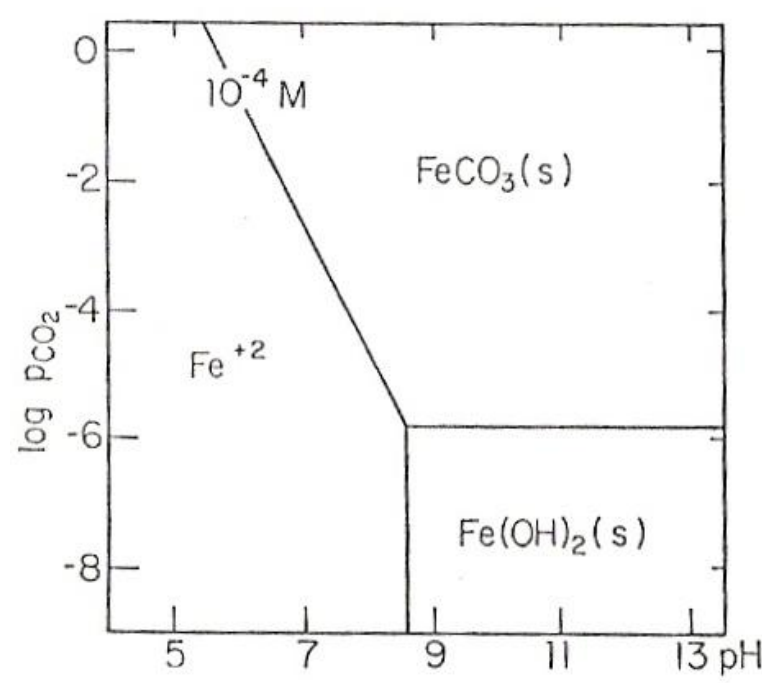

Figure 1. Species of Fe(II) present in an aqueous environment, by concentration, along the $\mathrm{pH}$ gradient in the presence of $\mathrm{CO}_{2}$. Adapted from "Aquatic Chemistry: An Introduction Emphasizing Chemical Equilibria in Natural Waters."(pg. 186) by W. Stumm and J.J. Morgan, 1970, New York City, WileyInterscience.

yielded by this reaction at neutral $\mathrm{pH}$ [17].

The redox potential $\left(E_{\mathrm{o}}{ }^{\prime}\right)$ of the $\mathrm{Fe}^{3+} / \mathrm{Fe}^{2+}$ couple is $\mathrm{pH}$-dependent and becomes more positive in acidic conditions, so iron oxidation is more exergonic at neutral $\mathrm{pH}$ than at acidic $\mathrm{pH}[17,18]$. At $\mathrm{pH} 2$ the standard redox potential of $\mathrm{Fe}^{3+} / \mathrm{Fe}^{2+}$ is $+0.77 \mathrm{~V}$ 
$\left(\Delta G_{\mathrm{o}}{ }^{\prime}=-8.7 \mathrm{~kJ}\right.$ per mole Fe $)$, while at $\mathrm{pH} 7$ it is only $+0.20 \mathrm{~V}\left(\Delta G_{\mathrm{o}}{ }^{\prime}=-63.7 \mathrm{~kJ}\right.$ per mole $\mathrm{Fe})$ [17]. At $\mathrm{pH} 7$ and in the presence of $\mathrm{CO}_{2}$ and $\mathrm{HCO}^{3-}, \mathrm{Fe}^{2+}$ is primarily in the form of $\mathrm{FeCO}_{3}$, with a redox potential of $+0.1 \mathrm{~V}$ [19]. The complete oxidation of 1 mole of $\mathrm{Fe}^{2+}$ to $\mathrm{Fe}^{3+} \mathrm{OOH}$ or $\mathrm{Fe}^{3+}(\mathrm{OH})_{3}$ at $\mathrm{pH} 7$ yields 2 moles of $\mathrm{H}^{+}[20]$. Under acidic conditions, it is estimated that 120 moles of $\mathrm{Fe}^{2+}$ are needed to synthesize one mole of glucose, therefore massive amounts of $\mathrm{Fe}^{2+}$ must be utilized for growth [21, 22].

\section{Bacterial Oxidation of Fe (II)}

Iron oxidizing bacteria are common in nature. They can be found in anaerobic and aerobic environments, in both fresh and salt water, across a large gradient of temperatures and from acidic to neutral $\mathrm{pH}$ 's $[16,21]$. Iron oxidizers can be autotrophic or heterotrophic, and some are even phototrophic [21].

Iron oxidizing bacteria have been described in a variety of phylogroups from both the bacteria and archaea. Iron oxidizers are found in the archaeal genera Ferroplasma and Ferroglobus, and the bacterial genera Acidothiobacillus, Acidovorax, Gallionella, Leptospirillum, Leptothrix, Marinobacter, Mariprofundus, Pseudomonas, Sideroxydans, and Sphaerotilus. Several newly described iron oxidizers come from the phylum Proteobacteria and include bacteria from the classes $\alpha$-, $\gamma$ - and $\delta$-Proteobacteria. These bacteria are not similar to any previously known neutrophilic iron oxidizers [16, 20, 23]. Since Fe(II) is more stable at low pH's and at oxygen concentrations below atmospheric levels, iron oxidizers are often tolerant of acidic or microaerophilic conditions [16].

\section{Microbial Degradation of Glass and Iron Containing Minerals}

The microbial degradation of silicates is a well documented phenomenon that impacts both natural occurring silica-based minerals such as quartz as well as man-made 
silica-based composites such as sodium borosilicate glasses [24-27]. Minerals which contain iron such as olivine $\left((\mathrm{Mg}, \mathrm{Fe})_{2} \mathrm{SiO}_{4}\right)$, and biotite $\left(\mathrm{K}(\mathrm{Mg}, \mathrm{Fe})_{3} \mathrm{AlSi}_{3} \mathrm{O}_{10}(\mathrm{~F}, \mathrm{OH})_{2}\right)$ are also subject to microbial bio-weathering as are composites of minerals that contain iron, such as granite [28-30]. The microbial communities involved in bio-weathering have been found to consist of a diverse mix of organisms that can include bacteria, algae, fungi and in aquatic communities, diatomaceous algae [26, 29]. In one microbial community that was involved in the bio-weathering of a Medieval stained glass window over 100 separate micro-organisms were isolated from a single crust [31].

The colonization of both historic glass and naturally occurring minerals by these microbial communities has been directly linked to the mineral composition and in some cases with the presence of iron [27, 30]. The bio-weathering of these materials is accomplished by the microorganisms involved using two predominate strategies, chemical dissimilation and physical degradation. Some microbial communities cause the breakdown and dissolution of glass and minerals by the excretion of chemicals capable of etching these materials [26, 29]. This activity can be used alone, where it causes the formation of small depressions in the material which represent the footprint of the microbe performing the dissolution or, in the case of fungi, coupled with a physical exploitation of possible micro-fractures present in the material being attacked $[25,29$, 32]. The exploitation of micro-fractures causes a significantly larger amount of damage than the simple chemical etching of the material and can lead to exfoliation and incavation of the materials $[26,29]$.

Fungi are known to be involved in the colonization and degradation of medieval stained glass windows and other historical glass [24, 27, 33, 34]. The bio-weathering of 
this glass by fungi and other microbiota results in fissures and pits in the glass and the accumulation of crusts on the glass composed, in part, of Fe (III) oxides [27]. This precipitation of iron is also observed surrounding fungal colonies on other mineral bearing rocks, such as granite [28]. Fungi have also been found to preferentially colonize iron rich minerals in volcanic soils though they will colonize other materials including glass and K-feldspar [30]. When observed via electron microscopy ferromagnetic minerals colonized by fungi display the same patterns associated with mineral disassociation seen in the bacterial bio-weathering of similar materials [26]. Fungi are also capable of producing high-affinity iron permeases and it has been demonstrated that the presence of additional iron can facilitate fungal growth and spore survival rates in some species [30, 35-37]. This indicates that fungi have the capacity to both weather glass and extract the iron present there.

\section{Low Molecular Weight Organic Acids (LMWOA) as Fungal Exudates}

Fungi act as primary decomposers in many eco-systems [1]. They perform this function, in part, by excreting low molecular weight organic acids (LMWOA) such as oxalate and malate [38-40]. In mycorrhizal fungi these acidic exudates are thought to be responsible, to a certain extent, for the ability of the fungal hyphae to penetrate the root systems of the targeted plants [41]. They are also produced by mycorrhizal fungi that are in associations with plants in response to nutrient deficiencies in the local environment $[40,42]$. In this instance, the LMWOA act to breakdown the non-crystalline minerals in the surrounding soil rendering them bio-available for use by both the fungus and the plant. 
Many fungi also produce LMWOA in response to exposure to elevated levels of heavy metals, such as copper, zinc and cadmium [39, 43, 44]. One of the primary acids produced in these instances is oxalate but other LMWOA exudates can also be produced including EDTA, citrate and tartrate [38, 44-47]. These acids not only breakdown certain minerals in the environment surrounding the fungi, as in the case of oxalate but can also act as a ligands for many heavy metal ions, forming complexes with a high stability in solution [47-49]. The formation of these complexes can have many effects. They can cause the targeted metal ions to precipitate out of solution. They can cause the accumulation of the ligand-ion complex onto the fungal hyphae in an inert form. Finally, they can simply render the heavy metal ions biologically inert by stabilizing them in solution $[13,46]$.

The LMWOA can also act to push the equilibrium of certain metal ions towards a more biologically advantageous form, as in the case of $\mathrm{Fe}^{2+} / \mathrm{Fe}^{3+}$. The oxalate released in solution by the fungi causes a drop in the $\mathrm{pH}$ in proximity to the fungal hyphae as well as acting as a ligand for the $\mathrm{Fe} 3+$ in solution forming $\mathrm{C}_{6} \mathrm{Fe}_{2} \mathrm{O}_{12}\left(2 \mathrm{Fe}^{3+}+3\right.$ Oxalate). The reduction in $\mathrm{pH}$ allows for the natural oxidation of the iron in the complex to $\mathrm{Fe}^{2+}$ which is then released in solution where it remains stable and available for absorption by the fungi $[48,49]$.

\section{Endosymbionts}

Symbiotic relationships show a great amount of diversity in both the organisms involved and the functional nature of the relationship. Symbiotic relationships can occur between two eukaryotic organisms, as happens between mycorrhizal fungi

(Glomeromycota) and their host plants, or a fungus, primarily Ascomycota but other 
phyla as well, and an alga in lichonized relationships $[6,50]$. They can also take place between a prokaryote and a eukaryote. Some of the best characterized relationships of this type are those between bacteria and insects but eukaryotes in symbiotic relationships with bacteria have also been documented in protists, fungi, sponges and plants [51-57]. Perhaps the oldest and best known symbiotic relationship however, is the one that occurs between the mitochondrion, an apparent descendant of an $\alpha$-Proteobacterium, and eukaryotic cells $[51,58,59]$. This relationship is an example of a heritable symbiosis, where the symbiont is transferred vertically from parent to offspring and is also an example of an obligate association, where both symbiont and host are reliant upon the relationship to survive [52].

Not all symbiotic relationships are obligate or vertically transmitted however. It is possible for symbiotic relationships to be non-obligate, meaning that the host, the symbiont, or both, are capable of being free-living organisms. This is the case in the symbiosis that forms between Bradyrhizobium, a nodule forming, nitrogen-fixing soil bacteria and plants where both organisms are capable of living without the other [60, 61]. This relationship is also an example of a horizontal transmission strategy, where the seeds of host plants do not carry the Bradyrhizobium symbiont but infection with the bacteria occurs after root formation by the seedling $[62,63]$. Even if there is an obligate relationship between host and symbiont horizontal transmission can still be the mode of infection, as with $R$. microsporus and its symbionts, Burkholderia rhizoxinica or Burkholderia endofungorum, whose presence is necessary for vegetative reproduction in R. microsporus $[64,65]$. 
Bacterial and fungal endosymbionts carry out diverse roles for the organisms with which they are in symbiosis. Bacterial endosymbionts in insects, for instance, are known to supplement some host insects' diets by producing additional vitamins when the host's primary food source (examples: blood, sap or cereal grains) is lacking in key nutritional elements $[66,67]$. Mycorrhizal fungi have also been shown to excrete LMWOA in response to mineral nutrient deficiencies in the soil around the plants they infect, causing the breakdown of non-crystalline metal containing minerals to render the metal ions found in them bio-available for use by the plant and fungus [40]. In R. microsporus, its symbionts, B. rhizoxinica or B. endofungorum, excrete a hepatotoxin that is then excreted by the fungus into the environment surrounding the hyphae [64].

Another characteristic found among obligate endosymbionts is the reduction of their genomes in size and in functional genes [67-70]. For example, the endosymbiotic bacteria G. margarita was found to carry the smallest known genome in a $\beta$ -

Proteobacteria at only $1.4 \mathrm{Mb}$ [71]. This small genome size is not uncommon in obligate intercellular bacterium which are known to shed extranious genes from their genomes $[59,67,69,71,72]$. This reduction in genome size points to the fact that this could be an ancient obligate endocellular relationship [71]. Based upon the completed 16S rRNA sequencing the endosymbiont of G. margarita has been placed into a new taxon and renamed Candidatus Glomeribacter gigasporarum' gen. nov., sp. nov. [71, 73].

\section{Burkholderia}

The genus Burkholderia is composed of over 71 named species that can be found in a wide variety of ecological niches [74-76]. The Burkholderia are Gram-negative, motile, obligately aerobic, rod-shaped bacteria belonging to the family $\beta$-Proteobacteria 
that are found endemically in soil and fresh water [77]. As a genus they are known for their ability to utilize a diverse and large number of organic compounds as carbon and energy sources including, among others, 2,4,5-Trichlorophenoxyacetic acid, one of the primary defoliants used in Agent orange [77, 78]. Burkholderia are also well known as symbionts and have been found as both endo and ectosymbionts in plants, fungi and insects [79-81].

Some strains of Burkholderia are also known pathogens in humans, animals and plants $[75,82,83]$. Burkholderia mallei, as an example, is the causative agent in glanders, a disease of horses, donkeys and mules that can be zoonotic [84]. Because many of the bacteria within this species are known to cause disease, a significant amount of research has been done into seemingly innate antibiotic resistance in the Burkholderia. It was found that many of them carry efflux pumps capable of exporting multiple types of antibiotics as well as proteases capable of degrading many others, rendering them difficult to treat with normal courses of traditional antibiotics [82, 85]

\section{Bradyrhizobium}

In 1980, the genus Bradyrhizobium was segregated from the genus Rhizobium, a group of nitrogen-fixing nodule-forming bacteria of the family $\alpha$-Proteobacteria, based upon numerous factors [60]. The name Bradyrhizobium was derived using the Rhizobium base with the prefix Brady to designate its slow growth rate in culture where it produced colonies not larger than $1 \mathrm{~mm}$ in 5-7 days on carbohydrate media [60].

Bradyrhizobium is a Gram-negative, non-spore forming, polar-flagellated, rodshaped bacteria that demonstrates morphological changes when inside a plant nodule, forming slightly swollen rods, cocci or rarely, a branching form [60]. Members of this 
genus fix atmospheric nitrogen to form either ammonia $\left(\mathrm{NH}_{3}\right)$ or ammonium $\left(\mathrm{NH}_{4}{ }^{+}\right)$for utilization by the plant which they infect generally, though not always, fixing more nitrogen than needed by the plant thereby allowing its release into the soil adding to available soil nitrogen [86]. There are only 13 species currently named within this genus and because of the lack of significant genomic difference between them multi-locus sequence analysis using several housekeeping genes (examples: atpD, recA, gyrB, rpoB, and dnaK) is used to differentiate new species $[74,87,88]$. In addition to the ability to fix nitrogen one species, Bradyrhizobium japonicum frcB, has been found to also contain a diheme ferric iron reductase similar to those found within eukaryotic cells and shown to be capable of allowing the bacteria to reduce ferric iron from the environment to ferrous iron [89]. 


\section{Chapter 3}

\section{Fungal Isolation and}

\section{Metabolism Results and}

\section{Discussion}

\section{Plating and Microscopy}

Two fungal isolates were

obtained by Dr. Radu Popa and

Susan Holmes via isolation

streaking on whey agar plates

from the liquid that was being

used to clean a piece of

borosilicate lab glassware. This

liquid was a mix of concentrated

$\mathrm{HCl}$ and $\mathrm{dd}_{2} \mathrm{O}$ and contained no

known nutrient source. The two

isolated fungi they obtained, one

white and one dark green in color,

were given the designations of

Ver01 and Asp01, respectively

(Fig. 2 and Fig. 3). The hyphae of

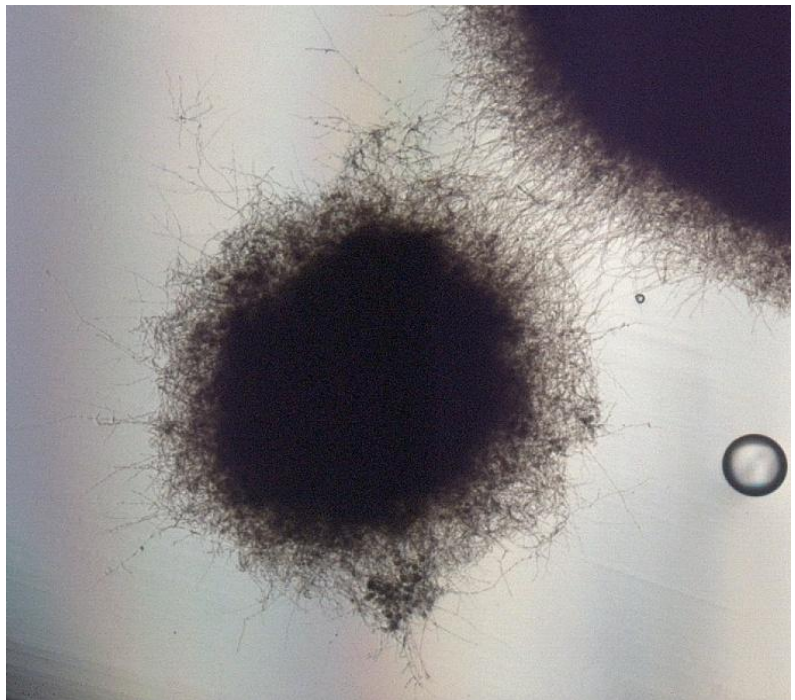

Figure 2 Color image of an Asp01 mycelium grown on a low-nutrient agarose plate. Image taken after 7 days of growth. 100X magnification.

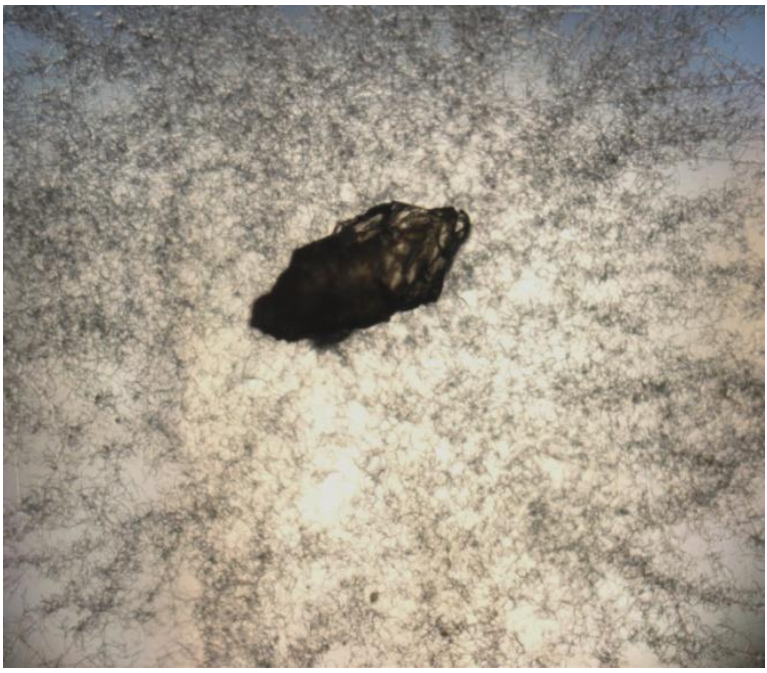

Figure 3. Color image of Ver01 mycelium grown on lownutrient agarose plates embedded with olivine sand. Large granule in the center of the image is a crystal of the olivine sand from which the hyphae have begun to extend. 100X magnification.

Ver01 had narrow cells $(\sim 1 \mu \mathrm{M})$ that were between $6-7 \mu \mathrm{M}$ in length and displayed simple lateral branching [90]. The ascocarps were sessile, pyriform in shape and inoperculate (Fig. 4). The cell membranes appeared colorless and small numbers of distinct vacuole- 
like structures could be seen at intermittent intervals along the length of the hyphae (Fig. 4). Movement of small intracellular bodies was observed within individual hyphae cells and less often within vacuoles. The hyphae of Asp01, had wider $(\sim 2-3 \mu \mathrm{M})$ cells that were between 5-6 $\mu \mathrm{m}$ in length and displayed cymose branching. The ascocarps were sessile, globose and inoperculate (Fig. 5). The cell membranes appeared green to dark green in color and distinct vacuole-like structures were abundant and spread throughout the mycelium. Movement of small intercellular bodies was also observed within hyphae cells but predominantly

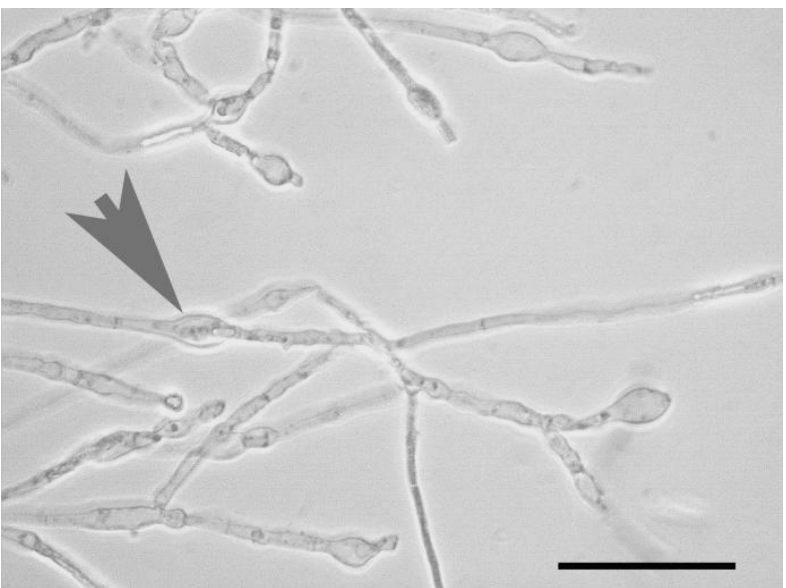

Figure 4. Optical microscopy of Ver01 hyphae grown at pH 2.4 without $\mathrm{Fe}(\mathrm{II})$, arrow indicates percurrent growth commonly found in the hyphae of this strain. Bar equals $10 \mu \mathrm{m}$.

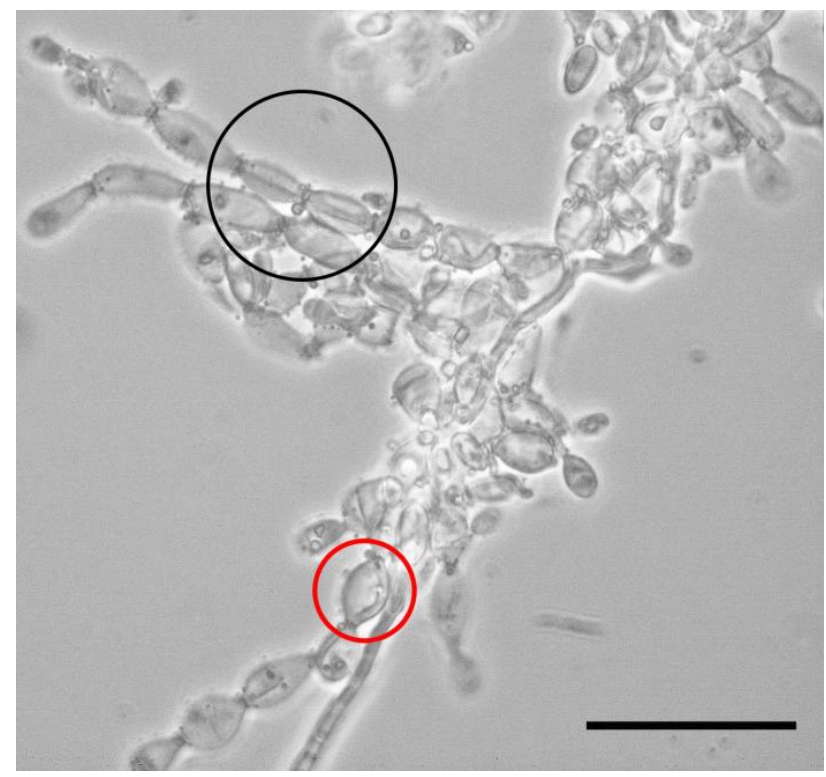

Figure 5. Optical microscopy of Asp01 hyphae grown on a glass slide with acidic liquid media and no Fe(II). Both percurant growth (black circle) and vacuoles (red circle) are evident. Bar equals $5 \mu \mathrm{m}$. 
within vacuoles

(Fig. 6). Both fungi

formed discrete

mycelia with little

to no turbidity in

solution when

grown in liquid

acidic media. The

mycelium appeared

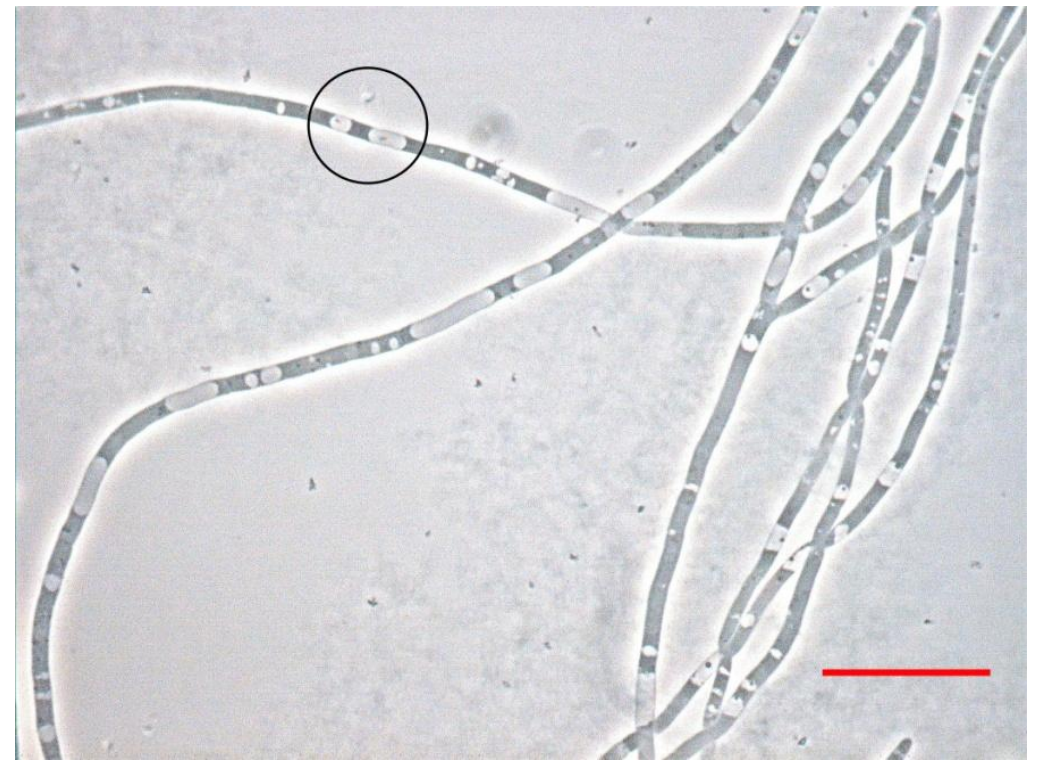

Figure 6. Color image of Ver01 grown in 1/10 diluted Luria broth soft agar

as large masses of

interwoven hyphae

stabs. A large number of vacuoles are visible in the hyphae. Two cells which contain the small intercellular bodies typically seen moving in the vacuoles of this isolate are circled though they are apparent throughout the hyphae. Bar equals $10 \mu \mathrm{m}$.

with increased density toward the center. Trypan blue staining indicated large numbers of

spores in the liquid of both cultures (Image not shown).

\section{Sequencing and phylogeny}

Based on a partial 18S rRNA sequence from Ver01 (918 bp) and Asp01 (1,021

bp) the strains were found to be phylogenetically closely related and belonging to the

Genus Verticillium in the phyla Ascomycota (Fig. 7).

\section{pH tolerance}




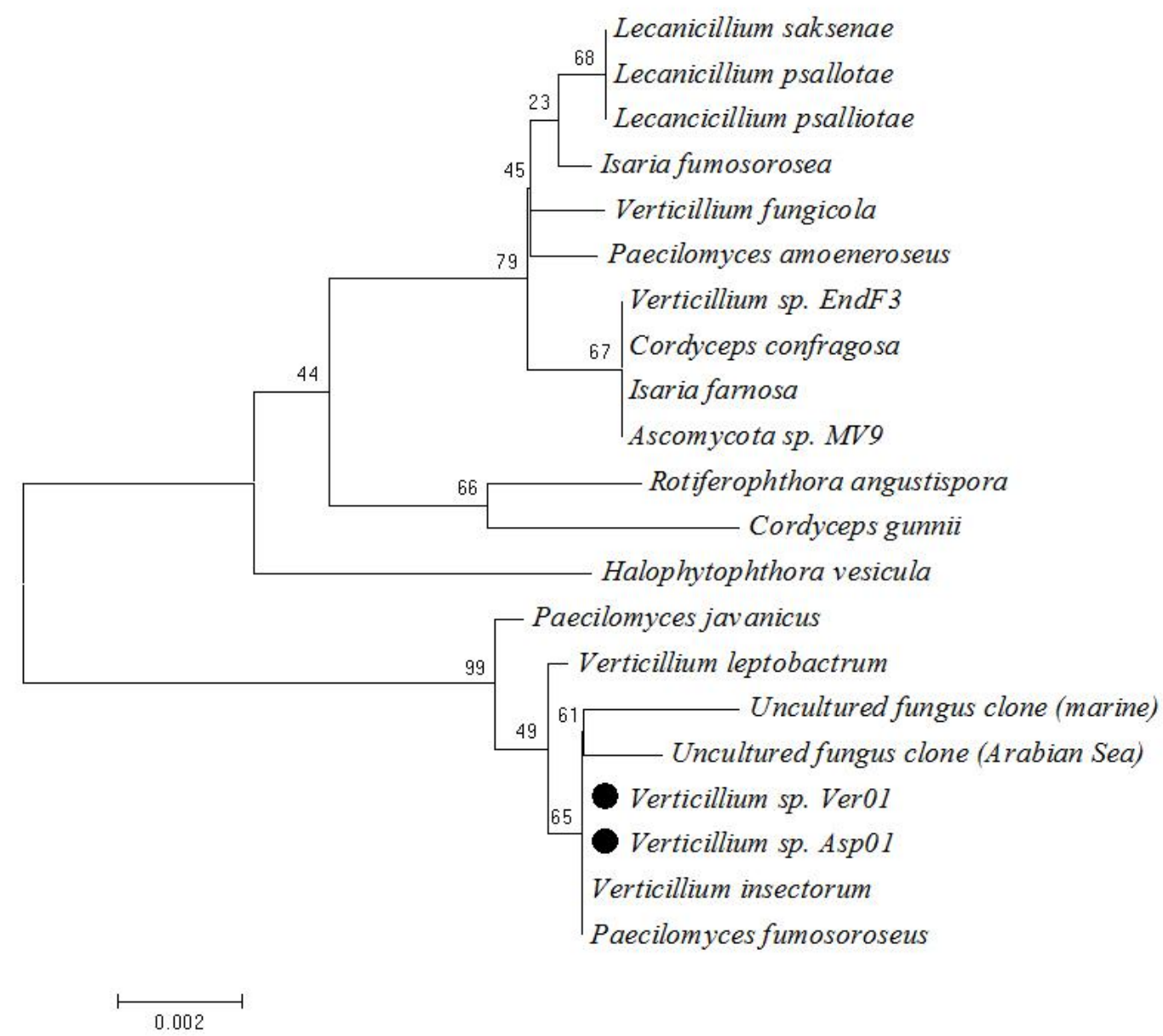

Figure 7. Molecular Phylogenetic analyses of fungal isolates by Maximum Likelihood. Fungal isolates from this study are marked with circles. All other fungal sequences were obtained from NCBI Genbank and represent organisms obtained using the Basic Local Alignment Search Tool. The evolutionary history was inferred by using the Maximum Likelihood method based on the Tamura-Nei model, bootstrap method with 500 replications. The tree with the highest log likelihood (-1345.9655) is shown. The percentage of trees in which the associated taxa clustered together is shown above the branches. Initial tree(s) for the heuristic search were obtained automatically as follows. When the number of common sites was $<100$ or less than one fourth of the total number of sites, the maximum parsimony method was used; otherwise BIONJ method with MCL distance matrix was used. The analysis involved 21 nucleotide sequences. All positions containing gaps and missing data were eliminated. There were a total of 800 positions in the final dataset. Bar equals two substitutions per 1,000 nucleotides. Evolutionary analyses were conducted in MEGA5.

The original $\mathrm{ddH}_{2} \mathrm{O} / \mathrm{HCl}$ solution in which the fungi were found growing by the original researchers had a $\mathrm{pH}$ of 2.5. So the fungi were maintained in liquid media at this $\mathrm{pH}$.

However, to quantify the lower $\mathrm{pH}$ limit at which the fungi would grow the $\mathrm{pH} 2.5$ 
minimal nutrient media in which

the fungal cultures were being

maintained was amended with

increasing volumes of $\mathrm{HCl}$.

Because fungi are known to alter

their environment by excreting

acids, the $\mathrm{pH}$ of the media was

taken after the fungi had been

allowed to grow for one week.

The fungi were capable of growth

from spores at an $\mathrm{pH}$ as low as
Table 1. Growth at low $\mathrm{pH}$ of fungal isolates and final $\mathrm{pH}$ readings in $10 \mathrm{~mL}$ of minimal nutrient media containing no buffering agent inoculated with fungal spore and amended with varying volumes of concentrated $\mathrm{HCl}$. Readings were taken after 1 week of growth. G stands for evidence of growth, NG for no evidence of growth.

\begin{tabular}{|l|l|l|}
\hline Added Conc.HCl & V. sp. Ver01 & V. sp. Asp01 \\
\hline $0.0 \mu \mathrm{L} \mathrm{HCl}$ & $\begin{array}{l}\mathrm{G} \\
\mathrm{pH} 1.93\end{array}$ & $\begin{array}{l}\mathrm{G} \\
\mathrm{pH} 1.90\end{array}$ \\
\hline $31.25 \mu \mathrm{L} \mathrm{HCl}$ & $\begin{array}{l}\mathrm{G} \\
\mathrm{pH} 1.65\end{array}$ & $\begin{array}{l}\mathrm{G} \\
\mathrm{pH} 1.62\end{array}$ \\
\hline $62.0 \mu \mathrm{L} \mathrm{HCl}$ & $\begin{array}{l}\mathrm{G} \\
\mathrm{pH} 1.44\end{array}$ & $\begin{array}{l}\mathrm{G} \\
\mathrm{pH} 1.42\end{array}$ \\
\hline $125 \mu \mathrm{L} \mathrm{HCl}$ & $\begin{array}{l}\mathrm{G} \\
\mathrm{pH} 1.23\end{array}$ & $\begin{array}{l}\mathrm{G} \\
\mathrm{pH} 1.24\end{array}$ \\
\hline $250 \mu \mathrm{L} \mathrm{HCl}$ & $\begin{array}{l}\mathrm{NG} \\
\mathrm{pH} 0.98\end{array}$ & $\begin{array}{l}\mathrm{NG} \\
\mathrm{pH} 0.99\end{array}$ \\
\hline
\end{tabular}

1.23 (Table 1). Although growth

was faster in circumneutral conditions $(\mathrm{pH} 7.3 \pm 0.2)$ this finding indicates that both isolates are tolerant of extreme acidic conditions (Data not shown).

Subsequent trials were conducted to find the upper $\mathrm{pH}$ range at which the fungi would grow. Mimicking the acid tolerance experiment, fungal spores were added to 10 $\mathrm{mL}$ of minimal nutrient media titrated to $\mathrm{pH} 7$ with $5 \mathrm{M} \mathrm{NaOH}$ which contained no buffering agent that was subsequently amended with $5 \mathrm{M} \mathrm{NaOH}$ in volumes from $0.0 \mu \mathrm{L}$ to $2.5 \mathrm{~mL}$. It was found that both isolates would grow at a $\mathrm{pH}$ as high as 13.55 , the upper range of the $\mathrm{pH}$ meter. After one week of incubation microscopic examination of the media was required to determine growth but growth was still evident in the tubes with the largest volume of $5 \mathrm{M} \mathrm{NaOH}(2.5 \mathrm{~mL})$ (Table not shown). This finding coupled with the 
other $\mathrm{pH}$ findings show that both species. Ver01 and Asp01, have a $\mathrm{pH}$ growth range from $\mathrm{pH} 1.23$ to at least $\mathrm{pH} 13.55$.

To determine if the possible endosymbionts were affecting the ability of the fungus to survive across such a broad $\mathrm{pH}$ range the $\mathrm{pH}$ growth experiments were repeated with the addition of the antibiotics erythromycin and tetracycline to the media at the concentrations established for the minimization of the bacteria within the fungal hyphae (see material and methods). Growth results were the same for media both with and without antibiotics. This indicates that the fungi themselves are responsible for the $\mathrm{pH}$ tolerances and that the presence of the possible endosymbiont does not alter or enhance the $\mathrm{pH}$ range at which the fungi can grow.

\section{Growth on Borosilicate Glass}

Characterization of how the two fungi grew in a nutrient free environment was undertaken by first examining from which possible source they could be deriving energy. While borosilicate glass is predominantly composed of borate oxoanions, primarily $\mathrm{BO}_{3}{ }^{-3}$ and $\mathrm{BO}_{4}$, and silicate, $\mathrm{SiO}_{2}$, there are trace amounts of cationic minerals added to balance the difference in oxidation states between the $\mathrm{Si}(\mathrm{IV})$ and $\mathrm{B}(\mathrm{III})$ [91-93]. Fungi are known to be capable of exploiting micro-fissures in solid materials to obtain minerals and other nutrients for growth. [26, 28, 29] These two facts imply that any cationic minerals found in borosilicate glass could be accessed by these fungi though the exploitation of micro-fractures in the glass. Then, the freed cations could be utilized to facilitate and support growth. It was therefore hypothesized that the fungi could be inducing bioweathering of the glass and obtaining the cationic minerals found there for chemotropic growth. 
To determine if any of the cations that can be found in borosilicate glassware could be utilized by the fungi Dr. Radu Popa and Susan Holmes added the minerals known to be micro-constituents of borosilicate lab glass to $\mathrm{pH} 2.5$ nutrient free media that was then inoculated with Asp01 and Ver01. They then visually monitored the cultures to determine if growth was occurring and how much bio-mass could be observed accumulating in each. They determined that fungal growth occurred in the presence of $\mathrm{Fe}(\mathrm{II})$ and $\mathrm{Mg}(\mathrm{II})$ with the most growth seen in the culture that contained $\mathrm{Fe}(\mathrm{II})$. Subsequent experimentation found that both fungal isolates were tolerant of $\mathrm{Fe}(\mathrm{II})$ in concentrations up to 50mM without any detrimental effects. Cultures were then maintained on nutrient poor $(0.5 \mathrm{mg} / \mathrm{L}$ yeast extract $) \mathrm{pH} 2.5$ agarose plates and in nutrient poor liquid media with $50 \mathrm{mM} \mathrm{Fe(II)} \mathrm{present.}$

If the growth of the fungus was dependant on the cations that it was obtaining from the glass, providing additional glass substrate should result in increased growth. To determine if this was the case, fungal cultures were tested using nutrient free media in borosilicate glass bottles with and without the presence of additional borosilicate glass beads. Visual inspection found that the bottles in which the glass beads were placed had a larger bio-mass accumulation than those without the beads, leading to the conclusion that presence of the glass and its corresponding ability to provide trace elements was inherent to the ability of the fungi to grow in "nutrient free" environments.

Examination of Ver01 and Asp01 cultures that had been allowed to grow in liquid media in borosilicate glassware for periods of one year or longer revealed that the fungal mycelia were attaching to the glassware. Rinsing of the glass with water failed to remove the hyphael networks and it was found that the use of a metal spatula and scraping were 
necessary to remove the mycelia. After removal, visible pitting of the glass where fungal myceliums were attached was observed. Microscopic examination of the glass showed that etching of the glass was in fact happening under the fungal mycelium.

\section{LMWOA Fungal Exudates}

To determine if the fungi were capable of producing the organic acids, such as oxalate, which are known to be involved in the bio-weathering of minerals, the presence and evolution of organic acids in fungal cultures were determined using gas chromatography and high-performance liquid chromatography [39, 43, 44, 46, 47]. The presence and evolution over time of other organic acids, including butyric acid, propanoic acid, and valeric acid that are known to be produced by fungi in increased amounts when they are exposed to high levels of heavy metals such as zinc, copper and cadmium [40, 43]. Acetate, known to be involved in iron reduction carried out by bacteria, was measured as well as organic acids capable of acting as iron ligands in solution [35, 94, 95]. In an effort to mimic a natural system, in which the availability of easily metabolized nutrients can decline or disappear in time, fungal hyphae that had been grown in low nutrient conditions were introduced to nutrient free media and acid evolution tracked. The nutrient free media and a sample of media from each wash step were also examined to determine if any organic acids were present. The presence of several different organic acids was observed to increase in the nutrient free media over time. Two of the key low molecular weight organic acids (LMWOA) were acetate, which is known to be involved in iron redox reactions carried out by bacteria and oxalate, which is known to be produced by fungi in response to exposure to heavy metals (Figure 8). 


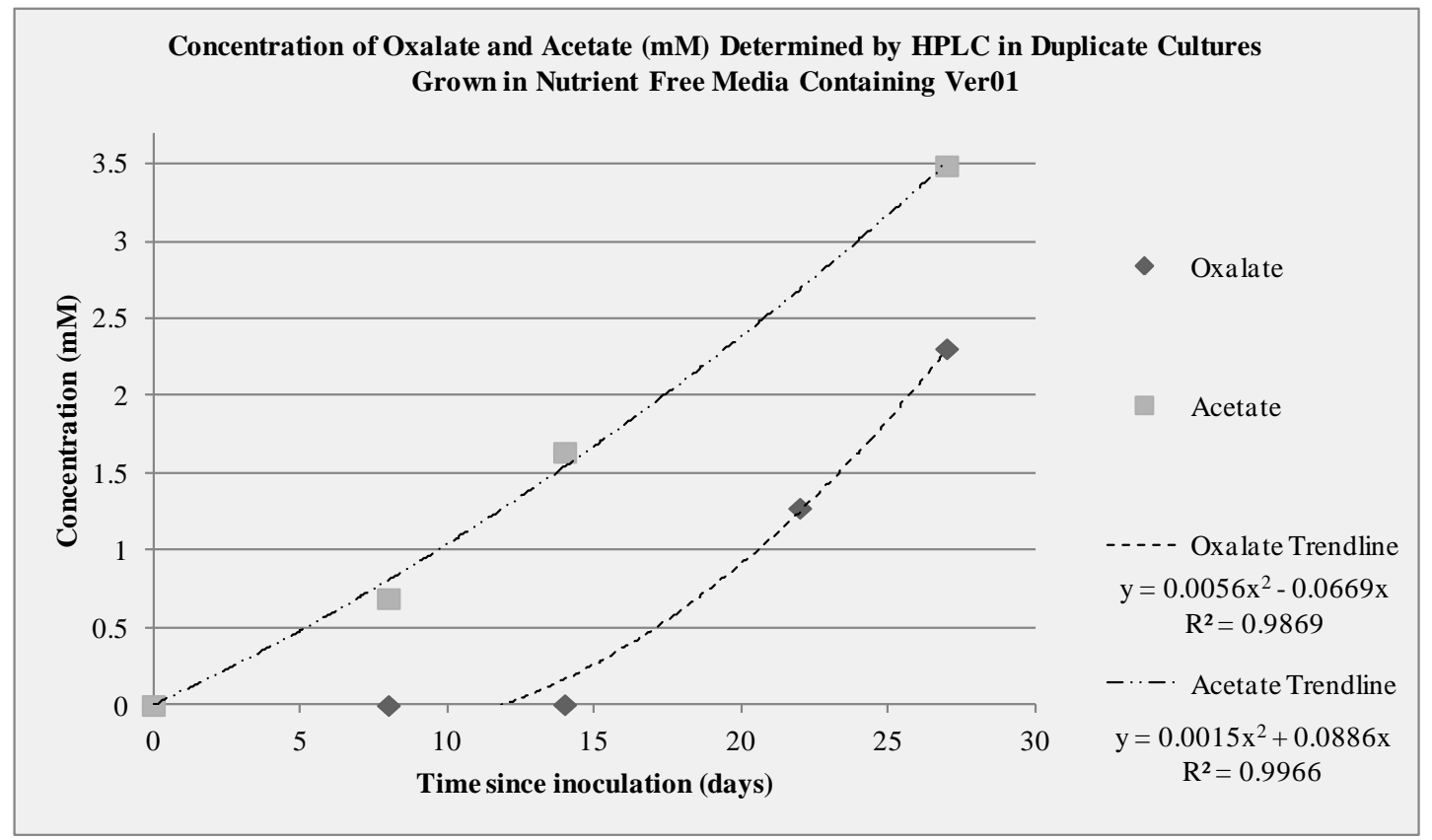

Figure 8 . Trends in the concentration of oxalate and acetate $(\mathrm{mM})$ in nutrient free media containing isolate Ver01as determined by HPLC analysis.

By HPLC neither oxalate nor acetate was detectable in the media on day zero.

Detectable acetate appeared in solution between day 0 and day 8 . Acetate increased steadily in concentration reaching a final concentration of $3.48 \mathrm{mM}$ in solution by day 27 when the experiment was discontinued. Detectable oxalate did not appear in solution until between day 12 and day 22 but it also increased in concentration until day 27 reaching a final concentration of $2.3 \mathrm{mM}$.

Acetate is used by many bacterial iron reducers as an electron donor and is important to anaerobic iron cycling (Formula 1) [10, 95-98]. Acetate can also be a byproduct of the reduction of Fe(III) with other organic compounds including but not limited to lactate and succinate. Acetate in the culture was found to increase in concentration over the course of 30 days, staring at day 7 , to a final concentration of 3.48mM in solution (Fig. 8). Oxalate is capable of acting as a ligand for both $\mathrm{Fe}(\mathrm{II})$ and 
$\mathrm{Fe}(\mathrm{III})$ and is produced by many soil fungi in environments contaminated with heavy metals $[43,44,46,99]$. Oxalate was first detected in the tested media at day 14 and continued to increase in concentration so that by day 27 the concentration had reached 2.3mM (Fig. 8).

Analysis of the same sample by GC indicated that other organic acid exudates in the media including but not limited to butyric acid, propanoic acid and isovaleric acid showed a distinctly different pattern (Fig. 9).

With the exception of butyric acid, which was detected in the culture at inoculation, propanoic, and isovaleric acids appeared in solution on day two only to slowly decline as the culture aged. At day eight the trend reversed itself and concentrations in solution began to increase again for all acids, with the exception of

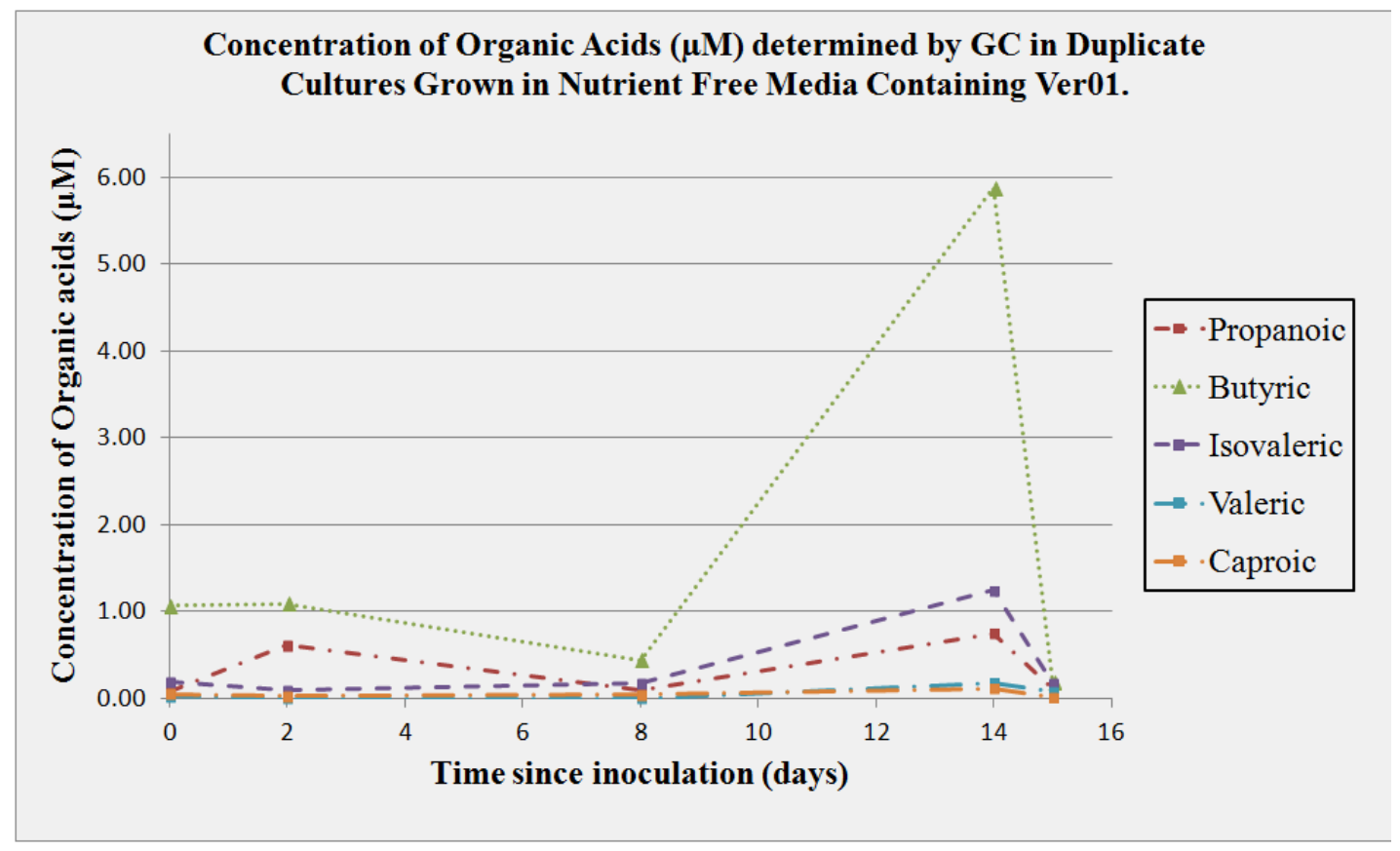

Figure 9. The evolution of organic acids in media inoculated with Ver01 as determined by GC analysis. 
valeric, over the course of the next six days, with all the acids peaking on day 14. On day 15 all the GC tracked acids were below detectable limits and did not re-appear. Peak concentrations of the acids all varied at the maximum with butyric acid showing the highest concentration at $5.8 \mu \mathrm{M}$, followed by valeric at $1.24 \mu \mathrm{M}$ and propanoic at 0.7 $\mu \mathrm{M}$. All of these concentrations were well below the levels reached by both acetate and oxalate in solution both of which reached concentration $\mathrm{s}$ in micromolar amounts. Regardless, the presence of these acids suggests that the fungus is capable of producing the LMWOA that are thought to be required for ion extraction from borosilicate glass and its utilization in a nutrient free environment [39, 43, 44, 46, 47].

To determine if the putative endosymbionts were contributing to the production of the LMWOA or if their presence was triggering the production of these exudates the

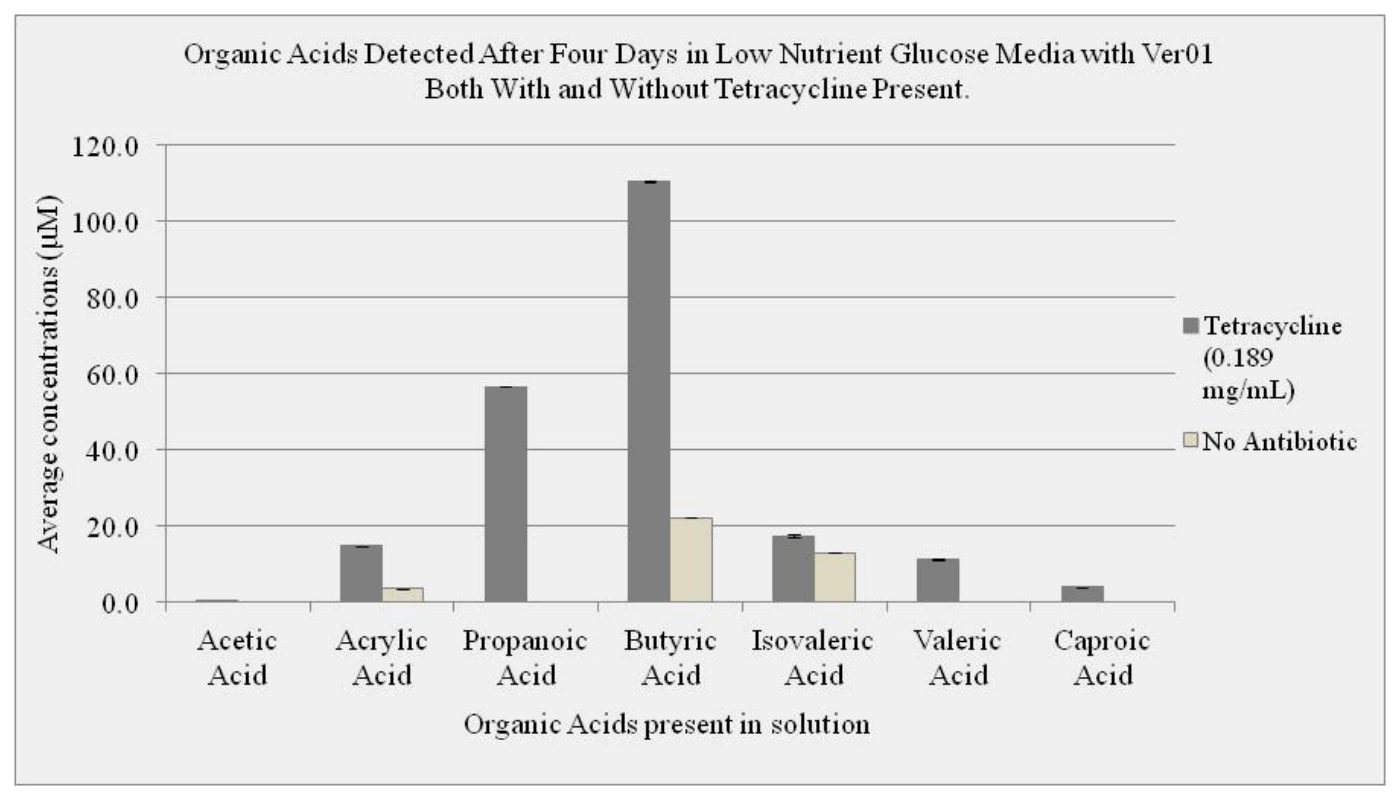

Figure 10. Organic acids present in solution in the presence of tetracycline. Black bars represent media which contained the antibiotic; grey bars represent the media which contained no antibiotic. Bars represent the average of triplicate samples; error bars are present and are one standard deviation. 
quantification of the LMWOA was repeated with the addition of tetracycline in media amended with glucose. Concentrations of LMWOA were measured via HPLC (data not shown) and GC at 24 hour intervals beginning on day three after inoculation and continuing until fungal growth visually appeared to plateau or cease, approximately 14 days (Fig. 10). In the media with antibiotics the presence of butyric, propanoic and valeric acids in solution at day four were found at levels that exceeded the concentrations seen at day 15 in figure 9 where no nutrient was present. The levels of acids were also significantly above the levels seen in the controls without antibiotics present (Fig. 10). Other organic substances that had not been seen previously or only at very low levels, including caproic acid, and acrylic acid, also appeared in the media which contained the tetracycline but not the media without. While readings were taken every 24 hours for 14 days the concentration of the acids in solution began diverging after day four in all bottles in the series. Repetitions of the experiment had the same conclusion, with bottles showing similar concentrations of acids early in the growth cycle and then diverging as the cultures aged.

The finding that reduction of the endosymbionts leads to higher levels of organic acids in culture could have several possible explanations. The fungus could be producing the additional organic acids in response to the stress from the reduction in number of the bacterial endosymbionts (see Figure 16). The bacterial endosymbionts could be using the organic acids as alternative energy sources, thereby reducing their concentration intercellularly which would translate directly into less acid available to excrete into solution (see chapter 5). The addition of the antibiotic could be stressing the fungus 
which results in incomplete metabolism of the available energy sources which corresponds to a rise in the byproducts being excreted in solution.

\section{$\mathrm{Fe}(\mathrm{II}) / \mathrm{Fe}(\mathrm{III})$ utilization}

To assess if the fungi was capable of utilizing any iron that is available in the glassware, measurements of growth in the presence of both $\mathrm{Fe}(\mathrm{III})$ and $\mathrm{Fe}(\mathrm{II})$ under $\mathrm{O}_{2}$ concentrations ranging from $1.6 \%$ to atmospheric levels (assumed: $21 \%$ ) were undertaken. Both iron species (Fe(II) and $\mathrm{Fe}(\mathrm{III})$ ) were investigated in an attempt to mimic the abiotic oxidation of $\mathrm{Fe}(\mathrm{II})$ in solutions to $\mathrm{Fe}(\mathrm{III})$ under most environmental conditions $[14,16]$. The culture was maintained at $\mathrm{pH} 2.5$ in an attempt to maximize the amount of $\mathrm{Fe}(\mathrm{II})$ preserved in the media though even at the low $\mathrm{pH}$ level all the of $\mathrm{Fe}$ (II) will naturally oxidize to $\mathrm{Fe}(\mathrm{III})$ in time $[10-12,100]$. This natural abiotic process means that accessing which species of iron is being utilized by the fungi in culture cannot be determined when only Fe(II) is provided in culture. Therefore, both species, Fe(II) and Fe(III), need to be assessed independently for possible contributions to the overall energy pool available to the fungi. The reduction in oxygen levels was chosen because biotic reduction of $\mathrm{Fe}$ (III) to $\mathrm{Fe}$ (II) is found to occur only in anoxic conditions [15, 96, 100, 101]. It was hypothesized that if the fungal culture was using Fe(III) as an electron donor, growth at the lower $\mathrm{O}_{2}$ levels would be higher than that seen at atmospheric oxygen levels. The only growth seen in the culture at atmospheric $\mathrm{O}_{2}$ level could be assumed to be from the provided organic nutrients and not from the reduction of $\mathrm{Fe}(\mathrm{III})$.

As opposed to the biotic reduction of $\mathrm{Fe}(\mathrm{III})$, the biotic oxidation of $\mathrm{Fe}(\mathrm{II})$ to Fe(III) can occur both anoxically and in aerobic conditions and while the redox potential of this couple if effected by $\mathrm{pH}$ it is not altered by the availability of oxygen $[17,18$, 
100]. This means that changing the oxygen levels available to the culture should not alter the amount of energy provided by this reaction. This would mean that a steady amount of growth should be seen in this culture if the fungi were oxidizing Fe(II). This growth was expected to be at the same level as that seen in the culture with no iron added plus any growth facilitated by the iron oxidation.

The energy produced by the fungal utilization of the provided organic nutrients should occur primarily in the presence of oxygen. It was assumed that as oxygen levels dropped a corresponding reduction in fungal biomass would occur in the cultures that were not provided with iron. The level of growth was expected to correspond to that seen in the Fe(III) series at atmospheric oxygen levels. Because neither the reduction or oxidation of either iron species is capable of supplying as much energy to the fungi as the metabolism of sugars or other carbohydrates the availability of other nutrient sources

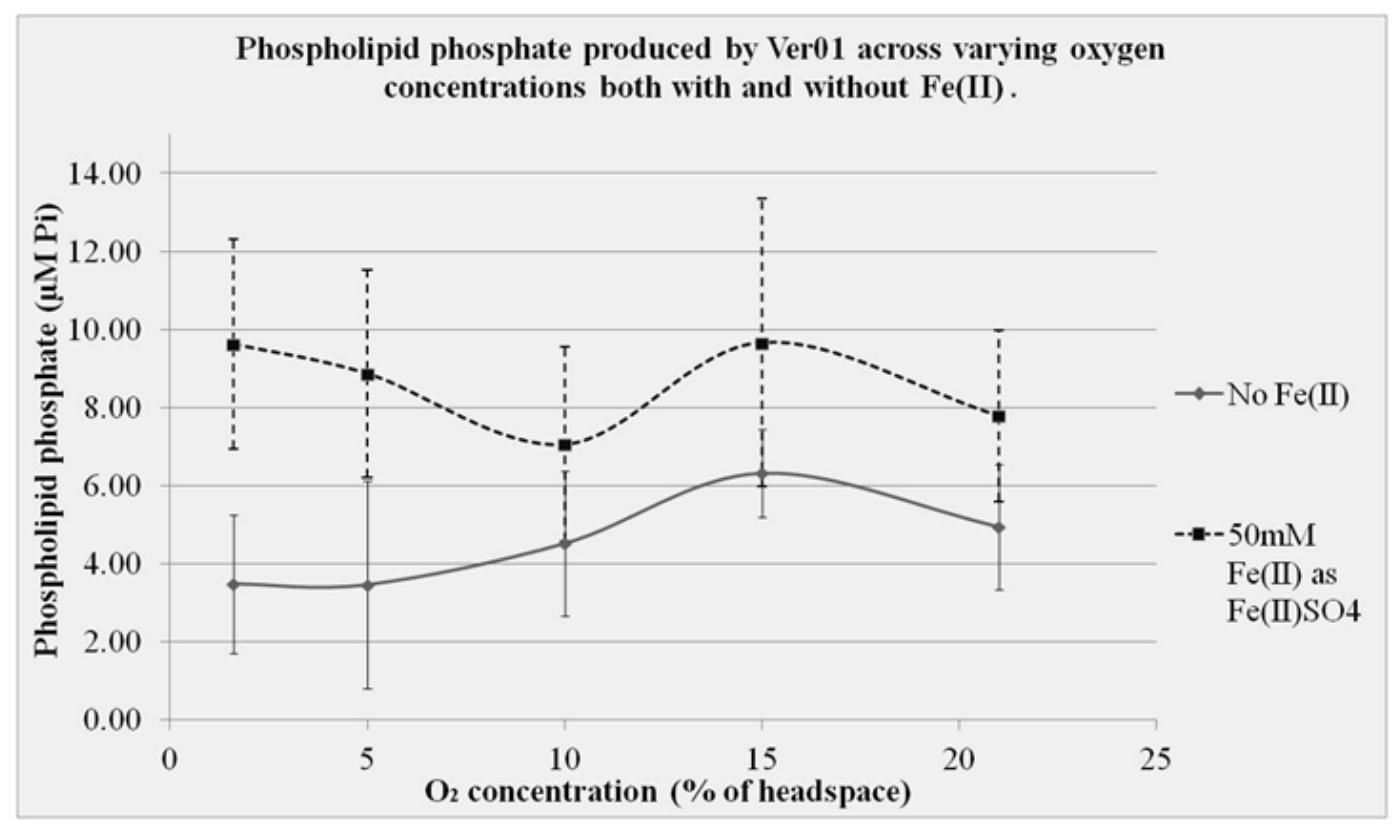

Figure 11. Phospholipid phosphate produced by Ver01 in varying oxygen concentrations both with and without $\mathrm{Fe}(\mathrm{II})$ as $\mathrm{Fe}(\mathrm{II}) \mathrm{SO}_{4}$. Growth was measured after 50 days of incubation. All readings and cultures were done in triplicate, error bars are one standard deviation. 
were limited in an effort to maximize the possibility of observing the growth from the iron redox reactions and minimize the possible masking effect of other organic energy sources at higher oxygen concentrations (Formulae 2, 3 and 4).

As a proxy for growth phospholipid phosphate levels were measured to determine how much bio-mass accumulation was occurring in each culture (Fig.11) [102-104].

Though higher across all given oxygen concentrations fungal bio-mass accumulation when $\mathrm{Fe}(\mathrm{II})$ (as $\mathrm{Fe}(\mathrm{II}) \mathrm{SO}_{4}$ ) was included in the media was not significantly different, as indicated by the error bars, than what was seen when no additional iron was added until oxygen levels reached $5 \%$. At $5 \%$ oxygen and below bio-mass accumulation with $\mathrm{Fe}(\mathrm{II})$ was significantly greater than in the absence of iron. In the $1.6 \%$ oxygen cultures the growth seen with $\mathrm{Fe}(\mathrm{II})$ was within that seen at the maximum implied growth point $\left(15 \% \mathrm{O}_{2}\right)$. This result points to the utilization of $\mathrm{Fe}(\mathrm{II})$ as an electron acceptor in an

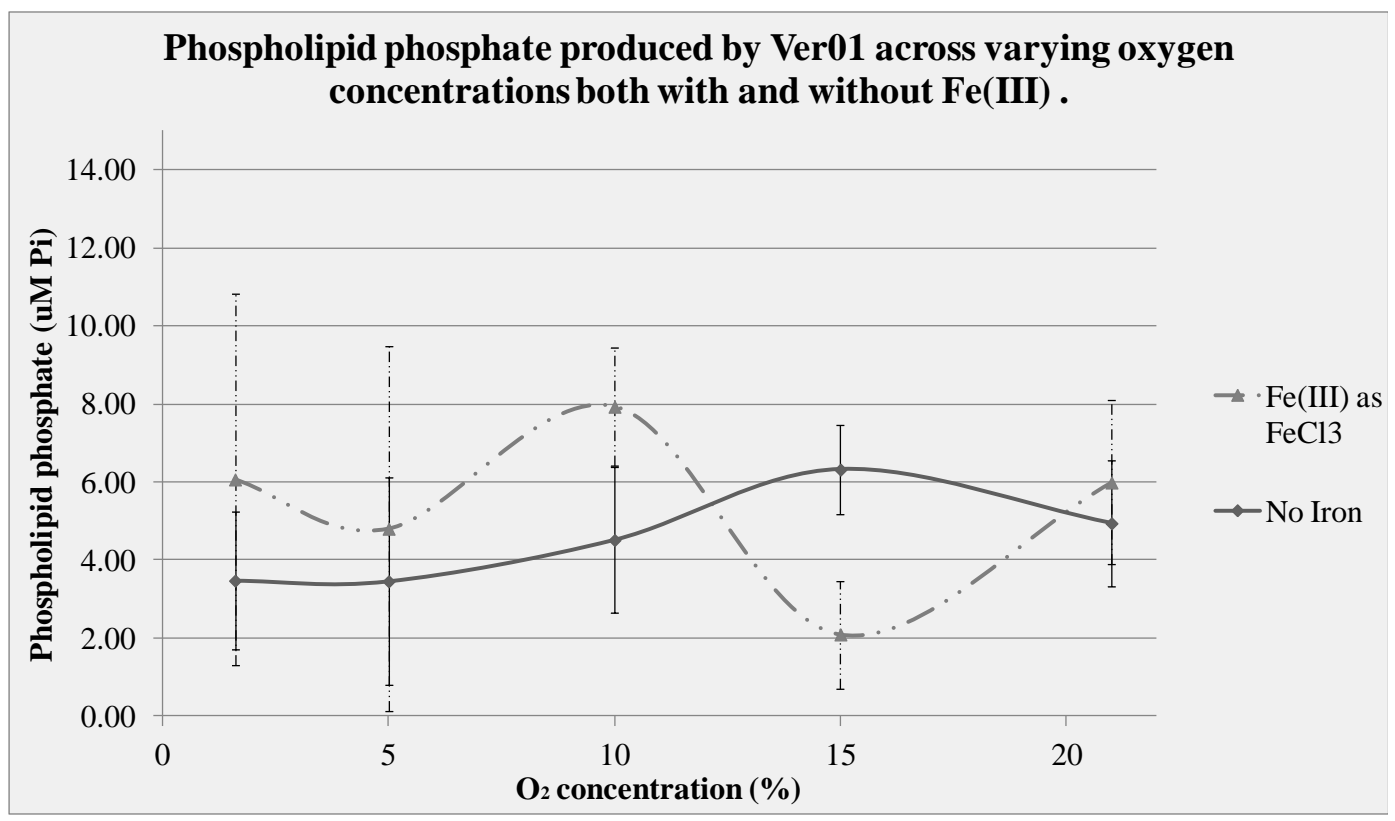

Figure 12. Phospholipid phosphate produced by Ver01 in varying oxygen concentrations both with and without $\mathrm{Fe}(\mathrm{III})$ as $\mathrm{FeCl}_{3}$. Growth was measured after 50 days of incubation. All series were done in triplicate, error bars are one standard deviation. 
alternative energy production pathway

that acts in tandem with the normal oxidative metabolism seen in eukaryotic cells as well as alone, when the cells are growing in low oxygen environments.

The presence of $\mathrm{Fe}(\mathrm{III})$ (as $\mathrm{FeCl}_{3}$ ) produced no definitive results. Growth was inconsistent across the provided oxygen concentrations, with no discernible pattern that could be either matched to the no iron control or to the reduction of the Fe(III) at lower oxygen levels (Fig. 12). The presence of Fe(III) in culture seemed to inhibit the fungal growth at some oxygen levels $(15 \%)$ and to encourage the additional accumulation of bio-mass at others $(10 \%)$. This data was inconsistent with either the utilization of the $\mathrm{Fe}(\mathrm{III})$ or the $\mathrm{Fe}(\mathrm{III})$ at this concentration acting as a toxin. Even though the concentration of the $\mathrm{Fe}(\mathrm{III})$ was minimal $(1 \mathrm{mM})$ when compared to the concentration of $\mathrm{Fe}(\mathrm{II})(50 \mathrm{mM})$ it was concluded that the $\mathrm{Fe}$ (III) could not be providing any additional energy via its reduction by the fungi and so it was discarded for further work. 


\section{Chapter 4}

\section{Intercellular staining, antibiotic treatment and isolation in culture of putative bacterial endosymbionts}

\section{Introduction}

The two most prominent endosymbiotic relationships in fungi have been found in fungi from the phylum Zygomycota. Zygomycete fungi from the genera Gigaspora and Rhizopus have both been found to harbor bacterial endosymbionts from the family $\beta$ Proteobacteria [7, 8, 105]. Gigaspora margarita's relationship with Glomeribacter gigasporarum is obligate for host and symbiont, transmission of the symbiont is vertical and the symbiont has been found in five out of six other fungi from the genus [106-108] . G. gigasporarum has the smallest genome of any other $\beta$-Proteobacterium, a characteristic shared among many obligate endosymbionts [67, 68, 71]. In Rhizopus microsporus' association with its symbionts, Burkholderia rhizoxinica or Burkholderia endofungorum, the relationship is non-obligate for the bacteria and is also not obligate for host survival $[8,109]$. However, the association is obligate for vegetative reproduction to occur in the host $[7,65]$. The transmission of $R$. microsporus' endosymbiont was found to be both horizontal and vertical, with spores from infected fungi carrying the endosymbiont but cured fungal hyphae also allowing the re-introduction of the symbiont in culture [110]. No symbionts were found in the cells of most clinical isolates of Rhizopus strains that were taken from patients suffering from Rhizopus zygomycoses but were found in environmental isolates worldwide $[110,111]$. In addition, all bacterial strains found within $R$. microsporus isolates from around the globe were determined to be from a common ancestor $[65,110,112]$. This is accordance with the environmental 
isolates of Gigaspora which also appeared to show a global distribution and common ancestor [111].

\section{Nucleic Acid Staining}

Microscopic examination

was undertaken with multiple

fluorescent nucleic acids stains to

ascertain if the motile small

intercellular bodies observed

within individual hyphae cells

and less often within vacuoles in

Ver01 and predominantly within

vacuoles in Asp01 were bacteria.

Staining with acridine orange

$\mathrm{AO})$ indicated that the small

bodies within the vacuole-like

structures of both strains

contained nucleic acids (Figure

13 Ver01; Asp 01 figure not

shown). Acridine orange

fluoresces green when bound to

double stranded DNA and

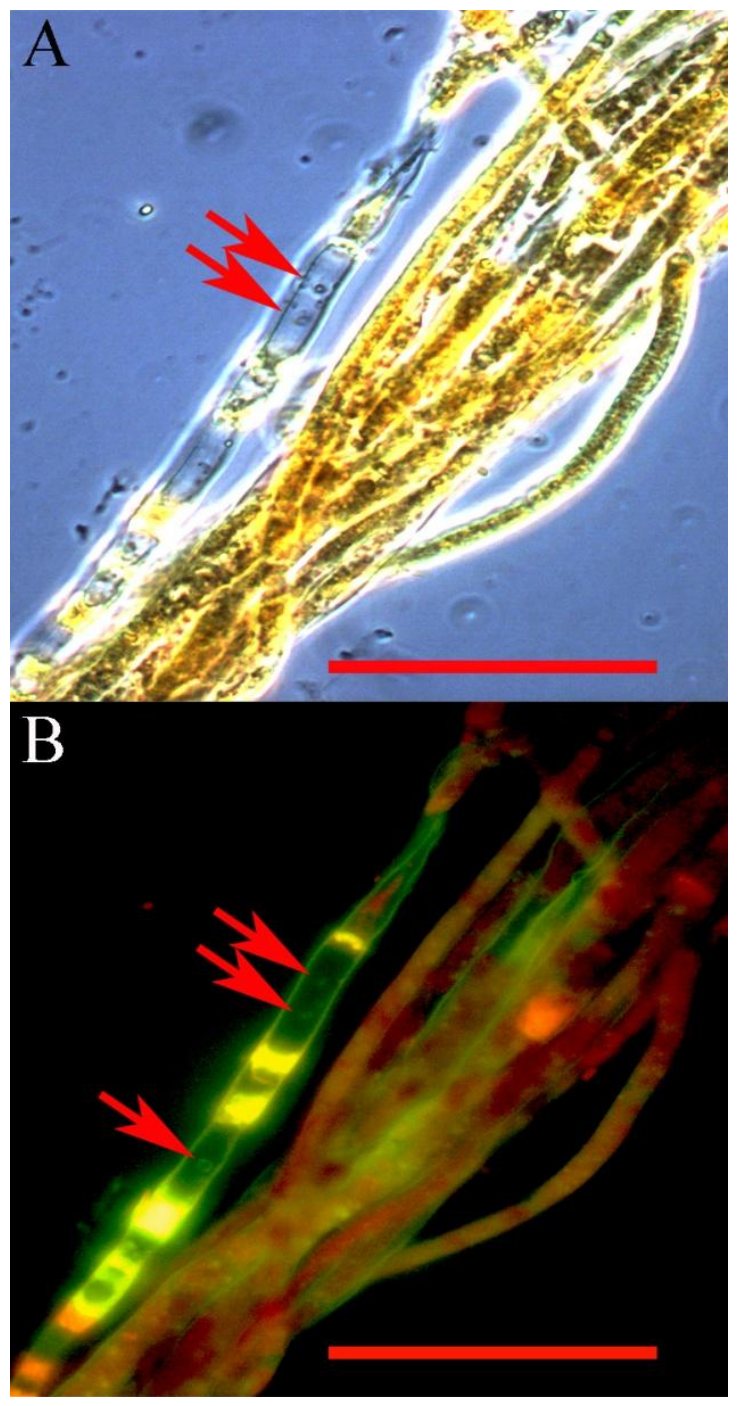

Figure 13. Hyphae of $V$. sp. Ver01 grown in lownutrient acidic liquid media without $\mathrm{Fe}(\mathrm{II})$ stained with Acridine orange. In image A (visible) the red arrows indicate small intercellular bodies that move rapidly within the vacuoles. In image B (fluorescence) the red arrows indicate the small intercellular bodies that stained with Acridine orange. Large green areas within the hyphae are presumably fungal nuclei. Bar equals 10 um.

orange-red when binding single stranded RNA or DNA. The nuclei of the two fungi strains had green fluorescence and often showed a granular appearance, while the 
intercellular bodies were sometimes green, sometimes orange-red (Fig. 13). Importantly, the vacuoles

themselves did not

stain with $\mathrm{AO}$, thus

they apparently did

not contain DNA,

mRNA, or ribosomes.

The intercellular

bodies staining within

vacuoles are too small

to be nuclei, thus we

characterize them as

putative

endosymbionts.

Using

Live/Dead Bac-light

staining the

intercellular bodies

consistently stained

with SYTO9 but not

with propidium

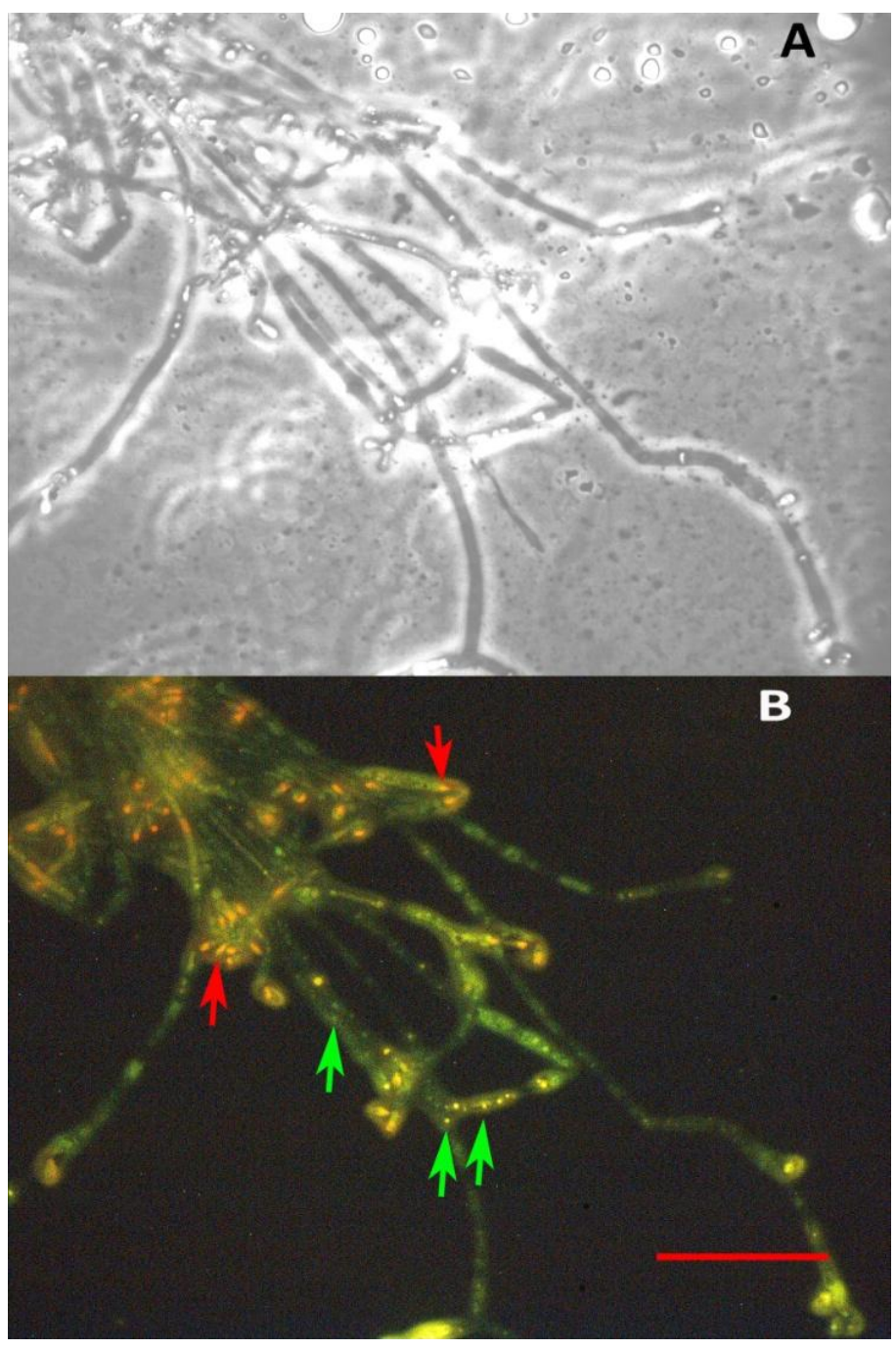

Figure 14. Ver01 grown in acidic liquid media with $50 \mathrm{mM} \mathrm{Fe(II)}$ stained with Invitrogen's BacLight Live Dead bacterial stain. Bacteria with intact membranes fluoresce yellow-green (SYTO9) and bacteria whose plasma membranes have been disrupted fluoresce red (propidium iodide). Fungal nuclei fluoresce red due to the porous nature of their nuclear membrane. Image A is visible light, image B is fluorescence. Red arrows in image B indicate fungal nuclei. Green arrows indicate the proposed bacteria. Bar equals $10 \mu \mathrm{m}$.

iodide, indicating the presence of an intact membrane. The fungal nuclei stained, as

expected [7, 8], red due to propidium iodide (Fig. 14). As with AO, no nucleic acid 


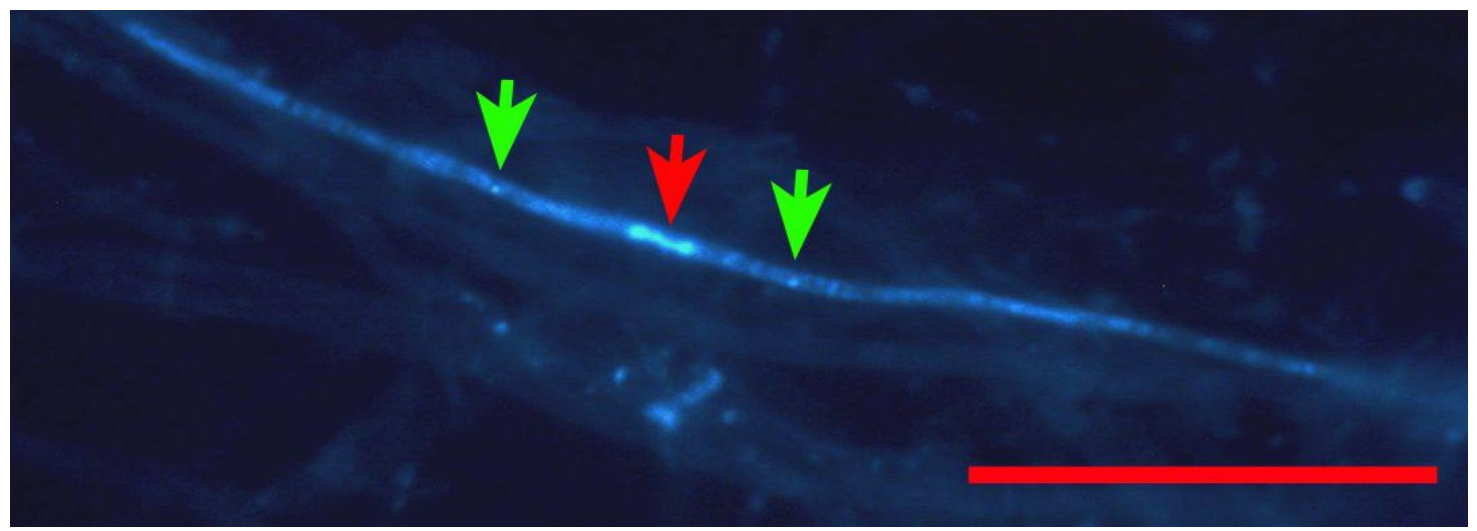

Figure 15. Hyphae of $V$. sp. Ver01 grown in low-nutrient acidic liquid media without Fe(II) and stained with DAPI. Hyphae were freeze fractured prior to staining. The red arrow indicates a fungal nucleus and green arrows indicate bodies within the hyphae that also contain DNA and are proposed bacterial endosymbionts. Bar equals $5 \mu \mathrm{m}$.

staining was seen other than the putative endosymbionts and fungal nuclei. DAPI

staining showed nuclei and also intercellular bodies in the cytoplasm (Fig. 15) and in the vacuoles (image not shown). Again, the vacuoles did not stain with DAPI.

\section{Antibiotic Treatment}

It was hypothesized that if the moving intercellular bodies are in fact prokaryotic endosymbionts then antibiotic treatments should reduce their number. Antibiotics were selected that did not result in precipitate in the culture medium and at the highest concentration found to have the least effect on the growth of the fungi and largest effect on the presence of the putative endosymbionts (Table 2). Resistance of the fungi and putative endosymbionts to five antibiotics: kanamycin (Kan), erythromycin (Ery), ampicillin (Amp), tetracycline (Tet) and rifamycin (Rif) were tested. Rifamycin was eliminated from this study because of precipitation in acid medium conditions.

Microscopic examination revealed that high concentration of Ampicillin (Amp) $(933 \mu \mathrm{g} / \mathrm{mL})$ and Kanamycin (Kan) $(16 \mu \mathrm{g} / \mathrm{mL})$ resulted in inhibition of fungal growth and no visible reduction in the number of of the putative symbionts. The highest 
concentrations of Erythromycin (Ery) and Tetracycline (Tet) where fungal growth was still observed were $189 \mu \mathrm{g} / \mathrm{mL}$ Tet and $2.490 \mathrm{mg} / \mathrm{mL}$ Ery. Concentrations of $60 \mu \mathrm{g} / \mathrm{mL}$

Table 2. Fungal growth from spore observed in low-nutrient acidic liquid media incubated with varying volumes of antibiotics. Starting media volume was $5 \mathrm{~mL}$. Plus signs indicate growth.

\begin{tabular}{|c|c|}
\hline $\begin{array}{l}\text { Volume Added } \\
(\mu \mathrm{L})\end{array}$ & Growth after 7 days \\
\hline \multicolumn{2}{|c|}{ Antibiotic: Ampicillin } \\
\hline 0 & +++ \\
\hline 2 & +++ \\
\hline 10 & +++ \\
\hline 50 & +++ \\
\hline 100 & +++ \\
\hline 200 & +++ \\
\hline 500 & +++ \\
\hline 1,000 & 0, total inhibition \\
\hline \multicolumn{2}{|c|}{ For all tubes with growth: fungal morphology was the characteristic puff ball shape. } \\
\hline \multicolumn{2}{|c|}{ Antibiotic: Tetracycline } \\
\hline $0 \mathrm{ul}$ & +++ \\
\hline $2 \mathrm{ul}$ & +++ \\
\hline $10 \mathrm{ul}$ & +++ \\
\hline $50 \mathrm{ul}$ & +++ \\
\hline $100 \mathrm{ul}$ & +++ Fungal mycelia stick to each other forming clumps \\
\hline $200 \mathrm{ul}$ & +++ Fungal mycelia stick to each other forming clumps \\
\hline $500 \mathrm{ul}$ & +++ Fungal mycelia stick to each other forming clumps \\
\hline $1 \mathrm{~mL}$ & ++ Fungal mycelia stick to each other forming clumps \\
\hline \multicolumn{2}{|c|}{ Antibiotic: Kanamycin } \\
\hline $0 \mathrm{ul}$ & +++ \\
\hline $2 \mathrm{ul}$ & +++ \\
\hline $10 \mathrm{ul}$ & +++ \\
\hline $50 \mathrm{ul}$ & +++ \\
\hline $100 \mathrm{ul}$ & +++ \\
\hline $200 \mathrm{ul}$ & +++ \\
\hline $500 \mathrm{ul}$ & +++ \\
\hline $1 \mathrm{~mL}$ & 0 \\
\hline \multicolumn{2}{|c|}{ For all tubes with growth: colony morphology was the characteristic puff ball shape. } \\
\hline \multicolumn{2}{|c|}{ Antibiotic: Rifamycin } \\
\hline $0 \mathrm{ul}$ & +++ \\
\hline $1 \mathrm{ul}$ & +++ , good size and density, very pale yellow media \\
\hline $5 \mathrm{ul}$ & $\begin{array}{l}++, \text { small size, number of mycelia is high, straw yellow } \\
\text { media }\end{array}$ \\
\hline
\end{tabular}




\begin{tabular}{|c|l|}
\hline $10 \mathrm{ul}$ & $\begin{array}{l}\text { 0, solution murky, unable to discern mycelia, med. yellow } \\
\text { media }\end{array}$ \\
\hline $20 \mathrm{ul}$ & $\begin{array}{l}\text { 0, solution murky but unable to discern mycelia, } \\
\text { yellow/orange media }\end{array}$ \\
\hline $50 \mathrm{ul}$ & $\begin{array}{l}0, \text { no growth seen, dark yellow/orange media } \\
0, \text { dark orange precipitate on bottom of tube, dark } \\
\text { yellow/orange media }\end{array}$ \\
\hline $100 \mathrm{ul}$ & $\begin{array}{l}0, \text { media dark yellow/orange in color, almost brown and } \\
100 \% \text { opaque }\end{array}$ \\
\hline $1 \mathrm{~mL}$ & +++ \\
\hline Antibiotic: Erythromycin \\
\hline $0 \mathrm{ul}$ & +++ good morphology and density \\
\hline $2 \mathrm{ul}$ &,+++ good morphology and density \\
\hline $10 \mathrm{ul}$ &,++ good morphology but low density in solution \\
\hline $50 \mathrm{ul}$ &,+++ good morphology and density \\
\hline $100 \mathrm{ul}$ &,+++ good morphology and density \\
\hline $200 \mathrm{ul}$ &,+++ good morphology and density, adhering to each other \\
\hline $500 \mathrm{ul}$ & $\begin{array}{l}++, \text { good morphology and density, size is smaller than in } \\
\text { other tubes and adhering to each other }\end{array}$ \\
\hline $1 \mathrm{~mL}$ &
\end{tabular}


Ery and $166 \mu \mathrm{g} / \mathrm{mL}$ Tet did not visibly inhibit the fungal growth but led to significant reduction in the number of vacuoles per hyphae and in the density of the putative symbionts. The abundance of putative endosymbionts in fungal cultures grown in four treatments: no antibiotics, $189 \mu \mathrm{g} / \mathrm{mL}$ Tet, $2,490 \mu \mathrm{g} / \mathrm{mL}$ Ery and a mixture of $189 \mu \mathrm{g} /$ $\mathrm{mL}$ Tet, $2,490 \mu \mathrm{g} / \mathrm{mL}$ Ery were analyzed (Fig. 16). The combination of both Ery and Tet reduced the number of fungal hyphae cells containing putative symbionts from $\sim 80 \%$ to $<16 \%$, and the number of cells carrying two or more putative endosymbionts to zero, but did not eliminate the putative endosymbionts entirely. Using both Ery and Tet seemed equivalent to either Ery or Tet used alone.

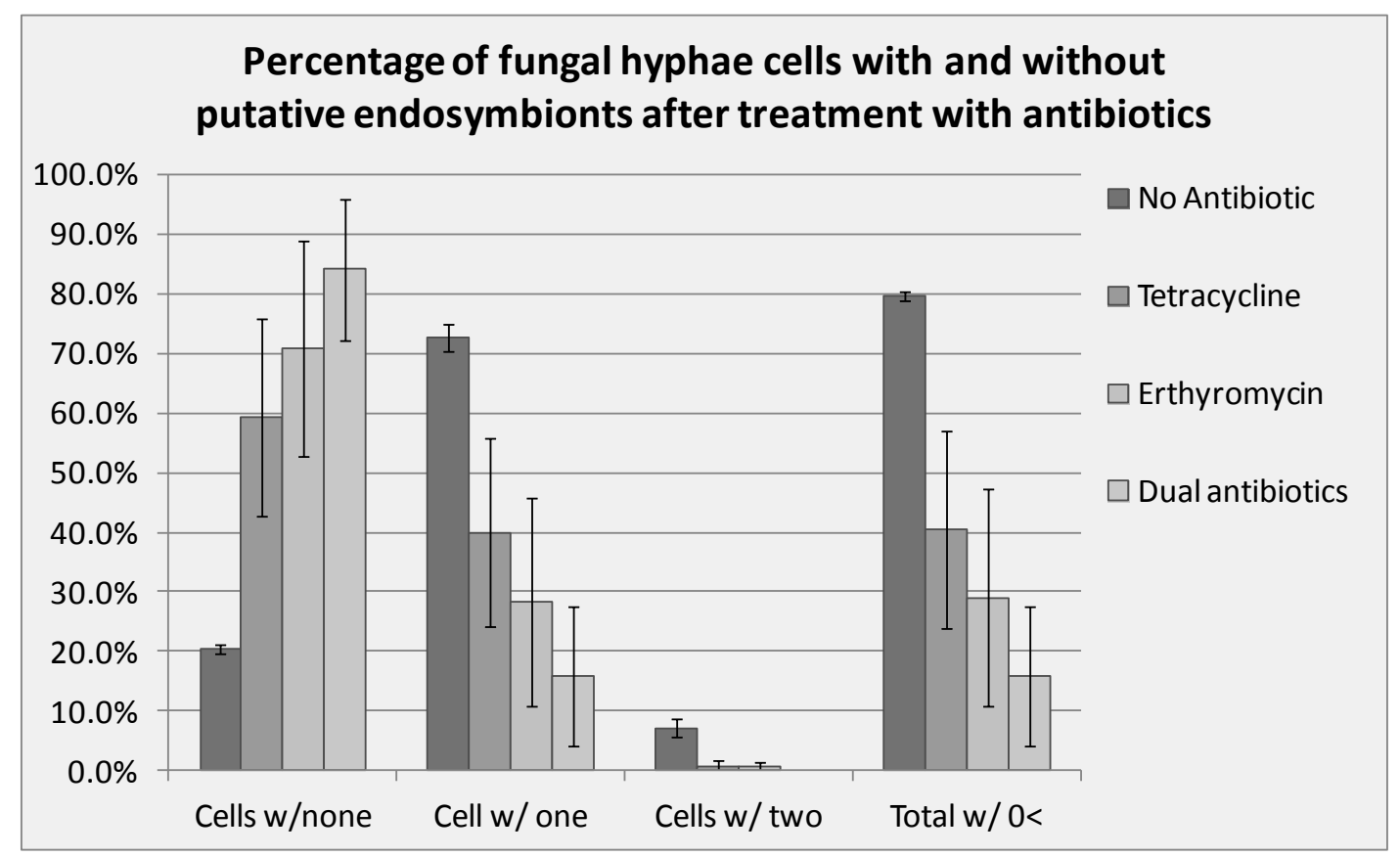

Figure 16. The percentage of fungal cells with and without putative endosymbionts after treatment with antibiotics. The bars represent the counts from five fields of view from each sample in triplicate cultures. Error bars are one standard deviation. 
The overall reduction in number of putative endosymbionts per cell in the fungi upon treatment with antibiotics supports the hypothesis that the motile intercellular bodies from the fungi vacuoles are bacterial endosymbionts. The two species of endosymbionts identified in this study (see below) belong to the genera Burkholderia and Bradyrhizobium. Earlier work has shown that Burkholderia carry efflux pumps that render them less susceptible to Ery and Tet but the resistance could be overwhelmed with sufficient concentrations of antibiotic $[83,86]$. There is also a possibility that antibiotic resistance is present in the Bradyrhizobium strain as well though other researchers have shown that $40 \mu \mathrm{g} / \mathrm{mL}$ Ery inhibits the majority of strains and $30 \mu \mathrm{g}$ Tet inhibited all but $15 \%$ of tested strains $[113,114]$. Even at high concentrations of antibiotics, $(2,490 \mu \mathrm{g} /$ $\mathrm{mL}$ Ery and $189 \mu \mathrm{g} / \mathrm{mL}$ Tet) and prolonged exposures (3 passages of durations of more than 3 days followed by constant exposure) we could not eliminate all putative symbionts. The failure of the treatments to totally eliminate the putative endosymbionts also might indicate that the fungal cells protect the endosymbionts from antibiotics in some fashion, that some of the putative symbionts may in fact be intercellular inclusions, that the antibiotics we have used are not optimal for these endosymbionts, or that the fungi cannot live without the endosymbionts.

\section{Bacterial Endosymbiont Isolation}




Culturing
of the
supernatant
obtained by
rupturing Asp01
hyphael cells in
TSB and then
streaking the
supernatant on to
TSB plates led to
a single colony
type containing

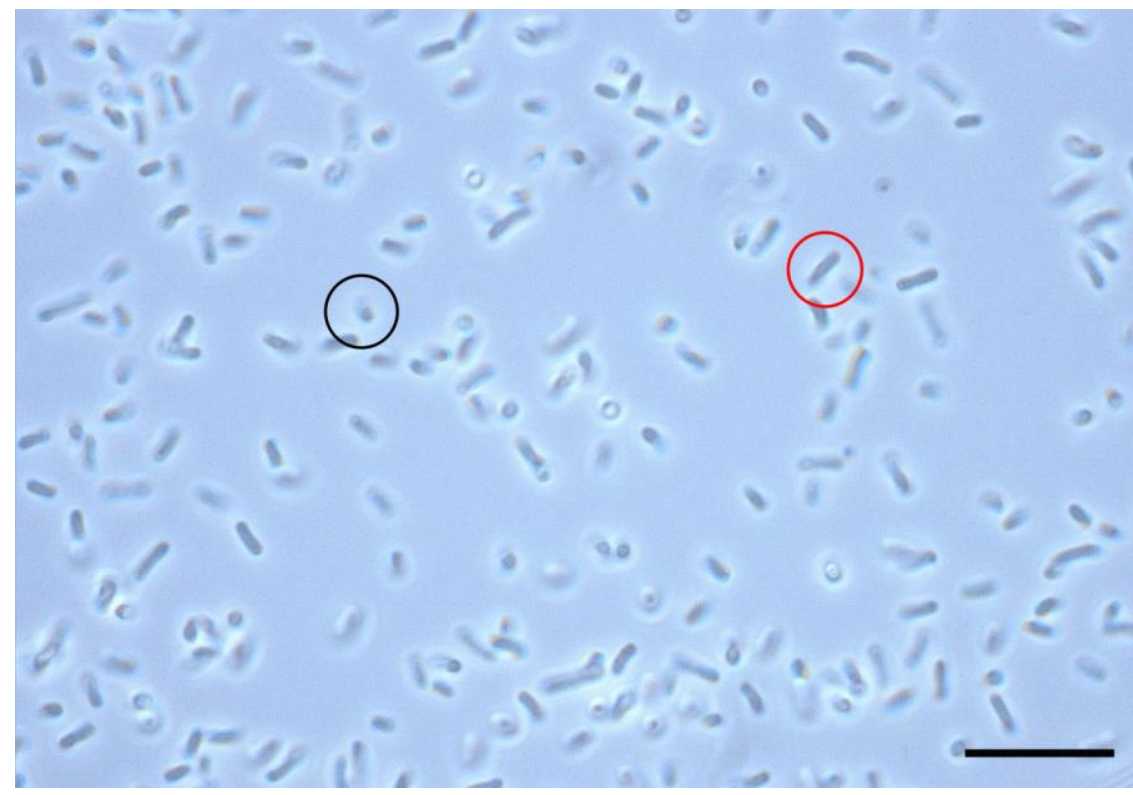

Figure 17. Mixed bacterial cultures from the TSA plates produced from the rupturing of the Asp01 hyphae and the plating of the resultant supernatant. The black circle indicates the squat shorter rod and the red circle shows the longer narrower rod. Subsequent vacuum filter separation attempts isolated the smaller of the two rods in culture which was then identified as Bradyrhizobium sp.. Bar equals $5 \mu \mathrm{M}$.

two morphologies of prokaryotic cells, one squat rod shape $(1-2 \mu \mathrm{M} \times 1 \mu \mathrm{M})$ and one slender rod-shaped (4-5 $\mu \mathrm{M}$ long x $1 \mu \mathrm{M})$, (Fig. 17). Based on similarity with the putative endosymbionts from the fungi we have studied we targeted the squat rod shaped bacterium for further isolation. An isolate of the squat rod-shaped bacterium was obtained after $2 \mu \mathrm{m}$ filtration (see materials and methods). 


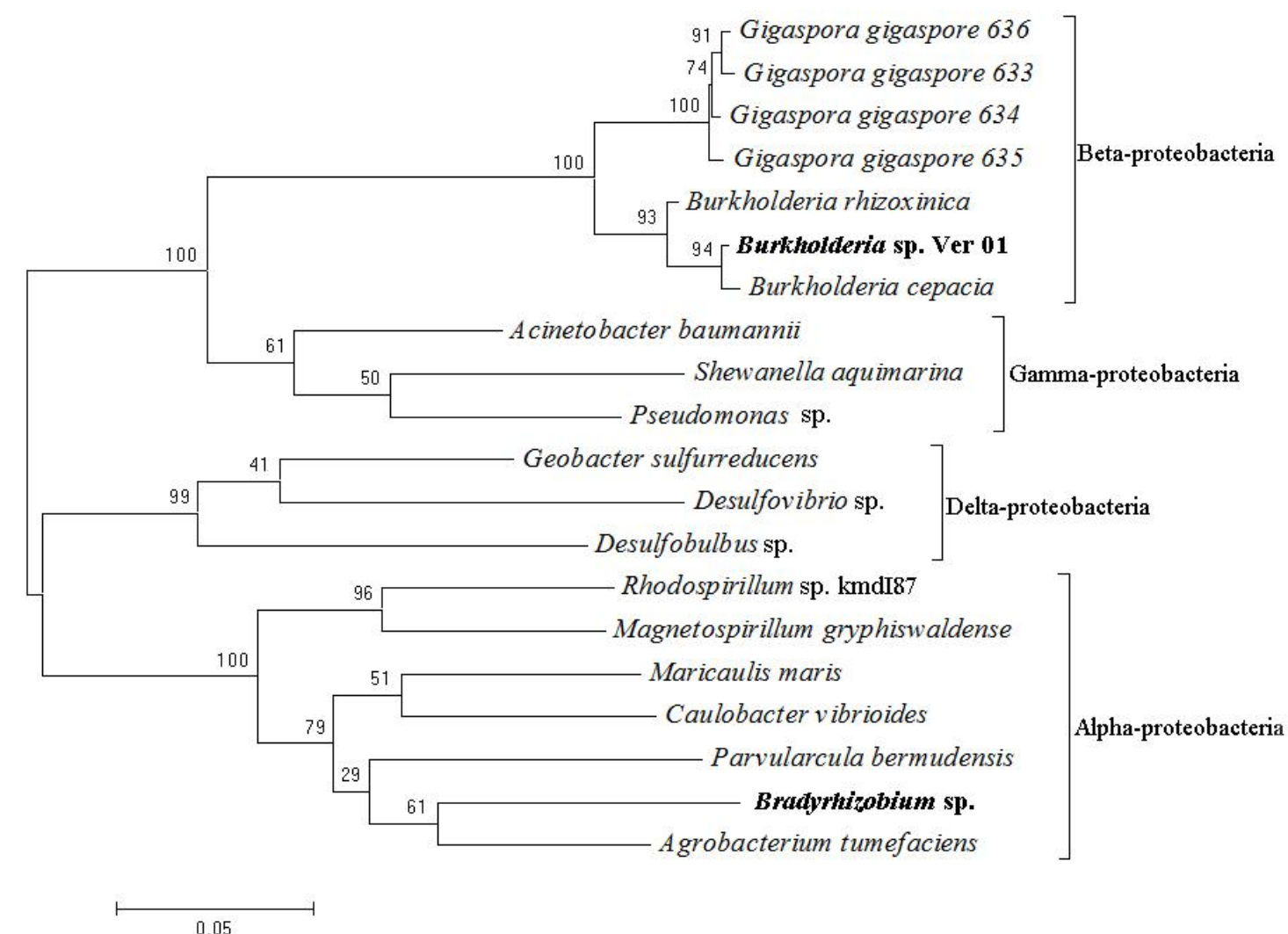

Figure 18. Molecular Phylogenetic analysis by Maximum Likelihood with the two putative bacterial endosymbionts, Burkholderia (from fungal gDNA) sp. and Bradyrhizobium sp. (from isolate) both in bold text. The $G$. gigaspore and B. rhizoxinica sequences represent the bacterial species found in the hyphae of fungus from the Zygomycota. Other bacterial sequences were obtained from bacterial taxonomy set \#1913456 on the NCBI website. The evolutionary history was inferred by using the Maximum Likelihood method based on the Tamura-Nei model, bootstrapped with 500 replications. The tree with the highest log likelihood (-6478.7247) is shown. The percentage of trees in which the associated taxa clustered together is shown above the branches. Initial tree(s) for the heuristic search were obtained automatically as follows. When the number of common sites was $<100$ or less than one fourth of the total number of sites, the maximum parsimony method was used; otherwise BIONJ method with MCL distance matrix was used. The tree is drawn to scale, with branch lengths measured in the number of substitutions per site. The analysis involved 20 nucleotide sequences. All positions containing gaps and missing data were eliminated. There were a total of 840 positions in the final dataset.

Evolutionary analyses were conducted in MEGA5

\section{PCR of Bacterial Isolates and in situ Bacteria from fungal gDNA}


Analysis of a

$1,076 \mathrm{bp}$ fragment of the

$16 \mathrm{~S}$ rDNA sequence from

the isolate obtained via

PCR using universal

bacterial primer set

$8 \mathrm{~F} / 1,391 \mathrm{R}$, revealed a

microbial phylotype $100 \%$

identical to

Bradyrhizobium, a genus

of the $\alpha$-Proteobacteria

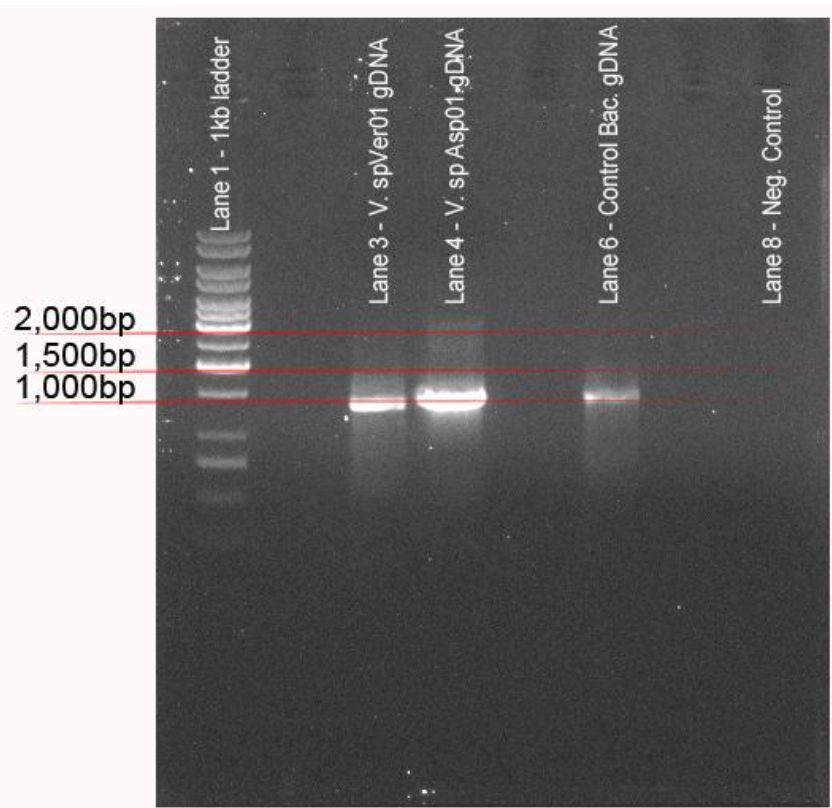

Figure 19. PCR product from fungal gDNA culture using generic bacterial $16 \mathrm{~S}$ primers $8 \mathrm{~F} / 1391 \mathrm{R}$. Lane 3 is V. sp. Ver01 gDNA, Lane 4 is V. sp. Asp01 gDNA, Lane 6 is gDNA from a Shewanella isolate, Lane 8 is the negative control using nuclease free water, unmarked lanes are blank

(Figure 18). Bradyrhizobium are known for being involved in nodule formation in legumes where they are involved in nitrogen fixation but they are also free living in the soil [60, 61, 115]. The Bradyrhizobium-specific primer Brady155 constructed based on the obtained isolate's rDNA sequence coupled with generic bacterial primer 1391R amplified DNA from both genomic fungal extracts but we could not obtain unambiguous sequences from these amplicons.

For bacterial culture independent analysis PCR was performed with various primers using the genomic fungal extract. No amplification occurred with the Archaeal primer pair 4F/1492R (image not shown), but amplification occurred with the bacterial primers 8F/1391R (Fig 19).

The sequencing of a 1,369 bp fragment of the $16 \mathrm{~S}$ gene from $V$. spVer01 and a similarly sized fragment from $V$. sp. Asp01 revealed a microbial phylotype $99 \%$ identical 
to Burkholderia sp. ( $\beta$-Proteobacteria), (Fig. 18). This finding is in accord with earlier works showing that strains of $\beta$-Proteobacteria closely related to Burkholderia are endosymbionts in species of the Zygomycota [7, 8].

\section{Fluorescent in situ Hybridization}

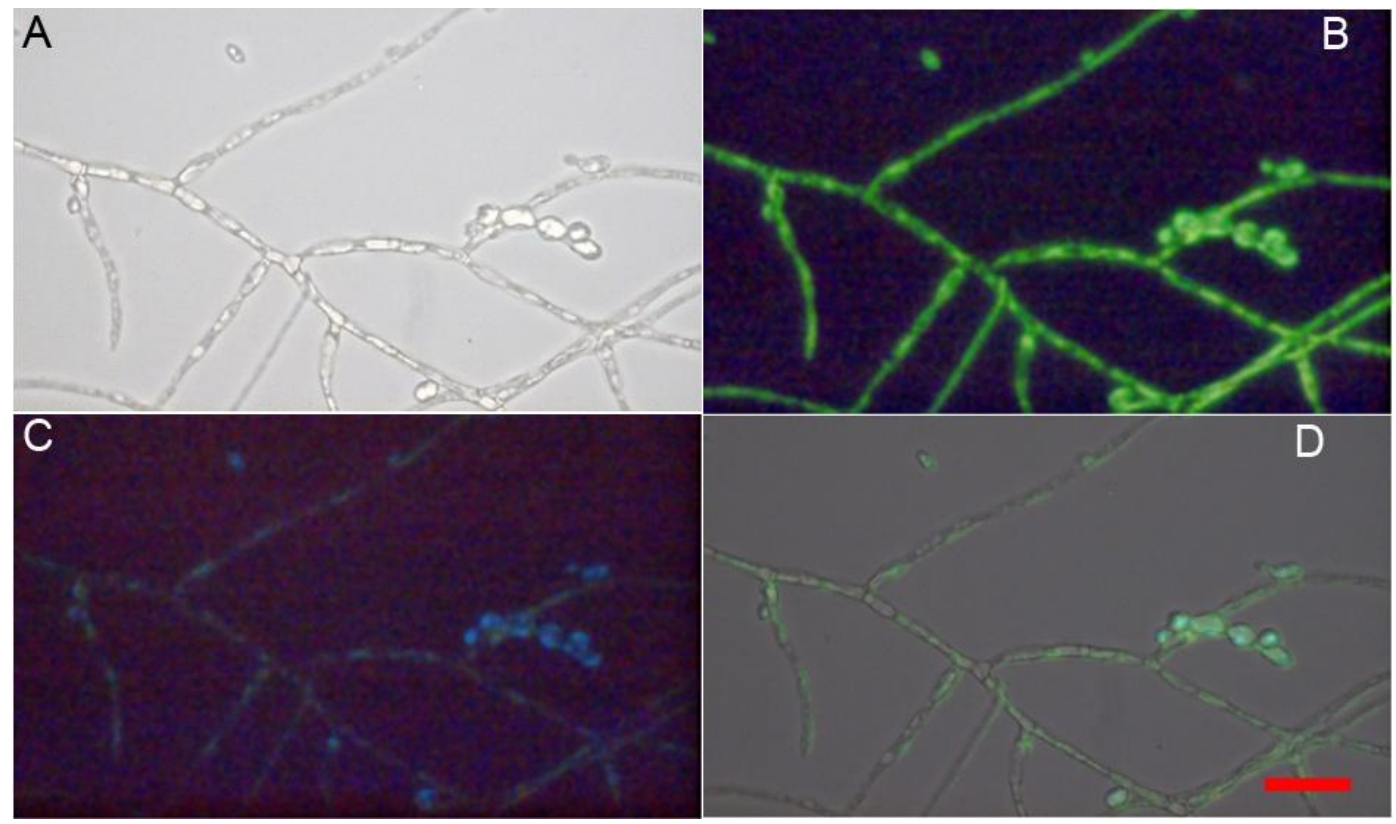

Figure 20. $V$. spAsp01 hybridized with fluorescent fungal probe VERT164 and fluorescent generic bacterial probe NON338. Image A is a light image of the fungal hyphae, image B is the EFM with porbe VERT164, image $\mathrm{C}$ is the EFM with generic bacterial probe NON338, image D is a merge of images $\mathrm{A}, \mathrm{B}$ and $\mathrm{C}$. Bar equals $10 \mu \mathrm{m}$.

Based on results shown above, the isolated strains of Verticilium fungi may contain one or two putative endosymbionts: members of Burkholderia sp. and Bradyrhizobium sp. In order to determine if either or both bacterial strains are present within the fungal hyphae, Fluorescent in situ hybridization (FISH) was performed using both fungal and bacterial probes (see materials and methods). An image of Verticillium 
sp. Asp01 hybridized with the fungal probe VERT164 and with the generic bacterial probe NON338 is shown in Figure 20 and $V$. sp. Ver01 is shown in Figure 21.

In both Figure 20 and Figure 21 the fungal probe is bound throughout the hyphae with concentrations around what is assumed to be the fungal nuclei. The bacterial probe

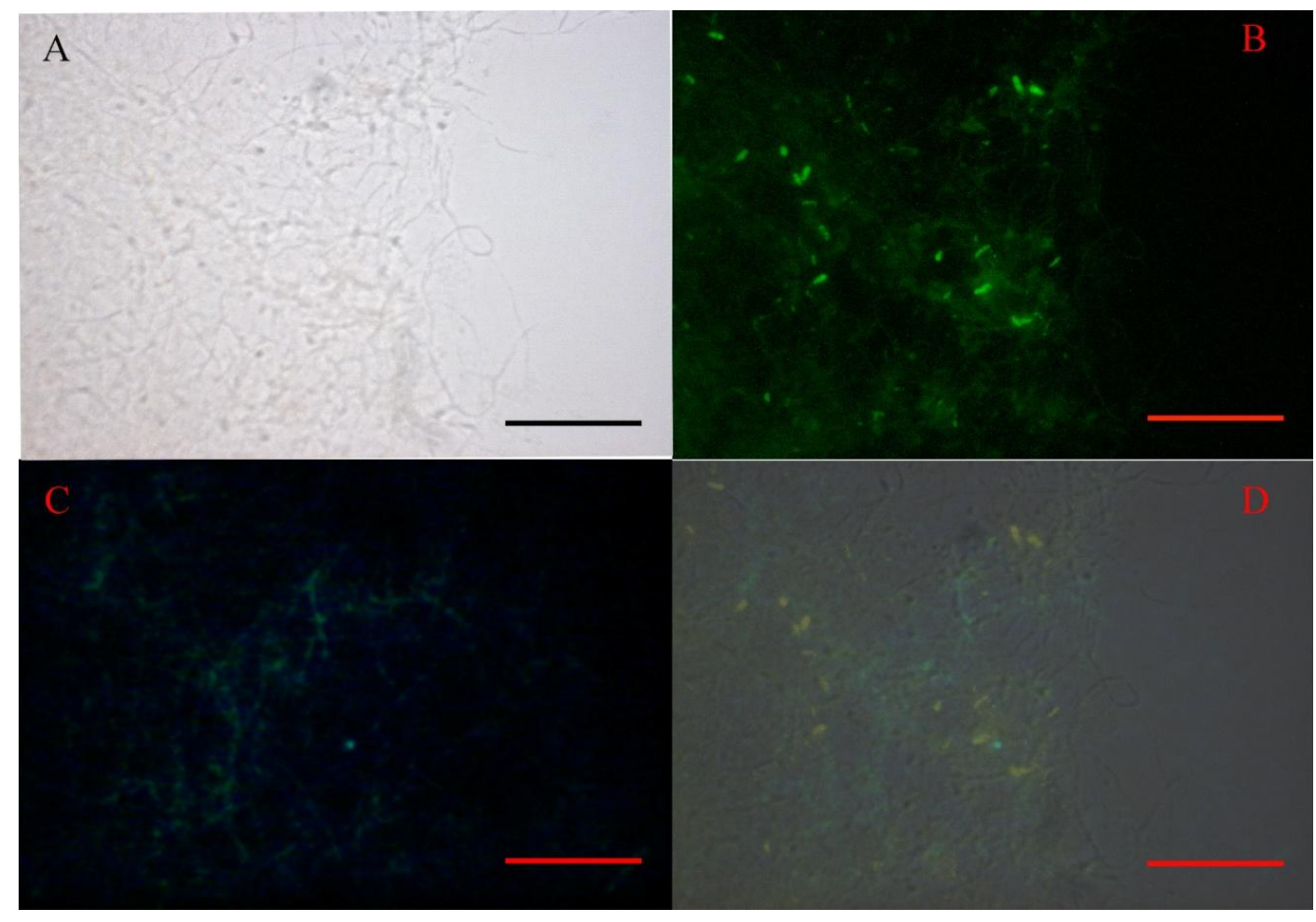

Figure 21. Verticillium sp Ver01 hybridized with florescent fungal probe VERT164 and fluorescent generic bacterial probe NON338. Image A is a light image of the fungal hyphae, image B is the EFM of the fungal probe, image $\mathrm{C}$ is the $\mathrm{EFM}$ of the generic bacterial probe, image $\mathrm{D}$ is a merge of images $\mathrm{A}, \mathrm{B}$ and C. Bar equals $10 \mu \mathrm{m}$.

is bound in specific areas of the hyphae concentrated in the vacuoles in Figure 20 and in the hyphae in Figure 21. This probe binding configuration of possible endosymbionts concentrated in vacuoles and distinct from fungal nuclei corresponds to that seen with phase and fluorescent microscopic examinations. 
These results indicate that putative bacterial endosymbionts are present in the fungal cells. The use of the fungal probe in conjunction with the bacterial probe also indicates that these bacteria are distinct and separate from the fungus, occupying cells within the hyphae.

In Verticillium sp. Ver01 the endosymbionts appeared to be localized within normal hyphael cells (Figure 21), while in $V$. sp. Asp01 the endosymbionts were more

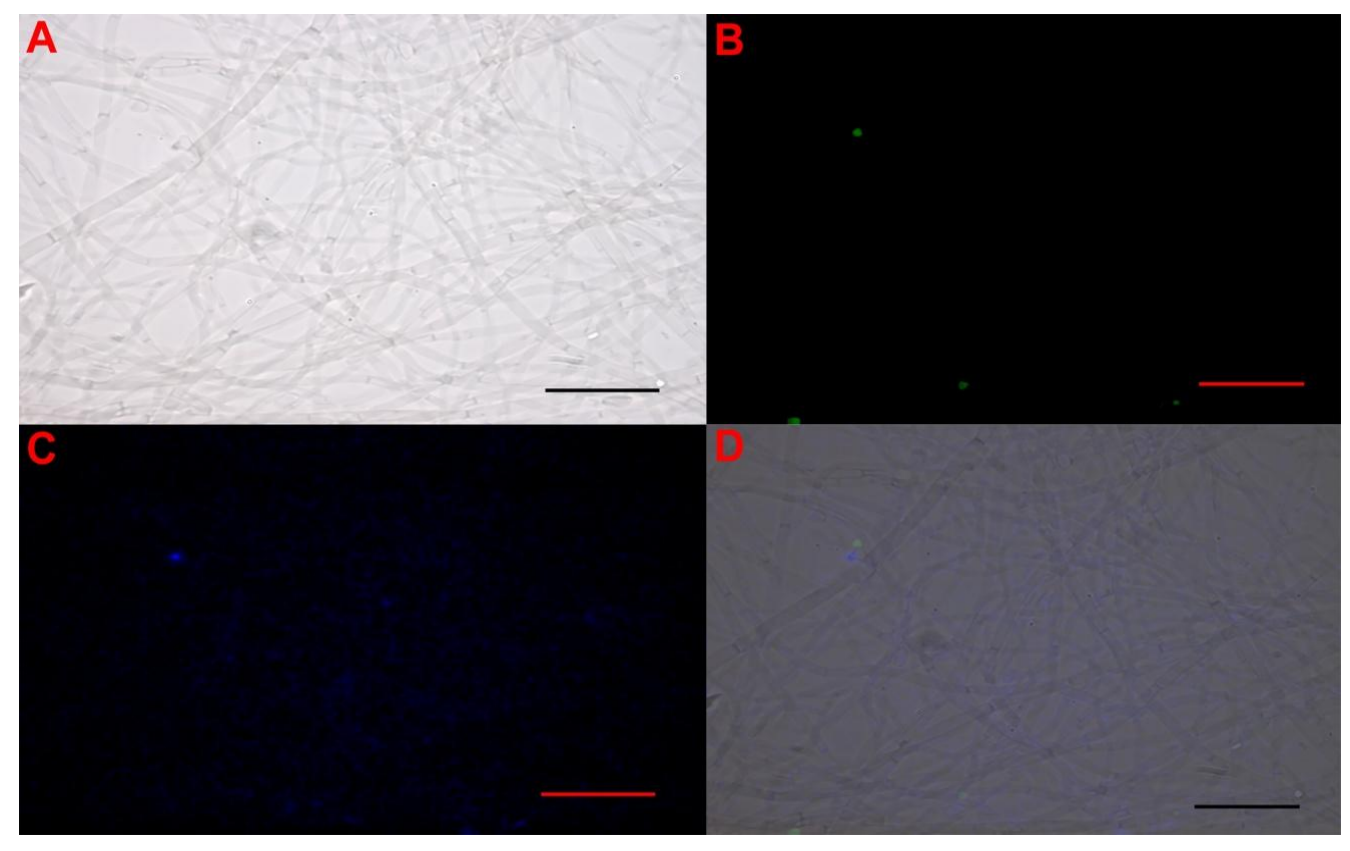

Figure 22. V. sp. Ver01 hyphae hybridized with specific bacterial probes BURK8 and BRAD865. Image A shows the light image, Image B is the probe BURK8, Image C is the probe BRAD865, Image D is an overlap of Images A, B and C. The two bacterial probes bind in independent areas that though near each other are in different hyphael cells. There is no indication of binding to fungal structures by either probe.

frequently concentrated in vacuoles (Figure 20). In both fungi the majority of fungal cells carry few or no endosymbionts. These results support our earlier observations of the distribution of the putative symbionts within hyphae and vacuoles (see figures 12 and 13). 
Double FISH staining of the hyphae with the probes BURK8 and BRAD865 indicated that both putative endosymbionts are present in the same hyphae, albeit in different cells (Fig 22 for Verticillium sp. Ver01; results not shown for Verticillium sp. Asp01).

Although some eukaryotes have already been shown to contain more than one species of endosymbionts, the presence of multiple symbionts in fungi has not yet been reported $[54,55,66]$. 


\section{Chapter 5}

\section{Characterization of isolated Bradyrhizobium strains}

\section{Isolated Bradyrhizobium observations}

Attempted isolation of the intercellular bacteria present in the hyphae of Verticilium sp. Ver01 and Verticillium sp. Asp01 produced one viable isolate, as described previously in chapter 4 . Sequencing of the $16 \mathrm{~S}$ rRNA gene indicated that this isolate was from the bacterial genus Bradyrhizobium (Figure 19), an endemic soil bacteria that forms nodules in association with legumes where it fixes nitrogen in a bio-available form for the plants.

The bacteria were slow growing, forming colonies on Luria broth plates incubated at $30^{\circ} \mathrm{C}$ that were $1 \mathrm{~mm}$ in diameter in approximately two weeks. Visual inspection indicated that the culture only grew slowly in TSB, Luria Broth and R2A liquid media but a higher density of cells was observed in $1 / 10$ dilute LB. In keeping with the anaerobic tolerance seen in

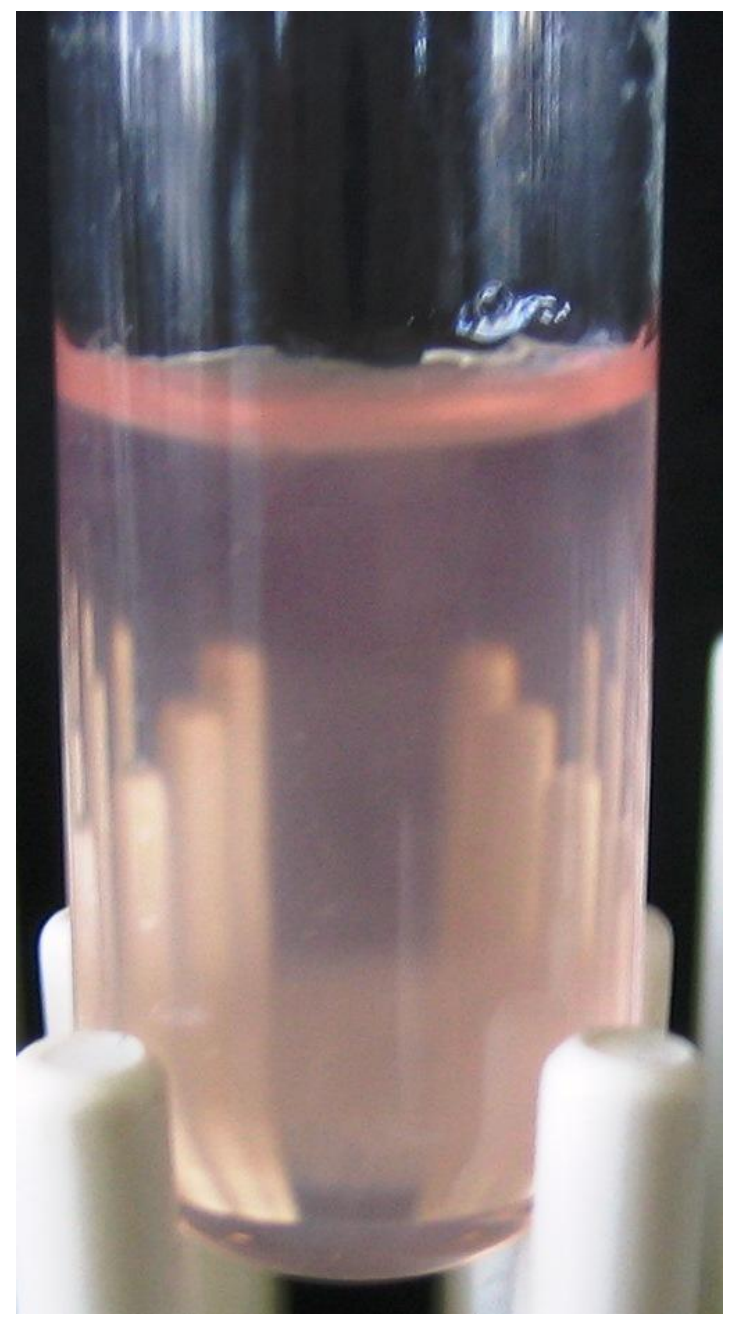

Figure 23. Bradyrhizobium isolate culture growing in 1/10 diluted LB agar with rezaurine redox indicator. 
Bradyrhizobium the isolate grew in the lower portion of dilute LB soft agar with resazurin as a redox potential indicator (Fig. 23) [60]. The culture is growing at the bottom of the test tube where the rezaurine is showing that the redox potential of the media is low. This is in keeping with the known anaerobic tolerance of this microbe.

The Bradyrhizobium isolate was tested for growth on multiple carbon sources including the organic acids that increased in concentration with the administration of antibiotics detected in the earlier GC/HPLC analysis (Figure 8). The bacteria could grow in media where a mix of butyric acid, propanoic acid, caproic acid and valeric acid was the provided energy source (data not shown). The best growth was observed when lactate, acetate, succinate and pyruvate (LASP) was provided (not shown). Each of the LASP components was then tested alone or in conjunction others and it was found that no growth was observed with the lactate alone and the addition of lactate in combination with any of the others did not produce any additional growth in culture (data not shown).

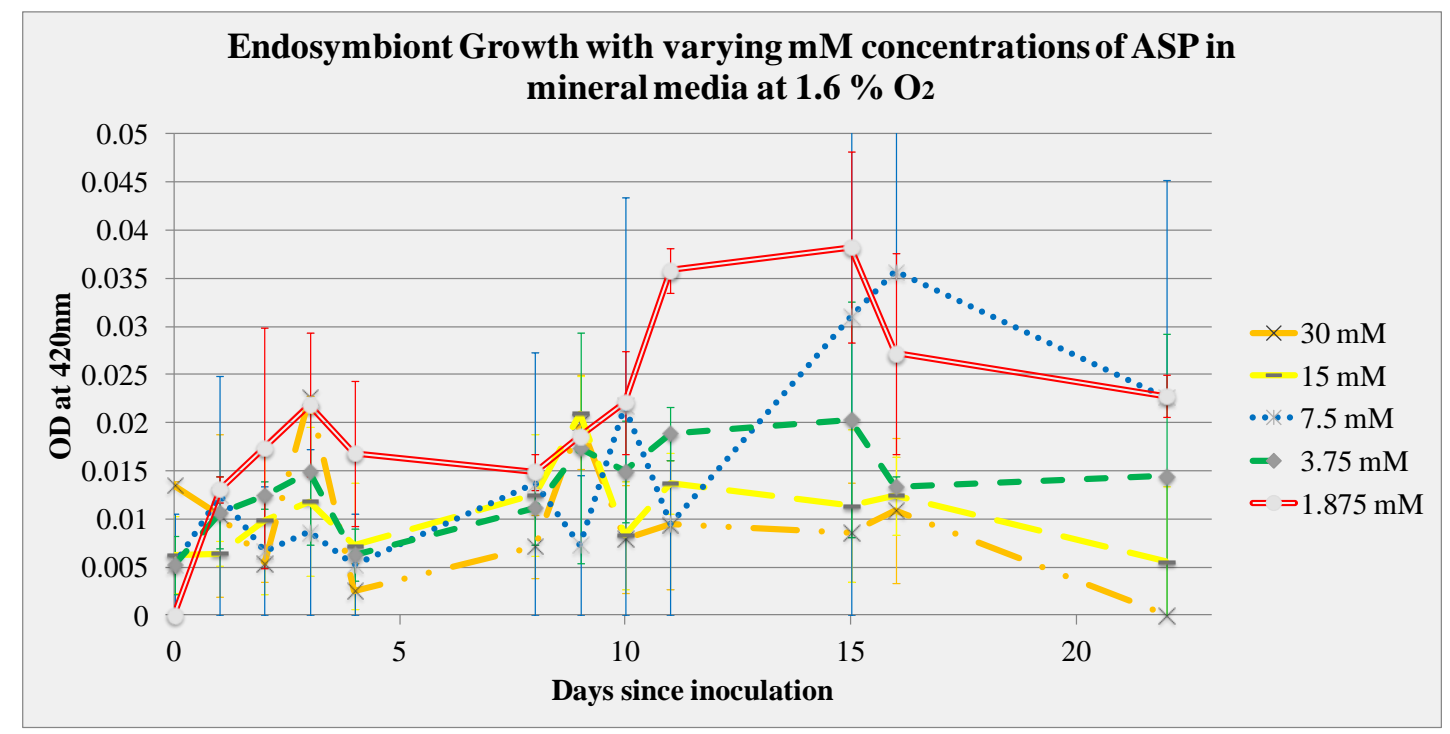

Figure 24 Bradyrhizobium isolate grown in 1.6\% oxygen with varying concentrations of ASP provided as an energy source. Error bars are one standard deviation. 
This is consistent with the inability of other Bradyrhizobium cultures to utilize lactate [60].

Bradyrhizobium grown in culture with declining concentrations of ASP (acetate, succinate and pyruvate) and $1.6 \%$ provided headspace $\mathrm{O}_{2}$ were analyzed to determine growth with these nutrient sources (Fig. 24). The most abundant growth was seen with the lowest concentration of ASP, $1.87 \mathrm{mM}$ but overall growth could not be predicted by the concentration of the energy sources in the media. Growth in culture was low overall as previously seen in visual inspections of cultures.

The Burkholderia sp. found in the fungal hyphae via PCR amplification and FISH probing was never successfully isolated in culture. Repeated culturing attempt using commercially available media (LB and TSA) as well as on lab produced plates selective for Burkholderia cepacia never produced the Burkholderia sp. localized within the fungal hyphae. Alteration in incubation temperatures (room temperature (approximately $22^{\circ} \mathrm{C}$ ), $30^{\circ} \mathrm{C}, 37^{\circ} \mathrm{C}$ and $50^{\circ} \mathrm{C}$ ) and oxygen levels (atmospheric and $1.6 \%$ $\mathrm{O}_{2}$ ) also failed to yield any growth of the bacteria. It is unknown as to why this bacterium could not be isolated. It could be the result of obligate symbiosis or it might also be that the correct media and growth condition have not been found. 


\section{Chapter 6}

\section{Conclusions and future work}

Two acid and alkali tolerant fungal isolates putatively from the genus Verticilium appear to carry two different Proteobacteria within their hyphael cells, one from the genus Burkholderia and one from the genus Bradyrhizobium. One of the bacteria, Bradyrhizobium sp., could be isolated and cultured outside of the fungal hyphae but the other, Burkholderia sp., could not be isolated from the fungal hyphae in the lab. This is not without precedent. Of the other fungal endosymbionts from the genus Burkholderia found within the Zygomycota, only the ones from R. microsporus have been cultured outside the fungal hyphae $[7,8,65,109]$. The other endosymbiont $G$. margarita, while extractable, did not reproduce outside the fungal hyphae and could be maintained in a lab setting for only short periods of time.[116]

The bacteria within the hyphae of these novel fungal isolates were also found to be resistant to elimination by erythromycin and tetracycline antibiotics as shown in figure 16. It is unknown if this represents an antibiotic resistance in the bacteria or a failure of the antibiotic to penetrate the fungal hyphae to reach the bacteria at the concentrations necessary to eliminate them. It might also point towards an obligate relationship between at least one of the bacteria and the fungus. Because only fungi with endosymbionts were seen post-antibiotic treatment this points to only fungal hyphae that can maintain at least some of their endosymbionts are seen in culture after the administration of antibiotics. Further work in this area could indicate not only which bacterial species survive the antibiotic treatments but also if they can be fully eliminated from the cells with antibiotic level that do not inhibit the fungal growth or other antibiotics not used here. 
Future work could also determine if either endosymbiont is a new species not before categorized within these genus'. Sequencing of more genes from the Bradyrhizobium isolate and a more complete sequencing of the Burkholderia DNA found with the fungal gDNA could give more clues as to possible origin of these two microbes. 


\section{Chapter 7}

\section{MATERIALS AND METHODS}

\section{Growth in oligotrophic and acid conditions}

\section{Fungal Isolation}

Isolation from the original acid solution by previous researchers (personal communication with Susan Holmes) was performed by streaking onto whey agar plates at $30^{\circ} \mathrm{C}$. Two distinct colony types were identified based upon color and morphology. White colonies were designated Ver01 and black colonies designated Asp01.

\section{Fungal media:}

\section{X $\mathrm{H}^{+}$Mc Basal salts mix}

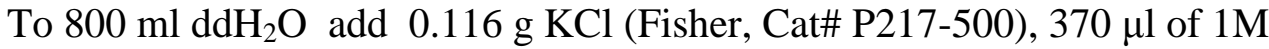
$\mathrm{K}_{2} \mathrm{HPO}_{4}$ in $\mathrm{ddH}_{2} \mathrm{O}$ (Spectrum, Cat\# P1383), $1 \mathrm{ml}$ of $1 \mathrm{M} \mathrm{NaHCO}_{3}($ Fisher Cat\# 144-55-8). Do not adjust the $\mathrm{pH}$, it will be approximately 8.3. Bring the volume to $1 \mathrm{~L}$ with $\mathrm{ddH}_{2} \mathrm{O}$ and store refrigerated in an acid washed glass (Pyrex) reagent bottle.

\section{$\mathrm{H}^{+} \mathrm{Mc}$ Trace elements solution}

To $800 \mathrm{~mL} \mathrm{ddH}_{2} \mathrm{O}$ add $3.0 \mathrm{~g} \mathrm{MgSO}_{4}$ x $7 \mathrm{H}_{2} \mathrm{O}$ (Fisher Cat \#10034-99-8), $0.05 \mathrm{~g}$ $\mathrm{Mn}(\mathrm{II}) \mathrm{Cl}_{2}$ x $4 \mathrm{H}_{2} \mathrm{O}$ (Sigma Cat\#203734), 0.1 g Fe(III)Cl $\mathrm{Cl}_{3}$ 6 $\mathrm{H}_{2} \mathrm{O}$ (Sigma Cat\#451641), $0.1 \mathrm{~g} \mathrm{CoCl}_{2}$ × $6 \mathrm{H}_{2} \mathrm{O}$ (Sigma Cat\# C8661), $0.1 \mathrm{~g} \mathrm{CaCl}_{2}$ x $2 \mathrm{H}_{2} \mathrm{O}$ (Sigma Cat\#C7902), 0.05 $\mathrm{g} \mathrm{ZnCl}_{2}$ (Sigma Cat\# 456805), $0.02 \mathrm{~g} \mathrm{CuCl}_{2}$ x2 $\mathrm{H}_{2} \mathrm{O}$ (Sigma Cat\# C3279), $0.01 \mathrm{~g}$ $\mathrm{AlK}\left(\mathrm{SO}_{4}\right)_{2}$ x $12 \mathrm{H}_{2} \mathrm{O}$ (Sigma Cat\#A6435), $0.01 \mathrm{~g} \mathrm{H}_{3} \mathrm{BO}_{3}$ (Sigma Cat\#B6768) and $0.01 \mathrm{~g}$ $\mathrm{Na}_{2} \mathrm{MoO}_{4} \times 2 \mathrm{H}_{2} \mathrm{O}$ (Sigma Cat\# M1651). Bring volume to $1 \mathrm{~L}$ with $\mathrm{ddH}_{2} \mathrm{O}$ and store in reagent bottle at $4^{\circ} \mathrm{C}$.

\section{Wolfe 10 vitamins mix}


In a Pyrex reagent bottle mix: 1 volume of $50 \mu \mathrm{g} / \mathrm{ml} \mathrm{p}$-Aminobenzoic acid, 1 volume of $50 \mu \mathrm{g} / \mathrm{ml}$ Biotin, 1 volume of $50 \mu \mathrm{g} / \mathrm{ml}$ Cyanocobalamin, 1 volume of 50 $\mu \mathrm{g} / \mathrm{ml}$ Folic acid, 1 volume of $1 \mathrm{mg} / \mathrm{ml}$ i-Inositol, 1 volume of $1 \mathrm{mg} / \mathrm{ml}$ Nicotinic acid, 1 volume of $1 \mathrm{mg} / \mathrm{ml}$ Pyridoxine, 1 volume of $1 \mathrm{mg} / \mathrm{ml}$ Panthotenic acid, 1 volume of $1 \mathrm{mg} / \mathrm{ml}$ Riboflavin, and 1 volume of $1 \mathrm{mg} / \mathrm{ml}$ Thiamine. Store at $4^{\circ} \mathrm{C}$ and filter sterilize prior to use. The 10 vitamins mix contains: $5 \mu \mathrm{g} / \mathrm{ml} \mathrm{p}$-aminobenzoic acid; $5 \mu \mathrm{g} / \mathrm{ml}$ biotin; $5 \mu \mathrm{g} / \mathrm{ml}$ cyanocobalamin; $5 \mu \mathrm{g} / \mathrm{ml}$ folic acid; $100 \mu \mathrm{g} / \mathrm{ml}$ i-inositol; $100 \mu \mathrm{g} / \mathrm{ml}$ nicotinic acid; $100 \mu \mathrm{g} / \mathrm{ml}$ pyridoxine; $100 \mu \mathrm{g} / \mathrm{ml}$ panthotenic acid; $100 \mu \mathrm{g} / \mathrm{ml}$ riboflavin and 1 $\mu \mathrm{g} / \mathrm{ml}$ thiamine.

\section{Acidic Fe(II) stock solution}

Titrate a desired volume of $\mathrm{ddH}_{2} \mathrm{O}$ to $\mathrm{pH} 2.4$ using concentrated $\mathrm{HCl}$. Add $\mathrm{Fe}(\mathrm{II}) \mathrm{SO}_{4} \times 6 \mathrm{H}_{2} \mathrm{O}$ to a concentration of $500 \mathrm{mM}$ with stirring. Solution must be used immediately or can be stored frozen in aliquots of up to $50 \mathrm{~mL}$ in sealed containers.

\section{pH neutral liquid media}

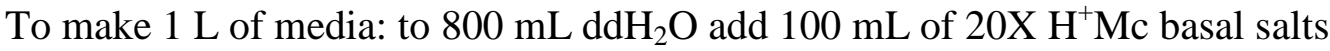
mix and $20 \mathrm{~mL} \mathrm{H}^{+} \mathrm{Mc}$ trace elements solution then adjust the $\mathrm{pH}$ to 7 using $5 \mathrm{M} \mathrm{NaOH}$ or concentrated $\mathrm{HCl}$. Add $1.00 \mathrm{~mL}$ of $1 \mathrm{M} \mathrm{NH}_{4} \mathrm{Cl}$ (Aldrich Cat. \# 32,637-2), $100 \mu 15 \mathrm{~g} / \mathrm{L}$ yeast extract (final conc. $=0.5 \mathrm{mg} / \mathrm{L}$ ), titrate to $\mathrm{pH} 7$ using $5 \mathrm{M} \mathrm{NaOH}$ or concentrated $\mathrm{HCl}$ and bring the volume $1 \mathrm{~L}$ using $\mathrm{ddH}_{2} \mathrm{O}$. Liquid media is then autoclaved at $121^{\circ} \mathrm{C}$ in desired container to sterilize. Add filter-sterilized Wolfe 10-vitamin mix to a concentration of $1 \mathrm{~mL} / \mathrm{L}$. Filter sterilized acidic Fe(II) stock solution $(\mathrm{pH} 2.4,500 \mathrm{mM}$ $\left.\mathrm{Fe}(\mathrm{II}) \mathrm{SO}_{4}\right)$ can be added after media has cooled from autoclaving to desired concentration. Yeast extract can be omitted to produce "nutrient-free" media. 


\section{Acidic liquid growth media (minimal nutrient media)}

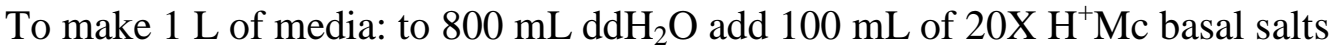
mix and $20 \mathrm{~mL} \mathrm{H}^{+} \mathrm{Mc}$ trace elements solution then adjust the $\mathrm{pH}$ to 2.4 using concentrated $\mathrm{HCl}$. Add $1.00 \mathrm{~mL}$ of $1 \mathrm{M} \mathrm{NH}_{4} \mathrm{Cl}$ (Aldrich Cat. \# 32,637-2), $100 \mu \mathrm{l} \mathrm{5g/L}$ yeast extract (final conc. $=0.5 \mathrm{mg} / \mathrm{L}$ ), titrate to $\mathrm{pH} 2.4$ using concentrated $\mathrm{HCl}$ and bring the volume $1 \mathrm{~L}$ using $\mathrm{ddH}_{2} \mathrm{O}$. Liquid media is then autoclaved at $121^{\circ} \mathrm{C}$ in desired container to sterilize. Add filter-sterilized Wolfe 10-vitamin mix to $1 \mathrm{~mL} / \mathrm{L}$. Filter

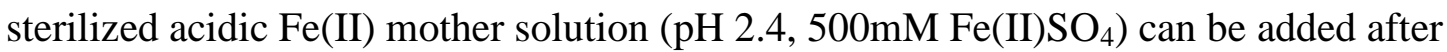
media has cooled from autoclaving to desired concentration. Yeast extract can be omitted to produce "nutrient-free" media.

\section{Acidic agarose Fe(II) Plates (pH 2.5, 3.5\% Agarose, 20mM Fe (II) $\mathrm{SO}_{4}$ )}

To a 1L screw top bottle add $100 \mathrm{~mL}$ of acidic liquid growth media. In a separate

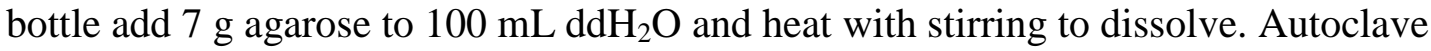
both bottles 15 minutes at $121^{\circ} \mathrm{C}$. Allow both solutions to cool in a $50^{\circ} \mathrm{C}$ water bath. Before the liquid growth media has cooled completely to $50^{\circ} \mathrm{C}$ add $0.2 \mathrm{~mL}$ of filter sterilized Wolfe 10-vitamin mix (final concentration: $1 \mathrm{~mL} / \mathrm{L}$ ) and $8 \mathrm{~mL}$ filter sterilized acidic $\mathrm{Fe}(\mathrm{II})$ mother solution ( $\mathrm{pH} 2.4,500 \mathrm{mM} \mathrm{Fe} \mathrm{II}) \mathrm{SO}_{4}$ ) (final concentration: $20 \mathrm{mM}$ ). When both solutions have cooled to $50^{\circ} \mathrm{C}$, pour the liquid growth media into the agarose solution carefully to avoid the formation of bubbles. Mix thoroughly but gently also avoiding the creation of bubbles and pour plates immediately.

\section{Low nutrient acidic glucose growth media}

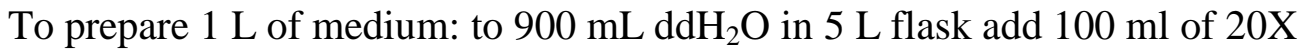
$\mathrm{H}^{+} \mathrm{Mc}$ basal salts mix and $10 \mathrm{ml} \mathrm{H} \mathrm{Hc}^{+}$trace elements solution and adjust the $\mathrm{pH}$ to 2.4 
using concentrated $\mathrm{HCl}$. Add $1 \mathrm{~mL}$ of $1 \mathrm{M} \mathrm{NH}_{4} \mathrm{Cl}$ (Aldrich, 32,637-2) and $1 \mathrm{~g}$ glucose then titrate to $\mathrm{pH} 2.4$ with concentrated $\mathrm{HCl}$. Bring the volume to $1 \mathrm{~L}$ with $\mathrm{ddH}_{2} \mathrm{O}$ and transfer to desired container, autoclave at $121^{\circ} \mathrm{C}$ for 15 minutes to sterilize.

\section{Re-suspended fungal inoculants}

Fungal inoculants were created using the mycelium from liquid media or scraped from an isolated colony on an agarose plate. Mycelium were placed in $50 \mathrm{~mL}$ Falcon tubes with the desired volume of filter sterilized $\mathrm{pH} 2.4$ liquid media containing enough Wolfe 10-vitamin mix to deliver a final concentration of $1 \mathrm{~mL} / \mathrm{L}$ of vitamin mix to the final media. This mixture was then vortexed for 20 minutes followed by centrifugation at 3,000 RPMs in a bench top centrifuge for 5 minutes. The supernatant was then used for inoculations.

\section{Antibiotic testing and efficacy}

\section{Tolerance for antibiotics in fungal hyphae}

Five $\mathrm{mL}$ of acidic liquid media with $50 \mathrm{mg} / \mathrm{L}$ yeast extract was added to $16 \mathrm{~mL}$ test tubes and sealed. The tubes were autoclaved at $121^{\circ} \mathrm{C}$ to sterilize and $100 \mu \mathrm{L}$ of Ver01 inoculant as above was added to each tube. Antibiotic mother solutions were made by vortexing antibiotic in $\mathrm{ddH}_{2} \mathrm{O}$ to the following concentrations: ampicillin $112 \mathrm{mg} / 20$ $\mathrm{mL}$, tetracycline $1 \mathrm{mg} / 2 \mathrm{~mL}$, kanamycin $100 \mu \mathrm{g} / \mathrm{mL}$, and erythromycin $1 \mathrm{mg} / 5 \mathrm{~mL}$. Rifamycin was suspended in ethanol at a concentration of $20 \mathrm{mg} / \mathrm{mL}$. Filter sterilized antibiotics were added from the stock solutions in the following amounts: $0 \mu \mathrm{L}, 2 \mu \mathrm{L}, 10$ $\mu \mathrm{L}, 50 \mu \mathrm{L}, 100 \mu \mathrm{L}, 200 \mu \mathrm{L}, 500 \mu \mathrm{L}$ and $1 \mathrm{~mL}$. Growth of the fungus was observed visually for 7 days to check for inhibition of growth (see Table 2). The fungus in the last tube that grew without inhibition was re-inoculated into media with the same 
concentration of antibiotic and allowed to grow for an additional 7 days. This was then repeated again and after 3 pasages through the antibiotic media, fungal hyphae were than assessed for intercellular movement using microscopic inspection, both unstained and stained with Invitrogen Live/Dead Baclight stain. Cultures which had a reduction or loss of putative endosymbionts were maintained in the corresponding antibiotic for further testing.

\section{Antibiotic media for culture and HPLC/GC}

Prepare fungal acidic minimal nutrient glucose growth media, transfer $50 \mathrm{~mL}$ to $250 \mathrm{~mL}$ screw top serum bottles, autoclave to sterilize and allow to cool. In a laminar flow hood add to half of the bottles filter sterilized tetracycline stock (Concentration: 100 $\mathrm{mg} / 200 \mathrm{~mL}$ ) was added to a concentration of $0.189 \mathrm{mg} / \mathrm{mL}$. To all bottles add $50 \mu \mathrm{L}$ of low-nutrient grown Ver01 culture inoculant. Incubate at $30^{\circ} \mathrm{C}$, taking $1 \mathrm{~mL}$ samples via sterile pipetting into a sterile Micro-centrifuge tube every 24 hours beginning at day 3 and continuing until growth ceased, approximately 14 days. Samples were frozen until analysis or analyzed immediately. Prior to injection into either the HPLC or GC samples are centrifuged at $<10,000 \mathrm{RPMs}$ in a table top centrifuge for five minutes to pellet all large organic material.

\section{Count of moving bodies within fungal hyphae grown with antibiotics}

$50 \mathrm{~mL}$ of minimal nutrient acidic glucose growth media was added to $250 \mathrm{~mL}$ screw cap bottles and autoclaved at $121^{\circ} \mathrm{C}$ to sterilize. $500 \mu \mathrm{L}$ of liquid from a resuspended Ver01 inoculant was pipetted into nine bottles. Filter-sterilized erythromycin stock solution was added to a final concentration of $2.49 \mathrm{mg} / \mathrm{mL}$ to three inoculated bottles and one uninoculated control. Tetracycline stock solution was added via filter 
sterilization to a concentration of $0.189 \mathrm{mg} / \mathrm{mL}$ to three inoculated bottles and one uninoculated control. Three bottles with fungi and one without were left without antibiotic. Cultures were allowed to grow for one week at $30^{\circ} \mathrm{C}$ then individual hyphae removed via pipettor and placed on a microscope slide. Five fields of hyphael networks were inspected per slide and counts made of the number of cells with movement, the number of cells without movement and if movement was detected, the number of moving bodies per cell.

\section{Bacterial Isolation and Growth}

\section{Intercellular bacterial isolation}

Both fungi were grown from re-suspended inoculants at $30^{\circ} \mathrm{C}$ in $50 \mathrm{~mL}$ of minimal nutrient acidic liquid media without iron in $250 \mathrm{~mL}$ screw cap bottles until distinct mycelium were observed. The medium was decanted off the mycelium and sterile $\mathrm{pH}$ neutral liquid media was poured over the cultures to fill the bottle. The mycelia were allowed to settle and the medium was decanted off. This procedure was repeated twice. Fungal mycelium were transferred via pipetting with $1 \mathrm{~mL}$ of the final wash media to 1.5 mL micro-centrifuge tubes that had been sterilized with a small volume of zirconia beads in them and vortexed vigorously for 15 minutes. The micro-centrifuge tubes were then centrifuged at 3,000 RPMs for 15 minutes in a table top centrifuge. The tubes were carefully removed from the centrifuge so as to not disturb the pellet and the supernatant streaked onto LB plates. The plates were incubated at $30^{\circ} \mathrm{C}$ and observed daily for growth. Isolated bacterial colonies were re-streaked onto LB plates to isolate bacteria. Microscopic examination of the bacteria from isolated colonies determined that two morphotypes, a large rod (4-5uM in length) and a small rod (1-2 $\mu \mathrm{m}$ in length) were 
present in the colonies. Subsequent plating was unable to separate the two morphotypes from one another.

\section{Bacterial separation}

Bacteria from acolony produced on the LB plates were grown in 1/10 dilute LB broth at $30^{\circ} \mathrm{C}$ and microscopically examined to determine if both morphotypes were present in the culture. The liquid culture was then vacuum-filtered on a sterilized column filtration unit using a sterile $2.0 \mu \mathrm{M}$ nylon filter. The liquid filtrate was streaked onto LB agar incubated at $30^{\circ} \mathrm{C}$ and the resultant colonies microscopically examined. An isolated colony of the small bacteria was picked for transfer to a new LB plate and assessed for homogeneity on the microscope. The pure culture was transferred to LB agar slants for maintenance at $30^{\circ} \mathrm{C}$ and $1 / 10$ diluted LB broth for biomass accumulation. After identification cultures were also maintained at $30^{\circ} \mathrm{C}$ on Bradyrhizobium japonicum selective media (BJSM).

\section{Burkholderia isolation}

Procedures for bacterial isolation from the fungal hyphae were repeated as above but plating of the supernatant was done onto Burkholderia cepacia selective agar (BSCA). The subsequent plates were incubated both aerobically and in $1.6 \% \mathrm{O}_{2}$ at varying temperatures $\left(22^{\circ} \mathrm{C}, 30^{\circ} \mathrm{C}, 37^{\circ} \mathrm{C}\right.$ and $\left.50^{\circ} \mathrm{C}\right)$. Plates were observed daily for growth and isolated colonies microscopically assessed for homogeneity. Pure colonies were transferred to BCSA agar for maintenance, TSA (Sigma Aldrich Cat. \# 22091) for colony morphology assessment and TSB (Sigma Aldrich Cat. \# 22092) for biomass growth.

\section{Endosymbiont Media:}




\section{Liquid growth media}

Fungal acidic liquid growth media titrated to $\mathrm{pH} 7$ instead of $\mathrm{pH} 2.5$ with either 5 $\mathrm{M} \mathrm{NaOH}$ or concentrated $\mathrm{HCl}$, yeast extract omitted amended with $2 \mathrm{mM}$ of succinate, acetic acid, pyruvate, and lactate (LASP) or with $2 \mathrm{mM}$ each of succinate, acetic acid, and pyruvate (ASP). Combinations of $2 \mathrm{mM}$ of succinate, acetic acid, pyruvate, of lactate can also be added to produce individual, duplex or triplex nutrient sources.

\section{Bradyrhizobium japonicum selective media (BJSM)}

To one liter of AG medium (per liter of ddH2O: $1.0 \mathrm{~g}$ glucose, $1.5 \mathrm{~g}$ glycerol, 5.0 g peptone, $5.0 \mathrm{~g}$ yeast extract, $2.0 \mathrm{~g}$ malt extract, and $\left.7.0 \mathrm{~g} \mathrm{CaCO}_{3} \cdot[117]\right)$ add $0.1 \mathrm{ug} / \mathrm{mL}$ Brilliant Green and agar to $1.5 \%$ concentration. The media was then autoclaved for 15 minutes at $121^{\circ} \mathrm{C}$ to sterilize. After cooling to $50^{\circ} \mathrm{C}$, filter sterilized stock $\mathrm{ZnCl}_{2}$ dissolved in $\mathrm{ddH}_{2} \mathrm{O}$ was added for a final concentration of $83 \mu \mathrm{g} / \mathrm{mL}$, filter sterilized stock $\mathrm{CoCl}_{2}$ dissolved in $\mathrm{ddH}_{2} \mathrm{O}$ was added for a final concentration of $88 \mu \mathrm{g} / \mathrm{mL}$ and filter sterilized cycloheximide dissolved in $\mathrm{ddH}_{2} \mathrm{O}$ was added for a final concentration of $60 \mathrm{mg} / \mathrm{mL}$ the media mixed by swirling and poured as plates. [118]

\section{Burkholderia cepacia selective agar (BSCA)}

Per liter of ddH2O: $5.0 \mathrm{~g} \mathrm{NaCl}, 10.0 \mathrm{~g}$ sucrose, $10.0 \mathrm{~g}$ lactose, $0.08 \mathrm{~g}$ phenol red, $0.002 \mathrm{~g}$ crystal violet, $10.0 \mathrm{~g}$ trypticase peptone, $1.5 \mathrm{~g}$ yeast extract and $14 \mathrm{~g}$ agar. The media was autoclaved for 15 minutes at $121^{\circ} \mathrm{C}$ to sterilize. Filter sterilized Vancomycin suspended in $\mathrm{ddH}_{2} \mathrm{O}$ added for a final concentration of $2.5 \mathrm{mg} / \mathrm{L}$ and the media poured as plates.[119]

\section{Bradyrhizobium growth curves}


$10 \mathrm{~mL}$ of ASP growth media lacking ASP was placed in Hungate tubes and $1 \mathrm{M}$ ASP stock solution added to three tubes to bring the ASP concentration to the following concentrations: $30 \mu \mathrm{M}, 15 \mu \mathrm{M}, 7.5 \mu \mathrm{M}, 3.75 \mu \mathrm{M}$ and $1.875 \mu \mathrm{M}$ with a control tube left with no ASP to serve as a control blank. The tubes were sealed with rubber stoppers and crimped. The stoppers were then punctured with large gauge needles that reached down into the liquid media and a venting syringe needle added. Tank $\mathrm{N}_{2}$ with $1.6 \% \mathrm{O}_{2}$ was bubbled through all tubes for 15 minutes to produce a $1.6 \% \mathrm{O}_{2}$ environment. The needles were then removed, the tubes autoclaved for 15 minutes at $121^{\circ} \mathrm{C}$ and allowed to cool.

After cooling the stopper were swabbed with ethanol and flamed to sterilize them. Then using a sterile syringe $10 \mu \mathrm{L}$ of Bradyrhizobium culture that had been scraped from a TSA plate and re-suspended in ASP growth media with no ASP added was injected into each tube containing the ASP media. The tubes were then read on a HP 8452A Diodearray UV - Visible Spectrophotometer ( $\pm 0.005 \mathrm{AU}$ at $440 \mathrm{~nm})$ at $420 \mathrm{~nm}$ using the uninoculated Hungate tube as the blank. All tubes were marked when initial reading were taken to ensure that all readings were obtained from the same point on the tube's surface.

\section{Staining}

\section{Invitrogen's Live/Dead Bac-light:}

Approximately $10 \mu \mathrm{L}$ of liquid culture plus a fungal mycelium was transferred onto a glass microscope slide. A chemwipe was used to absorb as much of the liquid medium as possible without touching the fungal mycelium. One $\mu \mathrm{L}$ of live/dead stain was pipetted onto the mycelium and the slide covered to minimize evaporation. The stain was then incubated for a minimum of ten minutes with dense mycelium being incubated longer. After incubation enough sterile medium was added to the slide to bring the 
volume of the droplet to $\sim 10 \mu \mathrm{L}$ and a cover slip added then gently pressed to compress the mycelium. The stained mycelium was then viewed on a Carl Zeiss, Axioscope epifluorescent microscope using filter set 05 (Excitation BP 395-440, Beam splitter FT 460, Emission LP 470).

\section{Acridine orange (AO)}

One $\mathrm{mL}$ of liquid culture media plus a fungal mycelium was pipetted into a 1.5 mL Micro-centrifuge tube and 100uL of lab prepared filter sterilized AO stock solution ( $1 \mathrm{mg} / \mathrm{mL}$ AO to lab prepared $\mathrm{pH}$ 7.4 PBS) was added. The mycelium was then allowed to incubate in the dark for 10 minutes. After incubation the fungal mycelium was transferred to an Micro-centrifuge tube filled with $1 \mathrm{~mL}$ filter-sterilized phosphate buffered saline (PBS) carrying as little of the supernatant from the staining mixture as possible. The mycelium was then allowed to de-stain in PBS for 15 minutes. The stained mycelium was then transferred with $\sim 15 \mu \mathrm{L}$ of PBS to a clean glass slide, a cover slip added and compressed with gentle pressure. The stained mycelium was then viewed on a Carl Zeiss, Axioscope epifluorescent microscope using filter set 05 (Excitation BP 395440, Beam splitter FT 460, Emission LP 470).

\section{DAPI}

Fungal mycelium was transferred to a glass slide from a liquid culture along with a small volume of media. The slide was then covered and placed in a $-20^{\circ} \mathrm{C}$ freezer for 30 minutes or until the liquid on the slide was frozen through. The slide was then removed from the freezer, allowed to thaw completely and replaced in the freezer, again until frozen through. The slide was removed from the freezer and allowed to thaw for a second time. In the dark $100 \mu \mathrm{L}$ of DAPI stock solution $(5 \mu \mathrm{g} / \mathrm{mL})$ was pipetted onto the top of 
the mycelium. A cover slip was added, compressed with gentle pressure and the slide incubated in the dark for 30 minutes. The stained mycelium was then viewed on a Carl Zeiss, Axioscope epifluorescent microscope using filter set 02 (Excitation G 365, Beam splitter FT 395, Emission LP 420).

Identification of fungus, bacteria and putative endosymbionts by PCR of genomic DNA

Fungal identification was performed using the following PCR primers:

Table 3. Fungal PCR Primers

\begin{tabular}{|c|c|c|c|c|}
\hline $\begin{array}{c}\text { Name of the } \\
\text { primer and } \\
\text { direction }\end{array}$ & Position & $\begin{array}{c}\text { Sequence } \\
\text { (5' to 3') }\end{array}$ & $\begin{array}{c}\text { Length } \\
\text { (bases) }\end{array}$ & Source \\
\hline $\begin{array}{c}\text { NS1 } \\
\text { Forward }\end{array}$ & $1-21$ & GTAGTCATATGCTTGTCTC & 19 & {$[120]$} \\
\hline $\begin{array}{c}\text { NS3 } \\
\text { Forward }\end{array}$ & $637-617$ & GCAAGTCTGGTGCCAGCAGCC & 21 & {$[120]$} \\
\hline $\begin{array}{c}\text { NS4 } \\
\text { Reverse }\end{array}$ & 1127 & CTTCCGTCAATTCCTTTAAG & 20 & {$[120]$} \\
\hline $\begin{array}{c}\text { NS7 } \\
\text { Reverse }\end{array}$ & $1638-$ & GAGGCAATAACAGGTCTGTGATGC & 24 & {$[120]$} \\
\hline
\end{tabular}

PCR reactions $(20 \mu \mathrm{L}$ volume $)$

$10 \mu \mathrm{L} 2 \mathrm{x}$ Thermo Scientific* Fermentas PCR Master Mix, 1.6 $\mu$ L Primer cocktail $(0.8 \mu \mathrm{L}$ of $10 \mu \mathrm{M}$ forward primer, $0.8 \mu \mathrm{L}$ of $10 \mu \mathrm{M}$ reverse primer), $2.0 \mu \mathrm{L} 1 \mathrm{ng} / \mu \mathrm{L}$ fungal gDNA, and $6.4 \mu \mathrm{L}$ Nuclease Free $\mathrm{H}_{2} \mathrm{O}$.

PCR Cycle: 
35 cycles, 5 minutes - Initial denaturation $95^{\circ} \mathrm{C}, 30$ seconds - Denaturation $95^{\circ} \mathrm{C}, 30$ seconds - Annealing Tm from reference in table, 2 minutes - Elongation $72^{\circ} \mathrm{C}$, 7 minutes - Final Elongation $72^{\circ} \mathrm{C}$, and $4^{\circ} \mathrm{C}-\infty$.

Bacterial identification was performed using the following PCR primers:

Table 4. Bacterial PCR Primers.

\begin{tabular}{|c|c|c|c|c|c|c|c|}
\hline $\begin{array}{l}\text { Name of the } \\
\text { primer and } \\
\text { direction }\end{array}$ & $\begin{array}{c}\text { Positio } \\
\text { n }\end{array}$ & $\begin{array}{l}\text { Sequence } \\
\text { (5' to 3') }\end{array}$ & $\begin{array}{l}\text { Length } \\
\text { (bases) }\end{array}$ & Archaea & Eubacteria & Eukarya & Source \\
\hline $\begin{array}{c}4 \mathrm{~F} \\
\text { Forward }\end{array}$ & $3-20$ & $\begin{array}{l}\text { TCCGGT } \\
\text { TGATCC } \\
\text { TGGCRG }\end{array}$ & 18 & + & - & - & [121] \\
\hline $\begin{array}{c}8 \mathrm{~F} \\
\text { Forward }\end{array}$ & $8-27$ & $\begin{array}{c}\text { AGAGTT } \\
\text { TGATCC } \\
\text { TGGCTC } \\
\text { AG }\end{array}$ & 20 & - & + & - & $\begin{array}{c}{[121,122} \\
]\end{array}$ \\
\hline $\begin{array}{c}1391 \mathrm{R} \\
\text { Reverse }\end{array}$ & $\begin{array}{l}1,408- \\
1,391\end{array}$ & $\begin{array}{c}\text { GACGG } \\
\text { GCGGT } \\
\text { GWGTR } \\
\text { CA }\end{array}$ & 17 & ++ & ++ & ++ & [122] \\
\hline $\begin{array}{c}1492 \mathrm{R} \\
\text { Reverse }\end{array}$ & $\begin{array}{l}1,510- \\
1,492\end{array}$ & $\begin{array}{c}\text { GGTTAC } \\
\text { CTTGTT } \\
\text { ACGACT } \\
\mathrm{T} \\
\end{array}$ & 19 & + & + & + & $\begin{array}{l}{[121,} \\
122]\end{array}$ \\
\hline
\end{tabular}

\section{Bradyrhizobium isolate specific primer}

Possible priming sequences within the $16 \mathrm{~S}$ rDNA sequence obtained from the Bradyrhizobium isolate were identified using the NCBI website primer-BLAST feature. All forward primers generated were then compared to known Burkholderia 16S sequences to eliminate any that had possible homology to it. The following primer was chosen based upon its lack of priming spots with the $16 \mathrm{~S}$ sequence of the Burkholderia sp. from the fungal gDNA as well as the length of amplicon that would be generated using the reverse primer 1391R.

(Brady155) 5' CCGAAAGATCGGCCCGCGTC 3'. 
PCR reactions ( $20 \mu \mathrm{L}$ volume $)$

$10 \mu \mathrm{L} 2 \mathrm{x}$ Thermo Scientific* Fermentas PCR Master Mix, 1.6 $\mu$ L Primer cocktail ( $0.8 \mu \mathrm{L}$ of $10 \mu \mathrm{M}$ forward primer, $0.8 \mu \mathrm{L}$ of $10 \mu \mathrm{M}$ reverse primer), $2.0 \mu \mathrm{L} 10 \mathrm{ng} / \mu \mathrm{L}$ bacterial gDNA or 1ng/ $\mu \mathrm{L}$ Fungal gDNA, and $6.4 \mu \mathrm{L}$ Nuclease Free $\mathrm{H}_{2} \mathrm{O}$.

PCR Cycle:

35 cycles, 5 minutes - Initial denaturation $95^{\circ} \mathrm{C}, 30$ seconds - Denaturation $95^{\circ} \mathrm{C}, 30$ seconds - Annealing $54^{\circ} \mathrm{C}, 2$ minutes - Elongation $72^{\circ} \mathrm{C}, 7$ minutes - Final Elongation $72^{\circ} \mathrm{C}$ and $4^{\circ} \mathrm{C}-\infty$

PCR products were then examined via gel electrophoresis on a $0.7 \%$ agarose gel containing ethidium bromide. Cleaning of the PCR product for sequencing was performed using Mo-Bio UltraClean ${ }^{\circledR}$ PCR Clean-Up Kit, as recommended by manufacturer.

\section{Fluorescent In Situ Hybridization (FISH)}

To verify if the putative endosymbionts, identified either by isolation or by direct PCR sequencing of fungal genomic DNA, were present within the fungal hyphae we produced ssDNA probes labeled with one of three fluorophores: Alexa Fluor ${ }^{\circledR} 488$ (Absorption 496 nm, Emission 519 nm), Pacific Blue (Absorption 456 nm, Emission 451 $\mathrm{nm}$ ); BODIPY TR-X (Absorption $588 \mathrm{~nm}$ Emission $616 \mathrm{~nm}$ ). All probes were purchased from Life Technologies, https://www.lifetechnologies.com/us/en/home.html.

Three probes were designed by me using the Probe_Design tool in the ARB software package [120]. The 16S rDNA sequences for both Burkholderia sp. and the Bradyrhizobium isolate were used individually to generate probes for each bacteria and 
the $18 \mathrm{~S}$ rDNA sequence from $V$. sp Ver01 used to generate a probe for the fungal isolates. All probes generated with an $\mathrm{A}+$ rating were evaluated for sequence identity to related species and probes with no homology were chosen for use.

Fluorescent In Situ Hybridization (FISH) combined various probes. The approach used is a combination of earlier FISH methods and were performed using combinations of the four following probes:

1. A specific fungal $18 \mathrm{~S}$ rRNA probe designed for a consensus sequence found in both fungal isolates. The $18 \mathrm{~S}$ rDNA sequence for $V$. sp. Ver01 was used to design the fungal probe (VERT164). All probes generated for $V$. sp Ver01 that were given an A+ rating were check against the $18 \mathrm{~S}$ sequence of $V$. sp Asp01 to ensure that the probe chosen would hybridize to both isolates.

2. The $16 \mathrm{~S}$ rDNA sequences for both Burkholderia sp. and the Bradyrhizobium isolate were used individually to generate probes for each bacterium. All probes generated with an A+ rating were evaluated for identity to other species and probes with low identity were chosen for use.

3. A generic $16 \mathrm{~S}$ rRNA bacterial probe from probeBase (NON338) was also chosen and verified against the two known putative endosymbionts $16 \mathrm{~S}$ sequences to ensure compatibility [121].

Fungal Probe (VERT164) Microscope filter set 05 used 5' Alexa 488-AACCAATGCCCTTTGGGCTC 3'.

Generic bacterial NONEUB (EUB338) Microscope filter set 02 used 5' Pacific Blue-ACTCCTACGGGAGGCAGC 3'. 
Burkholderia probe (BURK8) Microscope filter set 05 used

5' BODIPY TR-X - TTGGTAGGCCTTTACCCCA 3'.

Bradyrhizobium probe (BRAD865) Microscope filter set 02 used

5' Pacific Blue-AAAAGCCGTCTCAGTTCGGA 3'.

Hyphae permeabilization and hybridization was preformed as follows: mycelium networks were grown in TSB, this will minimize hyphae rupturing due to the $\mathrm{pH}$ difference between the media and the phosphate buffered saline. The mycelium were extracted from the media using a $1 \mathrm{~mL}$ pipette and placed in a $1.5 \mathrm{~mL}$ Micro-centrifuge tube containing $1 \mathrm{~mL} 6 \%$ by weight paraformaldehyde suspended in PBS solution and incubated on ice for 1 hour. (PBS solution: $0.01 \mathrm{~mol} / \mathrm{L}$ phosphate buffer stock solution, $0.0027 \mathrm{~mol} / \mathrm{L} \mathrm{KCl}, 6 \%$ paraformaldehyde by weight, $\mathrm{pH}$ 7.4) The mycelium were then removed with a hooked sterile hypodermic needle and suspended in $1 \mathrm{~mL}$ of PBS solution without paraformaldehyde in a $1.5 \mathrm{~mL}$ micro-centrifuge tube and allowed to incubate for 5 minutes. The mycelia were then transferred to a new $1.5 \mathrm{~mL}$ microcentrifuge tube also containing $1 \mathrm{~mL}$ of PBS solution and incubated for an additional 5 minutes. The mycelium were then transferred to a $1.5 \mathrm{~mL}$ micro-centrifuge tube containing $500 \mu \mathrm{L}$ of a $1 / 1$ ethanol/PBS solution for 10 minutes. They were then placed on a poly-L-lysine coated slide with approximately $25 \mu \mathrm{L}$ of the ethanol/PBS solution and allowed to air dry. $100 \mu \mathrm{L}$ of Triton X-100 solution (Triton X-100 1\% in buffer, 50 $\mathrm{mM}$ Tris $\mathrm{HCl} \mathrm{pH}$ 7.2, $40 \mathrm{mM}$ EDTA, $100 \mathrm{mM} \beta$-mercaptoethanol) was then placed on the hyphae and they were incubated for 15 minutes at $40^{\circ} \mathrm{C}$ wrapped with aluminum foil to prevent evaporation of the solution. The slide was then tipped to allow the Triton X100 to run off the mycelia and $100 \mu \mathrm{L}$ of a solution of $0.4 \mathrm{~g}$ glycerol in $1 \mathrm{~g}$ of $\mathrm{H}_{2} \mathrm{O}$ was 
added to the top of the hyphae and they were incubated on ice for 30 minutes. The prepared hyphae were then stored on their sides at $8^{\circ} \mathrm{C}$ in a closed slide box until needed.

Fixed fungal mycelia were covered with $100 \mu \mathrm{L}$ of hybridization buffer prewarmed to $47^{\circ} \mathrm{C}$ containing a concentration of $50 \mathrm{ng} / \mu \mathrm{L}$ of probe per probe used. (Hybridization buffer: 900mM NaCl, $20 \mathrm{mM}$ Tris $\mathrm{HCl} \mathrm{pH}$ 7.2, $0.01 \%$ w/v sodium dodecyl sulfate with v/v deionized formamide per Table5). The slides were then placed in a dark humidified container and incubated for four hours at $47^{\circ} \mathrm{C}$. Slides were placed in a opaque pre-warmed staining jar containing enough washing buffer with a $\mathrm{NaCl}$ concentration pre-established to wash all the probe from the extra-cellular matrix but allow some probe to remain bound to the bacterial ribosomes to cover the hybridized mycelium and incubated for 10 minutes at $42^{\circ} \mathrm{C}$. (Washing buffer: $20 \mathrm{mM}$ Tris- $\mathrm{HCl} \mathrm{pH}$ 7.2, $\mathrm{NaCl}$ concentration per Table 5, $0.01 \%$ sodium dodecyl sulfate) The slides were then rinsed with $\mathrm{diH}_{2} \mathrm{O}$ and allowed to air dry in a covered container. The stained mycelium was then viewed on a Carl Zeiss, Axioscope epifluorescent microscope using filter set 02 (Excitation G 365, Beam splitter FT 395, Emission LP 420) and filter set 05 (Excitation

Table 5. v/v deionized formamide used in FISH protocol with corresponding $\mathrm{NaCl}$ concentration used in the washing buffer. $\mathrm{NaCl}$ concentrations obtained from Arb-Silva FISH Probe protocol http://www.arbsilva.de/fileadmin/graphics_fish/SILVA_FISH_protocols_mono_101025_V2_2.pdf.

\begin{tabular}{|c|c|c|}
\hline Probe Set & \% deionized formamide & NaCl conentration \\
\hline VERT164/EUB338 & 30 & $112 \mathrm{mM}$ \\
\hline Vert164/BURK8 & 35 & $80 \mathrm{mM}$ \\
\hline BURK8/BRAD865 & 35 & $80 \mathrm{mM}$ \\
\hline
\end{tabular}

BP 395-440, Beam splitter FT 460, Emission LP 470). 


\section{Phospholipid Phosphate Analysis}

$25 \mathrm{~mL}$ of liquid acidic minimal nutrient fungal growth media was placed in serum bottles, the bottles sealed with rubber stoppers and crimped. The stoppers were then punctured with large gauge needles that reached down into the liquid media and a venting syringe needle added. Pure tank $\mathrm{H}_{2}$ gas was bubbled through the media designated to be at $0.0 \% \mathrm{O}_{2}$ for 15 minutes to produce an anaerobic environment, tank $\mathrm{N}_{2}$ containing $1.6 \%$ $\mathrm{O}_{2}$ bubbled through all other bottles to be below $21 \% \mathrm{O}_{2}$ to produce a $1.6 \% \mathrm{O}_{2}$ environment, and no bubbling for atmospheric $\mathrm{O}_{2}$ level bottles. Using a $15 \mathrm{~mL}$ syringe atmospheric air was then reintroduced in varying volumes into bottle gassed with $\mathrm{N}_{2}$ and designated to be between $5 \%$ and $15 \% \mathrm{O}_{2}$. The bottles were allowed to rest for 10 minutes and the syringe removed from the needle to allow the pressure to equalize, then the needle removed from the bottle. The bottles were then autoclaved.

The stoppers of the bottles were flamed with ethanol and $0.5 \mathrm{~mL}$ of re-suspended Ver01 inoculant added to each bottle with a sterile syringe. Three bottles of each of the following treatments were then added into the fungal cultures with a sterile syringe:

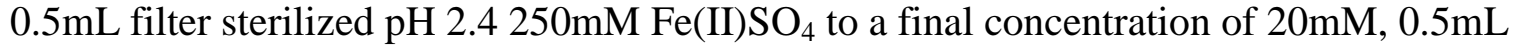
filter sterilized $\mathrm{pH} 2.412 .5 \mathrm{mM} \mathrm{Fe}(\mathrm{III})$ to a final concentration of $1 \mathrm{mM}$ or $0.5 \mathrm{~mL}$ filter sterilized $\mathrm{pH} 2.4 \mathrm{ddH}_{2} \mathrm{O}$. Cultures were then incubated for 4 weeks.

After four weeks the bottles were opened and an equal volume of methanol. Using a glass pipette excess media was drawn off the cultures via vacuum suction, being careful not to draw up fungal mycelium. Any remaining liquid was evaporated by blowing air into the bottles with a Pasteur pipette being careful not dip the pipette tip in the liquid. To the dry culture $13 \mathrm{~mL}$ of Extraction solution $(86.24 \mathrm{~mL}$ ddH2O, $220 \mathrm{~mL}$ methanol, 110 
$\mathrm{ml}$ Chloroform, $1.76 \mathrm{ml}$ conc. $\mathrm{HCl}$ ) was added, the bottle re-stoppered and the liquid swirled to ensure that all possible areas of growth were in contact with the extraction solution. The bottles were allowed to stand for 2-24 hours at room temperature, swirling occasionally, with a final rest with no agitation for a minimum of two hours prior to decanting. The bottles were opened and the liquid transferred to clean $25 \mathrm{~mL}$ glass tubes. $1.7 \mathrm{~mL}$ of chloroform was then added to the bottles, swirled to rinse the sides of the bottles and then transferred into the test tubes with the extraction solution. This was then repeated. $3.4 \mathrm{~mL}$ ddH2O was then added to the test tubes and the mixture vortexed. After being allowed to settle for 15 minutes at room temperature the upper aqueous layer was drawn off via vacuum suction until the lower chloroform layer could be reached by a pipette tip with no contact being made with the upper aqueous layer.

With a pipettor $2 \mathrm{~mL}$ of the chloroform layer was transferred into an empty COD tube wiping with a chemwipe before the addition to prevent the transfer of any possible water from the upper aqueous layer of the solution. The chloroform was then evaporated

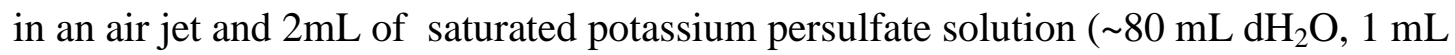
$\mathrm{H}_{2} \mathrm{SO}_{4}, 5 \mathrm{~g}$ of potassium persulfate, bring the volume to $100 \mathrm{~mL}$ with $\mathrm{dH}_{2} \mathrm{O}$ ) added to each COD tube. The tubes were then tightly sealed, boiled in a water bath for 2 hours and allowed to cool.

$150 \mu \mathrm{L}$ of each sample was then transferred to a well of a 96 microtiterplate and $150 \mathrm{uL}$ of fresh Reagent $\mathrm{C}$ (4 volumes $\mathrm{ddH}_{2} \mathrm{O}_{2} 2$ volumes of $2.5 \%$ Ammonium molybdate, 2 volumes of $10 \%$ Ascorbic acid, 2 volumes of $6 \mathrm{~N} \mathrm{H}_{2} \mathrm{SO}_{4}$ ) added to each well. $150 \mu \mathrm{L}$ of $\mathrm{PO}_{4}{ }^{3-}$ standards in the following concentrations $(0 \mu \mathrm{M}, 1 \mu \mathrm{M}, 5 \mu \mathrm{M}, 10$ $\mu \mathrm{M}, 50 \mu \mathrm{M}$, and $100 \mu \mathrm{M}$ ) were then added to unused wells on the plate and $150 \mu \mathrm{L}$ of 
fresh Reagent $\mathrm{C}$ added. The plate was covered and incubated at $40^{\circ} \mathrm{C}$ for 2 hours. The plate was then read on a BioTek UQuant $M Q X 200$ Spectrophotometer.

\section{Gas Chromatography (GC)}

All Gas chromatography was done on a Shimadzu GC-2010 (Detection Limits 3pg C/s) using a Stabilwax-DA (Restek catalog \# 11023), 30 m x 0.32 mm ID column. Samples were centrifuged in a table top centrifuge at $>10,000$ RPMs for five minutes to pellet any large debris and $10 \mu \mathrm{L}$ of sample injected per run.

\section{High-Performance Liquid Chromatography (HPLC)}

All HPLC was performed with a DYNAMAX SD-300 instrument with ESA UV detector and REZEX $8 \mu$ organic acids column. Samples were centrifuged in a table top centrifuge at $>10,000$ RPMs for five minutes to pellet any large debris and $10 \mu \mathrm{L}$ of sample injected per run. 


\section{Formulae:}

Formula 1. Acetate ${ }^{-}+8 \mathrm{Fe}(\mathrm{III})+4 \mathrm{H}_{2} \mathrm{O}------>2 \mathrm{HCO}_{3^{-}}+8 \mathrm{Fe}(\mathrm{II})+9 \mathrm{H}^{+}$

Formula 2. $\mathrm{O}_{2}+4 \mathrm{H}^{+}+4 \mathrm{e}^{-}--->2 \mathrm{H}_{2} \mathrm{O}\left(\mathrm{E}^{0}=+1.23\right) \quad$ Reduction

Formula 3. $4 \mathrm{Fe}^{2+}--->4 \mathrm{Fe}^{3+}+4 \mathrm{e}^{-}$

Oxidation

Formula 4. $\mathrm{O}_{2}+4 \mathrm{Fe}^{2+}+4 \mathrm{H}^{+}--->4 \mathrm{Fe}^{3+}+2 \mathrm{H}_{2} \mathrm{O} \quad$ Redox Reaction

Formula 5. $\mathrm{Fe}^{3+}+\mathrm{e}^{---->} \mathrm{Fe}^{2+}\left(\mathrm{E}^{0}=+0.77\right) \mathrm{pH} 2$

Formula 6. $\mathrm{Fe}^{3+}+\mathrm{e}^{---->} \mathrm{Fe}^{2+}\left(\mathrm{E}^{0}=+0.20\right) \mathrm{pH} 7$

Formula 7. $\mathrm{Fe}^{2+}+1 / 2 \mathrm{O}_{2}+2 \mathrm{H}^{+} \rightarrow \mathrm{Fe}^{3+}+\mathrm{H}_{2} \mathrm{O}$

Formula 8. $\mathrm{Fe}^{2+}+1 / 2 \mathrm{O}_{2}+2 \mathrm{H}_{2} \mathrm{O} \rightarrow \mathrm{Fe}^{3+}(\mathrm{OH})_{3}+\mathrm{H}^{+}$

Formula 9. Acetate $^{-}+8 \mathrm{Fe}(\mathrm{III})+4 \mathrm{H} 2 \mathrm{O} \rightarrow 2 \mathrm{HCO}_{3}{ }^{-}+8 \mathrm{Fe}(\mathrm{II})+9 \mathrm{H}^{+}$ 


\section{References}

1. Schoch, C.L., et al., The Ascomycota Tree of Life: A Phylum-wide Phylogeny Clarifies the Origin and Evolution of Fundamental Reproductive and Ecological Traits. Systematic Biology, 2009. 58(2): p. 224-239.

2. Cornell, M.J., et al., Comparative genome analysis across a kingdom of eukaryotic organisms: Specialization and diversification in the Fungi. Genome Research, 2007. 17(12): p. 1809-1822.

3. Wang, B. and Y.L. Qiu, Phylogenetic distribution and evolution of mycorrhizas in land plants. Mycorrhiza, 2006. 16(5): p. 299-363.

4. Hibbett, D.S., et al., A higher-level phylogenetic classification of the Fungi. Mycological Research, 2007. 111: p. 509-547.

5. Piercey-Normore, M.D., Selection of algal genotypes by three species of lichen fungi in the genus Cladonia. Canadian Journal of Botany-Revue Canadienne De Botanique, 2004. 82(7): p. 947-961.

6. Sturmer, S.L., A history of the taxonomy and systematics of arbuscular mycorrhizal fungi belonging to the phylum Glomeromycota. Mycorrhiza, 2012. 22(4): p. 247-258.

7. Bianciotto, V., et al., An obligately endosymbiotic mycorrhizal fungus itself harbors obligately intracellular bacteria. Appl. Envir. Microbiol., 1996. 62(8): p. 3005-3010.

8. Partida-Martinez, L.P. and C. Hertweck, Pathogenic fungus harbours endosymbiotic bacteria for toxin production. Nature, 2005. 437(7060): p. 884888.

9. Hughes, S.J., Percurrent Proliferations In Fungi, Algae, And Mosses. Canadian Journal of Botany, 1971. 49(2): p. 215-\&.

10. Coby, A.J., et al., Repeated Anaerobic Microbial Redox Cycling of Iron. Applied and Environmental Microbiology, 2011. 77(17): p. 6036-6042.

11. Davison, W. and G. Seed, The kinetics of the oxidation of ferrous iron in synthetic and natural waters. Geochimica et Cosmochimica Acta, 1983. 47(1): p. 67-79.

12. Millero, F.J., S. Sotolongo, and M. Izaguirre, The oxidation kinetics of Fe(II) in seawater. Geochimica et Cosmochimica Acta, 1987. 51(4): p. 793-801.

13. Strumm, W., Morgan, James J., Aquatic Chemistry: An Introduction Emphasizing Chemical Equilibria in Natural Waters. 1970, New York: Wiley-Interscience. 583.

14. Halvorson, H.O. and R.I. Starkey, Studies on the transformation of iron in nature. I. Theoretical considerations. Journal of Physical Chemistry, 1927. 31: p. 626631.

15. Lovley, D.R., Organic Matter Mineralization with the Reduction of Ferric Iron: A Review. Geomicrobiology Journal, 1987. 5(3/4): p. 375-396.

16. Emerson, D., E.J. Fleming, and J.M. McBeth, Iron-Oxidizing Bacteria: An Environmental and Genomic Perspective, in Annual Review of Microbiology, Vol 64, 2010, S. Gottesman and C.S. Harwood, Editors. 2010, Annual Reviews: Palo Alto. p. 561-583. 
17. Widdel, F., et al., Ferrous Iron Oxidation By Anoxygenic Phototrophic Bacteria. Nature, 1993. 362(6423): p. 834-836.

18. Thauer, R.K., K. Jungermann, and K. Decker, Energy-Conservation In Chemotropic Anaerobic Bacteria. Bacteriological Reviews, 1977. 41(1): p. 100180.

19. Straub, K.L., et al., Anaerobic, nitrate-dependent microbial oxidation of ferrous iron. Applied and Environmental Microbiology, 1996. 62(4): p. 1458-1460.

20. Emerson, D. and C. Moyer, Isolation and Characterization of Novel IronOxidizing Bacteria That Grow at Circumneutral pH. Applied and Environmental Microbiology, 1997. 63(12): p. 4784-4792.

21. Konhauser, K.O., A. Kappler, and E.E. Roden, Iron In Microbial Metabolisms. Elements, 2011. 7(2): p. 89-93.

22. Konhauser, K.O., et al., Decoupling photochemical Fe(II) oxidation from shallow-water BIF deposition. Geochimica et Cosmochimica Acta, 2007. 71(15): p. A509-A509.

23. Wang, X.J., et al., Phylogenetic diversity of dissimilatory ferric iron reducers in paddy soil of Hunan, South China. Journal of Soils and Sediments, 2009. 9(6): p. 568-577.

24. Carmona, N., et al., Biodeterioration of historic stained glasses from the Cartuja de Miraflores (Spain). International Biodeterioration \& Biodegradation, 2006. 58(3-4): p. 155-161.

25. Schabereiter-Gurtner, C., et al., Analysis of fungal communities on historical church window glass by denaturing gradient gel electrophoresis and phylogenetic 18S rDNA sequence analysis. Journal of Microbiological Methods, 2001. 47(3): p. 345-354.

26. Brehm, U., A. Gorbushina, and D. Mottershead, The role of microorganisms and biofilms in the breakdown and dissolution of quartz and glass. Palaeogeography, Palaeoclimatology, Palaeoecology, 2005. 219(1-2): p. 117-129.

27. Drewello, R. and R. Weissmann, Microbially influenced corrosion of glass. Applied Microbiology and Biotechnology, 1997. 47(4): p. 337-346.

28. Abdulla, H., Bioweathering and Biotransformation of Granitic Rock Minerals by Actinomycetes. Microbial Ecology, 2009. 58(4): p. 753-761.

29. Grbic, M.L., et al., Biofilm Forming Cyanobacteria, Algae And Fungi On Two Historic Monuments In Belgrade, Serbia. Archives of Biological Sciences, 2010. 62(3): p. 625-631.

30. Wilson, M.J., et al., Does the preferential microbial colonisation of ferromagnesian minerals affect mineral weathering in soil? Naturwissenschaften, 2008. 95(9): p. 851-858.

31. Marvasi, M., et al., Bacterial community analysis on the Mediaeval stained glass window "Natività" in the Florence Cathedral. Journal of Cultural Heritage, 2009. 10(1): p. 124-133.

32. Carmona, N., et al., Biodeterioration of historic stained glasses from the Cartuja de Miraflores (Spain). International Biodeterioration \& Biodegradation. 58(3-4): p. 155-161. 
33. Marvasia, M., et al., Bacterial community analysis on the Mediaeval stained glass window "Nativita" in the Florence Cathedral. Journal of Cultural Heritage, 2009. 10(1): p. 124-133.

34. Schabereiter-Gurtner, C., et al., Analysis of fungal communities on historical church window glass by denaturing gradient gel electrophoresis and phylogenetic $18 S$ rDNA sequence analysis. Journal of Microbiological Methods, 2001. 47(3): p. 345-354.

35. Nyhus, K., A. Wilborn, and E. Jacobson, Ferric iron reduction by Cryptococcus neoformans. Infect. Immun., 1997. 65(2): p. 434-438.

36. Muller-Stovre, D. and J. Sauerborn, A Commercial Iron Fertilizer Increases the Survival of Fusarium oxysporium f.sp. orthocerus Propagules in a Wheat-Kaolin Formulation. Biocontrol Science and Technology, 2007. 17(5/6): p. 597-604.

37. Park, Y.-S. and E. Al, Functional identification of high-affinity iron permeases from Fusarium graminearum. Fungal Genetics and Biology, 2006. 43: p. 273282.

38. Makela, M.R., et al., Oxalate decarboxylase of the white-rot fungus Dichomitus squalens demonstrates a novel enzyme primary structure and non-induced expression on wood and in liquid cultures. Microbiology, 2009. 155(8): p. 27262738.

39. Jarosz-Wilkołazka, A. and M. Grąz, Organic acids production by white rot Basidiomycetes in the presence of metallic oxides. Canadian Journal of Microbiology, 2006. 52(8): p. 779-785.

40. Schöll, L.v., E. Hoffland, and N.v. Breemen, Organic Anion Exudation by Ectomycorrhizal Fungi and Pinus sylvestris in Response to Nutrient Deficiencies. New Phytologist, 2006. 170(1): p. 153-163.

41. Bonfante, P., Plants, Mycorrhizal Fungi and Endobacteria: a Dialog Among Cells and Genomes. Biol Bull, 2003. 204(2): p. 215-220.

42. Watteau, F. and J. Berthelin, Iron Solubilization by Mycorrhizal Fungi Producing Siderophores. Symbiosis, 1990. 9: p. 59-67.

43. Ahonen-Jonnarth, U., et al., Organic Acids Produced by Mycorrhizal Pinus sylvestris Exposed to Elevated Aluminium and Heavy Metal Concentrations. New Phytologist, 2000. 146(3): p. 557-567.

44. Fomina, M., et al., Role of Oxalic Acid Overexcretion in Transformations of Toxic Metal Minerals by Beauveria caledonica. Appl. Envir. Microbiol., 2005. 71(1): p. 371-381.

45. Green Iii, F. and C.A. Clausen, Copper tolerance of brown-rot fungi: time course of oxalic acid production. International Biodeterioration \& Biodegradation, 2003. 51(2): p. 145-149.

46. Borggaard, O.K., Dissolution of Poorly Crystalline Iron Oxides in Soils by EDTA and Oxalate. Zeitschrift für Pflanzenernährung und Bodenkunde, 1992. 155(5): p. 431-436.

47. Burgstaller, W. and F. Schinner, Leaching Of Metals With Fungi. Journal of Biotechnology, 1993. 27(2): p. 91-116. 
48. Qian, Y.H., B. Goodell, and C.C. Felix, The effect of low molecular weight chelators on iron chelation and free radical generation as studied by ESR measurement. Chemosphere, 2002. 48(1): p. 21-28.

49. Goodell, B., et al., Low molecular weight chelators and phenolic compounds isolated from wood decay fungi and their role in the fungal biodegradation of wood. Journal of Biotechnology, 1997. 53(2-3): p. 133-162.

50. Piercey-Normore, M.D., Selection of algal genotypes by three species of lichen fungi in the genus Cladonia. Canadian Journal of Botany, 2004. 82(7): p. 947961.

51. Moya, A., et al., Learning how to live together: genomic insights into prokaryoteanimal symbioses. Nature Reviews Genetics, 2008. 9(3): p. 218-229.

52. Moran, N.A., J.P. McCutcheon, and A. Nakabachi, Genomics and Evolution of Heritable Bacterial Symbionts, in Annual Review of Genetics. 2008. p. 165-190.

53. Schrallhammer, M., et al., Detection of a Novel Subspecies of Francisella noatunensis as Endosymbiont of the Ciliate Euplotes raikovi. Microbial Ecology, 2011. 61(2): p. 455-464.

54. Lemaire, B., E. Smets, and S. Dessein, Bacterial leaf symbiosis in Ardisia (Myrsinoideae, Primulaceae): molecular evidence for host specificity. Research in Microbiology, 2011. 162(5): p. 528-534.

55. Goodacre, S.L., Endosymbiont Infections in Spiders, in Advances in Insect Physiology, Vol 40: Spider Physiology and Behaviour - Physiology, J. Casas, Editor. 2011. p. 137-153.

56. Nowack, E.C.M. and M. Melkonian, Endosymbiotic associations within protists. Philosophical Transactions of the Royal Society B-Biological Sciences, 2010. 365(1541): p. 699-712.

57. Papaleo, M.C., et al., Sponge-associated microbial Antarctic communities exhibiting antimicrobial activity against Burkholderia cepacia complex bacteria. Biotechnology Advances, 2012. 30(1): p. 272-293.

58. Yutin, N., et al., The origins of phagocytosis and eukaryogenesis. Biology Direct, 2009. 4.

59. Moya, A., R. Gil, and A. Latorre, The evolutionary history of symbiotic associations among bacteria and their animal hosts: a model. Clinical Microbiology and Infection, 2009. 15: p. 11-13.

60. Jordan, D.C., NOTES: Transfer of Rhizobium japonicum Buchanan 1980 to Bradyrhizobium gen. nov., a Genus of Slow-Growing, Root Nodule Bacteria from Leguminous Plants. International Journal of Systematic Bacteriology, 1982. 32(1): p. 136-139.

61. de Souza, J.A.M., et al., Draft Genome Sequence of the Nitrogen-Fixing Symbiotic Bacterium Bradyrhizobium elkanii 587. Journal of Bacteriology, 2012. 194(13): p. 3547-3548.

62. Galiana, A., et al., Nitrogen fixation estimated by the N-15 natural abundance method in Acacia mangium Willd. inoculated with Bradyrhizobium sp and grown in silvicultural conditions. Soil Biology \& Biochemistry, 2002. 34(2): p. 251-262.

63. Vazquez, M.M., J.M. Barea, and R. Azcon, Impact of soil nitrogen concentration on Glomus spp.-Sinorhizobium interactions as affecting growth, nitrate reductase 
activity and protein content of Medicago sativa. Biology and Fertility of Soils, 2001. 34(1): p. 57-63.

64. Partida-Martinez, L.P., et al., Rhizonin, the First Mycotoxin Isolated from the Zygomycota, Is Not a Fungal Metabolite but Is Produced by Bacterial Endosymbionts. Appl. Environ. Microbiol., 2007. 73(3): p. 793-797.

65. Partida-Martinez, L.P., et al., Endosymboint-Dependent Host Reproduction Maintains Bacterial-Fungal Mutualism. Current Biology, 2007. 17: p. 773-777.

66. Feldhaar, H., Bacterial symbionts as mediators of ecologically important traits of insect hosts. Ecological Entomology, 2011. 36(5): p. 533-543.

67. Kirkness, E.F., et al., Genome sequences of the human body louse and its primary endosymbiont provide insights into the permanent parasitic lifestyle. Proceedings of the National Academy of Sciences of the United States of America, 2010. 107(27): p. 12168-12173.

68. Archibald, J.M. and C.E. Lane, Going, Going, Not Quite Gone: Nucleomorphs as a Case Study in Nuclear Genome Reduction. Journal of Heredity, 2009. 100(5): p. 582-590.

69. Bowman, D.D., Introduction to the Alpha-proteobacteria: Wolbachia and Bartonella, Rickettsia, Brucella, Ehrlichia, and Anaplasma. Topics in Companion Animal Medicine, 2011. 26(4): p. 173-177.

70. Dieterich, C. and R.J. Sommer, How to become a parasite-lessons from the genomes of nematodes. Trends in Genetics, 2009. 25(5): p. 203-209.

71. Jargeat, P., et al., Isolation, free-living capacities, and genome structure of "Candidatus glomeribacter gigasporarum," the endocellular bacterium of the mycorrhizal fungus Gigaspora margarita. Journal of Bacteriology, 2004. 186(20): p. 6876-6884.

72. Keeling, P.J., et al., The Reduced Genome of the Parasitic Microsporidian Enterocytozoon bieneusi Lacks Genes for Core Carbon Metabolism. Genome Biology and Evolution, 2010. 2: p. 304-309.

73. Valeria, B., et al., 'Candidatus Glomeribacter gigasporarum' gen. nov., sp. nov., an endosymbiont of arbuscular mycorrhizal fungi. International Journal of Systematic and Evolutionary Microbiology, 2003. 53(1): p. 121-124.

74. Eubezy, J.P. List of Prokaryotic names with Standing in Nomenclature. 2012 August 4, 2012 [cited 2012 August 6, 2012]; Available from: www.bacterio.cict.fr/b/burkholderia.html.

75. Compant, S., et al., Diversity and occurrence of Burkholderia spp. in the natural environment. Fems Microbiology Reviews, 2008. 32(4): p. 607-626.

76. Stoyanova, M., et al., Biodiversity and incidence of Burkholderia species. Biotechnology \& Biotechnological Equipment, 2007. 21(3): p. 306-310.

77. Madigan, M.T., Martinko, John M., Dunlap, Paul V., Clark, David P., Brock Biology of Microorganisms. 12th ed. 2009, San Francisco: Pearson Benjamin Cummings. 1061.

78. Daubaras, D.L., et al., Sequence-Analysis Of A Gene-Cluster Involved In Metabolism Of 2,4,5-Trichlorophenoxyacetic Acid By Burkholderia-Cepacia Ac1 100. Applied and Environmental Microbiology, 1995. 61(4): p. 1279-1289. 
79. Bontemps, C., et al., Burkholderia species are ancient symbionts of legumes. Molecular Ecology, 2010. 19(1): p. 44-52.

80. Lemaire, B., et al., Bacterial Leaf Symbiosis in Angiosperms: Host Specificity without Co-Speciation. Plos One, 2011. 6(9).

81. Kikuchi, Y., et al., Symbiont-mediated insecticide resistance. Proceedings of the National Academy of Sciences of the United States of America, 2012. 109(22): p. 8618-8622.

82. Chan, Y.Y., et al., BpeAB-OpRB, a multidrug efflux pump in Burkholderia pseudomallei. Antimicrobial Agents and Chemotherapy, 2004. 48(4): p. 11281135.

83. Burtnick, M.N., et al., The Cluster 1 Type VI Secretion System Is a Major Virulence Determinant in Burkholderia pseudomallei. Infection and Immunity, 2011. 79(4): p. 1512-1525.

84. CDC. Glanders. 2012 June 15, 2011 [cited 2012 August 6, 2012]; Available from: http://www.cdc.gov/glanders/index.html.

85. Hayashi, S., et al., The DsbA-DsbB disulfide bond formation system of Burkholderia cepacia is involved in the production of protease and alkaline phosphatase, motility, metal resistance, and multi-drug resistance. Microbiology and Immunology, 2000. 44(1): p. 41-50.

86. Shabaev, V.P., V.Y. Smolin, and L.T. Shirshova, Fixation of molecular nitrogen and yield of soya inoculated by nodule bacteria and rhizosphere pseudomonades. Eurasian Soil Science, 1998. 31(8): p. 889-895.

87. van Berkum, P., et al., Development and Application of a Multilocus Sequence Analysis Method for the Identification of Genotypes Within Genus Bradyrhizobium and for Establishing Nodule Occupancy of Soybean (Glycine max L. Merr). Molecular Plant-Microbe Interactions, 2012. 25(3): p. 321-330.

88. Rivas, R., et al., Multilocus sequence analysis of the genus Bradyrhizobium. Systematic and Applied Microbiology, 2009. 32(2): p. 101-110.

89. Small, S.K. and M.R. O'Brian, The Bradyrhizobium japonicum frcB Gene Encodes a Diheme Ferric Reductase. Journal of Bacteriology, 2011. 193(16): p. 4088-4094.

90. Talbot, P.H.B., Principles of fungal taxonomy. 1978, London: The Macmillan Press, Ltd. 274.

91. Goldman, D.S. and J.I. Berg, Spectral study of ferrous iron in Ca $\square$ Al $\square$ borosilicate glass at room and melt temperatures. Journal of NonCrystalline Solids, 1980. 38-39, Part 1(0): p. 183-188.

92. Cochain, B., et al., Effects of the Iron Content and Redox State on the Structure of Sodium Borosilicate Glasses: A Raman, Mössbauer and Boron K-Edge XANES Spectroscopy Study. Journal of the American Ceramic Society, 2012. 95(3): p. 962-971.

93. Dantas, N.O., et al., Effect of Fe2O3 concentration on the structure of the SiO2Na2O-Al2O3-B2O3 glass system. Spectrochimica Acta Part A: Molecular and Biomolecular Spectroscopy, 2011. 81(1): p. 140-143.

94. Nevin, K.P. and D.R. Lovely, Mechanisms for Fe(III) Oxide Reduction in Sedimentary Environments. Geomicrobiology, 2002. 19: p. 141-159. 
95. Lovley, D.R., Microbial Fe(III) reduction in subsurface environments. FEMS Microbiology Reviews, 1997. 20: p. 305-313.

96. Lovley, D.R., D.E. Holmes, and K.P. Nevin, Dissimilatory Fe(III) and Mn(IV) reduction. Advances in Microbial Physiology, 2004. 49: p. 219.

97. Lovley, D.R., E.J.P. Phillips, and F. Caccavo, Acetate Oxidation By Dissimilatory Fe(Iii) Reducers. Applied and Environmental Microbiology, 1992. 58(9): p. 32053206.

98. Picardal, F.W., et al., Microaerophilic, $\mathrm{Fe}(\mathrm{II})$-dependent growth and $\mathrm{Fe}(\mathrm{II})$ oxidation by a Dechlorospirillum species. Fems Microbiology Letters, 2011. 319(1): p. 51-57.

99. Milagres, A.M.F., et al., Production of metal chelating compounds by white and brown-rot fungi and their comparative abilities for pulp bleaching. Enzyme and Microbial Technology, 2002. 30(4): p. 562-565.

100. Weber, K.A., L.A. Achenbach, and J.D. Coates, Microorganisms pumping iron: anaerobic microbial iron oxidation and reduction. Nature Reviews Microbiology, 2006. 4(10): p. 752-764.

101. Küsel, K., U. Roth, and H.L. Drake, Microbial reduction of Fe(III) in the presence of oxygen under low pH conditions. Environmental Microbiology, 2002. 4(7): p. 414-421.

102. Findlay, R.H., G.M. King, and L. Watling, Efficacy Of Phospholipid Analysis In Determining Microbial Biomass In Sediments. Applied and Environmental Microbiology, 1989. 55(11): p. 2888-2893.

103. White, D.C., et al., Determination Of The Sedimentary Microbial Biomass By Extractable Lipid Phosphate. Oecologia, 1979. 40(1): p. 51-62.

104. Bligh, E.G. and W.J. Dyer, A Rapid Method Of Total Lipid Extraction And Purification. Canadian Journal of Biochemistry and Physiology, 1959. 37(8): p. 911-917.

105. Bianciotto, V., et al., 'Candidatus Glomeribacter gigasporarum' gen. nov., sp nov., an endosymbiont of arbuscular mycorrhizal fungi. International Journal of Systematic and Evolutionary Microbiology, 2003. 53: p. 121-124.

106. Bianciotto, V., et al., Detection and Identification of Bacterial Endosymbionts in Arbuscular Mycorrhizal Fungi Belonging to the Family Gigasporaceae. Appl. Environ. Microbiol., 2000. 66(10): p. 4503-4509.

107. Minerdi, D., R. Fani, and P. Bonfante, Identification and evolutionary analysis of putative cytoplasmic McpA-like protein in a bacterial strain living in symbiosis with a mycorrhizal fungus. Journal of Molecular Evolution, 2002. 54(6): p. 815824.

108. Bianciotto, V., et al., Vertical transmission of endobacteria in the arbuscular mycorrhizal Fungus gigaspora margarita through generation of vegetative spores. Applied and Environmental Microbiology, 2004. 70(6): p. 3600-3608.

109. Laila, P.P.-M., et al., Burkholderia rhizoxinica sp. nov. and Burkholderia endofungorum sp. nov., bacterial endosymbionts of the plant-pathogenic fungus Rhizopus microsporus. International Journal of Systematic and Evolutionary Microbiology, 2007. 57(11): p. 2583-2590. 
110. Lackner, G., et al., Global Distribution and Evolution of a Toxinogenic Burkholderia-Rhizopus Symbiosis. Appl. Environ. Microbiol., 2009. 75(9): p. 2982-2986.

111. Partida-Martinez, L.P., et al., Lack of evidence of endosymbiotic toxin-producing bacteria in clinical Rhizopus isolates. Mycoses, 2008. 51(3): p. 266-269.

112. Bianciotto, V., et al., Vertical Transmission of Endobacteria in the Arbuscular Mycorrhizal Fungus Gigaspora margarita through Generation of Vegetative Spores. Appl. Envir. Microbiol., 2004. 70(6): p. 3600-3608.

113. Saeki, Y., et al., Diversity of indigenous Bradyrhizobium strains isolated from three different Rj-soybean cultivars in terms of randomly amplified polymorphic DNA and intrinsic antibiotic resistance. Soil Science and Plant Nutrition, 2000. 46(4): p. 917-926.

114. Ahmad, I., et al., Metal and antibiotic resistance traits in Bradyrhizobium sp (cajanus) isolated from soil receiving oil refinery wastewater. World Journal of Microbiology \& Biotechnology, 2001. 17(4): p. 379-384.

115. Hayat, R., et al., Soil beneficial bacteria and their role in plant growth promotion: a review. Annals of Microbiology, 2010. 60(4): p. 579-598.

116. Salvioli, A., et al., Simultaneous detection and quantification of the unculturable microbe Candidatus Glomeribacter gigasporarum inside its fungal host Gigaspora margarita. New Phytologist, 2008. 180(1): p. 248-257.

117. List of recommended media for microorganisms, Leibniz Institute DSMZ-German Collection of Microorganisms and Cell Cultures.

118. Tong, Z.K., A selective medium for the isolation and quatification of Bradyrhizobium japonicum and Bradyrhizobium elkanii strains from soils and inoculants. Applied and Environmental Microbiology, 1994. 60(2): p. 581.

119. Henry, D.A., Identification of Burkholderia cepacia isolates from patients with cystic fibrosis and use of a simple new selective medium. Journal of Clinical Microbiology, 1997. 35(3): p. 614.

120. Ludwig, W., et al., ARB: a software environment for sequence data. Nucleic Acids Res, 2004. 32(4): p. 1363-71.

121. Amann, R.I., et al., Combination of $16 S$ rRNA-targeted oligonucleotide probes with flow cytometry for analyzing mixed microbial populations. Appl Environ Microbiol, 1990. 56(6): p. 1919-25. 


\section{Appendix A}

\section{Bacterial 16s and Fungal 18s Sequences}

\section{Burkholderia sp.}

GGGGGATAGCCCGGCGAAAGCCGGATTAATACCGCATACGATCTACGGATGA AAGCGGGGGACCTTCGGGCCTCGCGCTATAGGGTTGGCCGATGGCTGATTAG CTAGTTGGTGGGGTAAAGGCCTACCAAGGCGACGATCAGTAGCTGGTCTGAG AGGACGACCAGCCACACTGGGACTGAGACACGGCCCAGACTCCTACGGGAG GCAGCAGTGGGGAATTTTGGACAATGGGCGAAAGCCTGATCCAGCAATGCCG CGTGTGTGAAGAAGGCCTTCGGGTTGTAAAGCACTTTTGTCCGGAAAGAAAT CCTTGGCTCTAATACAGTCGGGGGATGACGGTACCGGAAGAATAAGCACCGG CTAACTACGTGCCAGCAGCCGCGGTAATACGTAGGGTGCGAGCGTTAATCGG AATTACTGGGCGTAAAGCGTGCGCAGGCGGTTTGCTAAGACCGATGTGAAAT CCCCGGGCTCAACCTGGGAACTGCATTGGTGACTGGCAGGCTAGAGTATGGC AGAGGGGGGTAGAATTCCACGTGTAGCAGTGAAATGCGTAGAGATGTGGAG GAACACCGATGGCGAAGGCAGCCCCCTGGGACAATACTGACGCTCATGCACG AAAGCGTGGGGAGCAAACAGGATTAGATACCCTGGTAGTCCACGCCCTAAAC GATGTCAACTAGTTGTTGGGGATTCATTTCCTTAGTAACGTAGCTAACGCGTG AAGTTGACCGCCTGGGGAGTACGGTCGCAAGATTAAAACTCAAAGGAATTGA CGGGGACCCGCACAAGCGGTGGATGATGTGGATTAATTCGATGCAACGCGAA AAACCTTACCTACCCTTGACATGGTCGGAATCCCGCTGAGAGGTGGGAGTGC TCGAAAGAGAACCGGCGCACAGGTGCTGCATGGCTGTCGTCAGCTCGTGTCG TGAGATGTTGGGTTAAGTCCCGCAACGAGCGCAACCCTTGTCCTTAGTTGCTA CGCAAGAGCACTCTAAGGAGACTGCCGGTGACAAACCGGAGGAAGGTGGGG ATGACGTCAAGTCCTCATGGCCCTTATGGGTAGGGCTTCACACGTCATACAAT GGTCGGAACAGAGGGTCGCCAACCCGCGAGGGGGAGCTAATCCCAGAAACC CGATCGTAGTCCGGATTGCAGTCTGCAACTCGACTGCATGAAGTTGGAATCG CTAGTAATCGCGGATCAGCATGCCGCGGTGAATACGTTCCCGGGTCTTGTAC ACACCGCCCGTCACACCATGGGAGTGGGTTTTACCAGAAGTGGTTAGTCTAA CCGCAAGGAGGACGGTTACCACGGTAGGATTCATGACTGGGGTGAAGTCGTA CAAAAGGTAACCCACAAA

\section{Bradirhizobium sp.}

ACACAGGGAAACTTGTGCTAATACCGGATAAGCCCTTACGGGGAAAGATTTA TCGCCGAAAGATCGGCCCGCGTCTGATTAGCTAGTTGGTAGGGTAATGGCCT ACCAAGGCGACGATCAGTAGCTGGTCTGAGAGGATGATCAGCCACATTGGGA CTGAGACACGGCCCAAACTCCTACGGGAGGCAGCAGTGGGGAATATTGGAC AATGGGGGCAACCCTGATCCAGCCATGCCGCGTGAGTGATGAAGGCCCTAGG GTTGTAAAGCTCTTTTGTGCGGGAAGATAATGACGGTACCGCAAGAATAAGC CCCGGCTAACTTCGTGCCAGCAGCCGCGGTAATACGAAGGGGGCTCGCGTTG CTCGGAATCACTGGGCGAAAAGGGTGCGTAGGCGGGTTTTTAAGTCAGGGGT GAAATCCTGGAGCTCAACTCCAGAACTGCCTTTGATACTGAAGATCTTGAGTC 
CGGGAGAGGTGAGTGGAACTGCGAGTGTAGAGGTGAAATTCGTAGATATTCG CAAGAACACCAGTGGCGAAGGCGGCTCACTGGCCCGGTACTGACGCTGAGG CACGAAAGCGTGGGGAGCAAACAGGATTAGATACCCTGGTAGTCCACGCCGT AAACGATGAATGCCAGCCGTTAGTGGGTTTACTCACTAGTGGCGCAGCTAAC GCTTTAAGCATTCCGCCTGGGGAGTACGGTCGCAAGATTAAAACTCAAAGGA ATTGACGGGGGCCCGCACAAGCGGTGGAGCATGTGGTTTAATTCGACGCAAC GCGCAGAACCTTACCAGCCCTTGACATGTCCAGGACCGGTCGCAGAGATGTG ACCTTCTCTTCGGAGCCTGGAACACAGGTGCTGCATGGCTGTCGTCAGCTCGT GTCGTGAGATGTTGGGTTAAGTCCCGCAACGAGCGCAACCCCCGTCCTTAGTT GCTACCATTTAGTTGAGCACTCTAAGGAGACTGCCGGTGATAAGCCGCGAGG AAGGTGGGGATGACGTCAAGTCCTCATGGCCCTTACGGGCTGGGCTACACAC GTGCTACAATGGCGGTGACAATGGGATGCTAAGGG

\section{Verticilium sp. Ver01}

TAGTACTTTACTACTTGGATAACCGTGGTAATTCTAGAGCTAATACATGCTAA AAATCCCGACTTCGGAAGGGATGTATTTATTAGATTAAAAACCAATGCCCTTT GGGCTCCTTGGTGAATCATGATAACTTCTCGAATCGCATGGCCTTGCGCCGGC GATGGTTCATTCAAATTTCTTCCCTATCAACTTTCGATGTTTGGGTATTGGCCA AACATGGTCGCAACGGGTAACGGAGGGTTAGGGCTCGACCCCGGAGAAGGA GCCTGAGAAACGGCTACTACATCCAAGGAAGGCAGCAGGCGCGCAAATTAC CCAATCCCGACTCGGGGAGGTAGTGACAATAAATACTGATACGAGGCTCTTT TGGGCCTTGTAATTGGAATGAGTACAATTTAAATCTCTTAACGAGGAACAATT GGAGGGCAAGTCTGGTGCCAGCAGCCGCGGTAATTCCAGCTCCAATAGCGTA TATTAAAGTTGTTGTGGTTAAAAAGCTCGTAGTTGAACCTTGGGCCTGGCTGG CCGGTCCGCCTCACCGCGTGTACTGGTCCGGCCGGGCCTTTCCCTCTGTGGAA CCTCATGCCCTTCACTGGGTGTGACGGGGAAGCAGGACTTTTACTGTGAAAA AATTAGAGTGCTCCAAGCAGGCCTATGCTCGAATACATTAGCATGGAATAAT AAAATAGGACGTGCGGTTCTATTTTGTTGGTTTCTAGGACCGCCGTAATGATT AATAGGGACAGTCGGGGGCATCAGTATTCAATTGTCAGAGGTGAAATTCTTG GATTTATTGAAGACTAACTACTGCGAAAGCATTTGCCAAGGATGTTTTCATTA ATCAGGAACGAAAGTTAGGGGATCGAAGACGATCAGATACCGTCGTAGTCTT AACCATAAACTATGCCGACTAGGGAT

\section{Verticilium sp. Asp01}

ATTATACGGCGACTGCGAATGGCTCATTATATAAGTTATCGTTTATTTGATAG TACTTTACTACTTGGATAACCGTGGTAATTCTAGAGCTAATACATGCTAAAAA TCCCGACTTCGGAAGGGATGTATTTATTAGATTAAAAACCAATGCCCTTTGGG CTCCTTGGTGAATCATGATAACTTCTCGAATCGCATGGCCTTGCGCCGGCGAT GGTTCATTCAAATTTCTTCCCTATCAACTTTCGATGTTTGGGTATTGGCCAAAC ATGGTCGCAACGGGTAACGGAGGGTTAGGGCTCGACCCCGGAGAAGGAGCC TGAGAAACGGCTACTACATCCAAGGAAGGCAGCAGGCGCGCAAATTACCCA 
ATCCCGACTCGGGGAGGTAGTGACAATAAATACTGATACGAGGCTCTTTTGG GCCTTGTAATTGGAATGAGTACAATTTAAATCTCTTAACGAGGAACAATTGG AGGGCAAGTCTGGTGCCAGCAGCCGCGGTAATTCCAGCTCCAATAGCGTATA TTAAAGTTGTTGTGGTTAAAAAGCTCGTAGTTGAACCTTGGGCCTGGCTGGCC GGTCCGCCTCACCGCGTGTACTGGTCCGGCCGGGCCTTTCCCTCTGTGGAACC TCATGCCCTTCACTGGGTGTGACGGGGAAGCAGGACTTTTACTGTGAAAAAA TTAGAGTGCTCCAAGCAGGCCTATGCTCGAATACATTAGCATGGAATAATAA AATAGGACGTGCGGTTCTATTTTGTTGGTTTCTAGGACCGCCGTAATGATTAA TAGGGACAGTCGGGGGCATCAGTATTCAATTGTCAGAGGTGAAATTCTTGGA TTTATTGAAGACTAACTACTGCGAAAGCATTTGCCAAGGATGTTTTCATTAAT CAGGAACGAAAGTTAGGGGATCGAAGACGATCAGATACCGTCGTAGTCTTAA CCATAAACTATGCCGACTAGGGATCGGACTTATTTTATTTTTTGACTCGTTCG GCACCTTACGAGAAATCAAAGTGT 


\section{Appendix B}

\section{Bacterial Counts per Fungal Cell After Antibiotic Exposure}

Control - No antibiotics

\begin{tabular}{|c|c|c|c|c|c|}
\hline \multicolumn{3}{|c|}{ Control - No antiblotics } & \multirow{2}{*}{\multicolumn{3}{|c|}{$\begin{array}{l}\text { \# of cells with } \\
\text { moving bodies }\end{array}$}} \\
\hline \multirow[b]{2}{*}{ Bottle \# } & \multirow[b]{2}{*}{ Field } & \multirow[b]{2}{*}{ Hyphae } & & & \\
\hline & & & $\mathbf{0}$ & 1 & 2 \\
\hline \multirow[t]{9}{*}{2} & 1 & 1 & 4 & 19 & 1 \\
\hline & & 2 & 2 & 9 & 1 \\
\hline & & 3 & 2 & 9 & 0 \\
\hline & 2 & 4 & 1 & 6 & 1 \\
\hline & 3 & 5 & 3 & 7 & 2 \\
\hline & & 6 & 3 & 9 & 1 \\
\hline & 4 & 7 & 2 & 4 & 0 \\
\hline & & 8 & 4 & 9 & 2 \\
\hline & & 9 & 2 & 6 & 1 \\
\hline \multirow[t]{17}{*}{3} & 1 & 1 & 0 & 4 & 2 \\
\hline & & 2 & 3 & 9 & 1 \\
\hline & & 3 & 2 & 8 & 0 \\
\hline & & 4 & 2 & 6 & 1 \\
\hline & 2 & 5 & 3 & 5 & 0 \\
\hline & & 6 & 3 & 0 & 0 \\
\hline & 3 & 7 & 0 & 4 & 0 \\
\hline & 4 & 8 & 0 & 3 & 0 \\
\hline & & 9 & 0 & 4 & 0 \\
\hline & 5 & 10 & 2 & 4 & 0 \\
\hline & 6 & 11 & 1 & 6 & 0 \\
\hline & & 12 & 3 & 4 & 0 \\
\hline & & 13 & 1 & 6 & 0 \\
\hline & 7 & 14 & 2 & 5 & 1 \\
\hline & & 15 & 1 & 4 & 0 \\
\hline & & 16 & 0 & 9 & 0 \\
\hline & & 17 & 0 & 5 & 2 \\
\hline \multirow[t]{14}{*}{4} & 1 & 1 & 4 & 1 & 0 \\
\hline & & 2 & 12 & 0 & 0 \\
\hline & & 3 & 8 & 0 & 0 \\
\hline & & 4 & 12 & 9 & 0 \\
\hline & & 5 & 7 & 3 & 0 \\
\hline & & 6 & 5 & 3 & 0 \\
\hline & 2 & 7 & 9 & 10 & 0 \\
\hline & & 8 & 0 & 11 & 0 \\
\hline & & 9 & 5 & 8 & 0 \\
\hline & & 10 & 18 & 43 & 0 \\
\hline & 3 & 11 & 13 & 8 & 0 \\
\hline & & 12 & 9 & 5 & 0 \\
\hline & & 13 & 11 & 9 & 0 \\
\hline & & 14 & 18 & 5 & 0 \\
\hline
\end{tabular}

Table 1. Fungal cells not exposed to antibiotics which contained moving bodies. Bottle \#1 was not inoculated with fungal spores as a control for this series. 
Table 2. Fungal cells exposed to erythromycin which contained moving bodies.

Bottle \#5 was not inoculated with fungal spores as a control for this series.

\begin{tabular}{|c|c|c|c|c|c|c|c|c|c|c|c|}
\hline \multicolumn{12}{|c|}{ Erythromycin } \\
\hline \multirow[b]{2}{*}{ Bottle \# } & \multirow[b]{2}{*}{ Field } & \multirow[b]{2}{*}{ Hyphae } & \multicolumn{3}{|c|}{$\begin{array}{l}\# \text { of cells with } \\
\text { moving bodies }\end{array}$} & \multirow[b]{2}{*}{ Bottle \# } & \multirow[b]{2}{*}{ Field } & \multirow[b]{2}{*}{ Hyphae } & \multicolumn{3}{|c|}{$\begin{array}{l}\# \text { of cells with } \\
\text { moving bodies }\end{array}$} \\
\hline & & & 0 & 1 & 2 & & & & 0 & 1 & 2 \\
\hline 6 & 1 & 1 & 2 & 2 & 1 & 8 & 1 & 1 & 19 & 0 & 0 \\
\hline & & 2 & 4 & 13 & 1 & & & 2 & 14 & 0 & 0 \\
\hline & & 3 & 6 & 2 & 0 & & & 3 & 12 & 0 & 0 \\
\hline & & 4 & 7 & 10 & 0 & & & 4 & 8 & 0 & 0 \\
\hline & 2 & 5 & 4 & 3 & 0 & & & 5 & 6 & 0 & 0 \\
\hline & & 6 & 1 & 3 & 0 & & 2 & 6 & 6 & 0 & 0 \\
\hline & & 7 & 3 & 10 & 0 & & & 7 & 20 & 0 & 0 \\
\hline & 3 & 8 & 4 & 13 & 1 & & & 8 & 2 & 4 & 0 \\
\hline & & 9 & 2 & 6 & 0 & & & 9 & 7 & 0 & 0 \\
\hline & & 10 & 1 & 3 & 0 & & & 10 & 8 & 0 & 0 \\
\hline & & 11 & 3 & 7 & 1 & & 3 & 11 & 9 & 0 & 0 \\
\hline & & 12 & 4 & 8 & 0 & & & 12 & 7 & 0 & 0 \\
\hline & & 13 & 4 & 4 & 0 & & & 13 & 8 & 4 & 0 \\
\hline 7 & 1 & 1 & 7 & 20 & 1 & & & 14 & 10 & 0 & 0 \\
\hline & & 2 & 18 & 24 & 0 & & & 15 & 9 & 0 & 0 \\
\hline & & 3 & 4 & 1 & 0 & & & 16 & 8 & 0 & 0 \\
\hline & & 4 & 3 & 1 & 1 & & & 17 & 13 & 0 & 0 \\
\hline & & 5 & 6 & 4 & 0 & & 4 & 18 & 4 & 9 & 0 \\
\hline & & 6 & 11 & 6 & 0 & & & 19 & 5 & 8 & 0 \\
\hline & & 7 & 16 & 3 & 1 & & & 20 & 8 & 0 & 0 \\
\hline & & 8 & 8 & 2 & 0 & & & 21 & 7 & 0 & 0 \\
\hline & 2 & 9 & 25 & 25 & 0 & & & 22 & 2 & 5 & 0 \\
\hline & & 10 & 6 & 0 & 0 & & & 23 & 10 & 0 & 0 \\
\hline & & 11 & 8 & 4 & 0 & & & 24 & 9 & 2 & 0 \\
\hline & & 12 & 16 & 3 & 0 & & & 25 & 11 & 3 & 0 \\
\hline & 3 & 13 & 9 & 7 & 0 & & 5 & 26 & 16 & 0 & 0 \\
\hline & & 14 & 7 & 2 & 0 & & & 27 & 5 & 0 & 0 \\
\hline & & 15 & 5 & 3 & 0 & & & 28 & 3 & 3 & 0 \\
\hline & & 16 & 4 & 6 & 0 & & & 29 & 9 & 0 & 0 \\
\hline & & 17 & 5 & 8 & 0 & & & & & & \\
\hline & & 18 & 4 & 0 & 0 & & & & & & \\
\hline & & 19 & 4 & 2 & 0 & & & & & & \\
\hline & & 20 & 10 & 9 & 2 & & & & & & \\
\hline & & 21 & 14 & 8 & 0 & & & & & & \\
\hline & & 22 & 20 & 18 & 0 & & & & & & \\
\hline & 4 & 23 & 12 & 4 & 0 & & & & & & \\
\hline & & 24 & 6 & 6 & 0 & & & & & & \\
\hline & & 25 & 23 & 2 & 0 & & & & & & \\
\hline & & 26 & 12 & 0 & 0 & & & & & & \\
\hline & & 27 & 16 & 0 & 0 & & & & & & \\
\hline & & 28 & 3 & 6 & 0 & & & & & & \\
\hline & & 29 & 5 & 3 & 0 & & & & & & \\
\hline & & 30 & 8 & 5 & 0 & & & & & & \\
\hline & 5 & 31 & 7 & 3 & 0 & & & & & & \\
\hline
\end{tabular}


Table 3. Fungal cells exposed to tetracycline which contained moving bodies. Bottle \#9 was not inoculated with fungal spores as a control for this series.

\begin{tabular}{|c|c|c|c|c|c|c|c|c|c|c|c|}
\hline \multicolumn{12}{|c|}{ Tetracyclin } \\
\hline \multirow[b]{2}{*}{ Bottle \# } & \multirow[b]{2}{*}{ Field } & \multirow[b]{2}{*}{ Hyphae } & \multicolumn{3}{|c|}{$\begin{array}{l}\text { \# of cells with } \\
\text { moving bodies }\end{array}$} & \multirow[b]{2}{*}{ Bottle \# } & \multirow[b]{2}{*}{ Field } & \multirow[b]{2}{*}{ Hyphae } & \multicolumn{3}{|c|}{$\begin{array}{l}\text { \# of cells with } \\
\text { moving bodies }\end{array}$} \\
\hline & & & 0 & 1 & 2 & & & & 0 & 1 & 2 \\
\hline 10 & 1 & 1 & 5 & 7 & 0 & 12 & 1 & 1 & 3 & 3 & 0 \\
\hline & & 2 & 3 & 4 & 0 & & & 2 & 9 & 4 & 0 \\
\hline & & 3 & 3 & 7 & 1 & & & 3 & 6 & 1 & 0 \\
\hline & & 4 & 3 & 3 & 0 & & & 4 & 7 & 0 & 0 \\
\hline & & 5 & 2 & 5 & 0 & & & 5 & 6 & 17 & 0 \\
\hline & 2 & 6 & 5 & 7 & 0 & & & 6 & 8 & 0 & 0 \\
\hline & & 7 & 3 & 2 & 0 & & & 7 & 11 & 0 & 0 \\
\hline & & 8 & 3 & 8 & 0 & & 2 & 8 & 10 & 6 & 0 \\
\hline & & 9 & 4 & 9 & 0 & & & 9 & 4 & 9 & 0 \\
\hline & 3 & 10 & 2 & 6 & 0 & & & 10 & 7 & 9 & 0 \\
\hline & & 11 & 6 & 7 & 0 & & & 11 & 17 & 10 & 0 \\
\hline & & 12 & 3 & 4 & 0 & & & 12 & 11 & 0 & 0 \\
\hline & 4 & 13 & 4 & 5 & 0 & & & 13 & 27 & 8 & 0 \\
\hline & & 14 & 5 & 3 & 0 & & 3 & 14 & 9 & 0 & 0 \\
\hline & & 15 & 3 & 3 & 2 & & & 15 & 18 & 3 & 0 \\
\hline & & 16 & 4 & 8 & 1 & & & 16 & 6 & 2 & 0 \\
\hline & & 17 & 13 & 8 & 0 & & & 17 & 14 & 0 & 0 \\
\hline & & 18 & 12 & 16 & 0 & & & 18 & 8 & 2 & 0 \\
\hline 11 & 1 & 1 & 6 & 10 & 0 & & 4 & 19 & 9 & 0 & 0 \\
\hline & & 2 & 4 & 2 & 0 & & & 20 & 11 & 0 & 0 \\
\hline & & 3 & 11 & 0 & 0 & & & 21 & 9 & 0 & 0 \\
\hline & & 4 & 9 & 5 & 0 & & & 22 & 7 & 2 & 0 \\
\hline & & 5 & 7 & 12 & 0 & & & 23 & 13 & 3 & 0 \\
\hline & 2 & 6 & 6 & 5 & 0 & & & 24 & 28 & 12 & 0 \\
\hline & 3 & 7 & 6 & 13 & 0 & & & & & & \\
\hline & & 8 & 5 & 9 & 0 & & & & & & \\
\hline & 4 & 9 & 7 & 3 & 0 & & & & & & \\
\hline & & 10 & 6 & 4 & 0 & & & & & & \\
\hline & & 11 & 7 & 4 & 0 & & & & & & \\
\hline & & 12 & 4 & 8 & 0 & & & & & & \\
\hline & & 13 & 9 & 5 & 0 & & & & & & \\
\hline & 5 & 14 & 2 & 3 & 0 & & & & & & \\
\hline & & 15 & 4 & 6 & 0 & & & & & & \\
\hline
\end{tabular}


Table 4. Fungal cells exposed to a mix of tetracycline and tetracycline which contained moving bodies. Bottle \#13 was not inoculated with fungal spores as a control for this series.

\begin{tabular}{|c|c|c|c|c|c|c|c|c|c|c|c|}
\hline \multicolumn{3}{|c|}{ Dual Antibiotics } & & & & \multirow[b]{3}{*}{ Bottle \# } & \multirow[b]{3}{*}{ Field } & \multirow[b]{3}{*}{ Hyphae } & \multirow{2}{*}{\multicolumn{3}{|c|}{$\begin{array}{l}\text { \# of cells with } \\
\text { moving bodies }\end{array}$}} \\
\hline \multirow[b]{2}{*}{ Bottle \# } & \multirow[b]{2}{*}{ Field } & \multirow[b]{2}{*}{ Hyphae } & \multicolumn{3}{|c|}{$\begin{array}{l}\text { \# of cells with } \\
\text { moving bodies }\end{array}$} & & & & & & \\
\hline & & & 0 & 1 & 2 & & & & 0 & 1 & 2 \\
\hline 14 & 1 & 1 & 7 & 4 & 0 & 16 & 1 & 1 & 9 & 0 & 0 \\
\hline & & 2 & 3 & 1 & 0 & & & 2 & 11 & 0 & 0 \\
\hline & & 3 & 10 & 2 & 0 & & & 3 & 6 & 0 & 0 \\
\hline & & 4 & 9 & 0 & 0 & & & 4 & 7 & 0 & 0 \\
\hline & & 5 & 8 & 1 & 0 & & & 5 & 7 & 0 & 0 \\
\hline & & 6 & 13 & 2 & 0 & & & 6 & 11 & 0 & 0 \\
\hline & 2 & 7 & 6 & 3 & 0 & & & 7 & 6 & 0 & 0 \\
\hline & & 8 & 10 & 8 & 0 & & & 8 & 14 & 0 & 0 \\
\hline & & 9 & 5 & 2 & 0 & & 2 & 9 & 4 & 0 & 0 \\
\hline & & 10 & 8 & 5 & 0 & & & 10 & 5 & 0 & 0 \\
\hline & & 11 & 6 & 4 & 0 & & & 11 & 11 & 4 & 0 \\
\hline & & 12 & 4 & 7 & 0 & & & 12 & 8 & 0 & 0 \\
\hline 15 & 1 & 1 & 12 & 0 & 0 & & & 13 & 6 & 3 & 0 \\
\hline & & 2 & 4 & 0 & 0 & & 3 & 14 & 12 & 0 & 0 \\
\hline & & 3 & 6 & 0 & 0 & & & 15 & 9 & 0 & 0 \\
\hline & & 4 & 5 & 0 & 0 & & & 16 & 13 & 0 & 0 \\
\hline & & 5 & 13 & 5 & 0 & & & 17 & 5 & 1 & 0 \\
\hline & 2 & 6 & 7 & 0 & 0 & & 4 & 18 & 7 & 0 & 0 \\
\hline & & 7 & 8 & 0 & 0 & & & 19 & 5 & 0 & 0 \\
\hline & & 8 & 9 & 2 & 0 & & & 20 & 4 & 6 & 0 \\
\hline & & 9 & 4 & 2 & 0 & & & & & & \\
\hline & & 10 & 12 & 0 & 0 & & & & & & \\
\hline & 3 & 11 & 10 & 0 & 0 & & & & & & \\
\hline & & 12 & 6 & 0 & 0 & & & & & & \\
\hline & & 13 & 7 & 0 & 0 & & & & & & \\
\hline & & 14 & 6 & 0 & 0 & & & & & & \\
\hline & & 15 & 8 & 1 & 0 & & & & & & \\
\hline & 4 & 16 & 6 & 0 & 0 & & & & & & \\
\hline & & 17 & 12 & 8 & 0 & & & & & & \\
\hline & & 18 & 11 & 4 & 0 & & & & & & \\
\hline & & 19 & 7 & 0 & 0 & & & & & & \\
\hline & & 20 & 16 & 4 & 0 & & & & & & \\
\hline
\end{tabular}


Appendix C

HPLC and GC Raw Data and Example Data Plot

Table 1. Example of Spreadsheet for Gas Chromatograph results for figure 9. Curve areas were calculated using PeakSimple Version 4.0.

\begin{tabular}{|c|c|c|c|c|c|c|c|c|c|}
\hline \multirow[b]{2}{*}{ Acid } & \multirow{2}{*}{$\begin{array}{c}\text { Standard } \\
\text { Conc. } \\
\text { (mM) }\end{array}$} & \multirow{2}{*}{$\begin{array}{c}\text { Area of } \\
\text { Sample } \\
\text { Curve }\end{array}$} & Day 2 & 5-Aug & \multirow[b]{2}{*}{ Acid } & \multirow{2}{*}{$\begin{array}{l}\text { Standard } \\
\text { Conc. } \\
\text { (mM) }\end{array}$} & \multirow{2}{*}{$\begin{array}{c}\text { Area of } \\
\text { Sample } \\
\text { Curve }\end{array}$} & \multirow{2}{*}{$\begin{array}{c}\text { Day } 15 \\
\begin{array}{c}\text { Area of } \\
\text { Curve }\end{array}\end{array}$} & \multirow{2}{*}{$\begin{array}{l}\text { 18-Aug } \\
\begin{array}{l}\text { Conc. } \\
(\mathrm{mM})\end{array}\end{array}$} \\
\hline & & & Area of Curve & $\begin{array}{l}\text { Conc. } \\
(\mathrm{mM})\end{array}$ & & & & & \\
\hline Propanoic & 134 & 5554.7 & 25.51 & 0.6154 & Propanoic & 134 & 5554.7 & 4.8 & 0.11579383 \\
\hline Butyric & 109 & 9968 & 99.45 & 1.08748 & Butyric & 109 & 9968 & 16.5 & 0.18042737 \\
\hline Isovaleric & 91 & 9885.7 & 10.34 & 0.09518 & Isovaleric & 91 & 9885.7 & 18.5 & 0.17029649 \\
\hline Valeric & 91 & 6819.5 & 0 & 0 & Valeric & 91 & 6819.5 & 5.7 & 0.07606129 \\
\hline Caproic & 79 & 5555.8 & 1.4 & 0.01991 & Caproic & 79 & 5555.8 & 0.5 & 0.00710969 \\
\hline \multirow[b]{2}{*}{ Acid } & \multirow{2}{*}{$\begin{array}{l}\text { Standard } \\
\text { Conc. } \\
\text { (mM) }\end{array}$} & \multirow{2}{*}{$\begin{array}{c}\text { Area of } \\
\text { Sample } \\
\text { Curve }\end{array}$} & Day 8 & 11-Aug & \multirow[b]{2}{*}{ Acid } & \multirow{2}{*}{$\begin{array}{l}\text { Standard } \\
\text { Conc. } \\
\text { (mM) }\end{array}$} & \multirow{2}{*}{$\begin{array}{c}\text { Area of } \\
\text { Sample } \\
\text { Curve }\end{array}$} & Day 22 & 25-Aug \\
\hline & & & Area of Curve & \begin{tabular}{|l|} 
Conc. \\
$(\mathrm{mM})$
\end{tabular} & & & & $\begin{array}{c}\text { Area of } \\
\text { Curve }\end{array}$ & $\begin{array}{l}\text { Conc. } \\
(\mathrm{mM}) \\
\end{array}$ \\
\hline Propanoic & 134 & 5554.7 & 31.05 & 0.74904 & Propanoic & 134 & 5554.7 & 0.71 & 0.01712784 \\
\hline Butyric & 109 & 9968 & 536.97 & 5.87176 & Butyric & 109 & 9968 & 0.00 & 0 \\
\hline Isovaleric & 91 & 9885.7 & 134.83 & 1.24114 & Isovaleric & 91 & 9885.7 & 8.65 & 0.07962512 \\
\hline Valeric & 91 & 6819.5 & 13.37 & 0.17841 & Valeric & 91 & 6819.5 & 7.49 & 0.09994721 \\
\hline Caproic & 79 & 5555.8 & 7.69 & 0.10935 & Caproic & 79 & 5555.8 & 0.00 & 0 \\
\hline \multirow[b]{2}{*}{ Acid } & \multirow{2}{*}{$\begin{array}{l}\text { Standard } \\
\text { Conc. } \\
\text { (mM) }\end{array}$} & \multirow{2}{*}{$\begin{array}{c}\text { Area of } \\
\text { Sample } \\
\text { Curve }\end{array}$} & Day 14 & 17-Aug & \multirow[b]{2}{*}{ Acid } & \multirow{2}{*}{$\begin{array}{l}\text { Standard } \\
\text { Conc. } \\
\text { (mM) }\end{array}$} & \multirow{2}{*}{$\begin{array}{c}\text { Area of } \\
\text { Sample } \\
\text { Curve }\end{array}$} & Day 27 & 30-Aug \\
\hline & & & Area of Curve & $\begin{array}{l}\text { Conc. } \\
(\mathrm{mM})\end{array}$ & & & & $\begin{array}{c}\text { Area of } \\
\text { Curve }\end{array}$ & $\begin{array}{l}\text { Conc. } \\
(\mathrm{mM})\end{array}$ \\
\hline Propanoic & 134 & 5554.7 & 3.65 & 0.08805 & Propanoic & 134 & 5554.7 & 0 & 0 \\
\hline Butyric & 109 & 9968 & 40.27 & 0.44035 & Butyric & 109 & 9968 & 0 & 0 \\
\hline Isovaleric & 91 & 9885.7 & 18.85 & 0.17352 & Isovaleric & 91 & 9885.7 & 4.36 & 0.04013474 \\
\hline Valeric & 91 & 6819.5 & 0 & 0 & Valeric & 91 & 6819.5 & 0 & 0 \\
\hline Caproic & 79 & 5555.8 & 3.07 & 0.04365 & Caproic & 79 & 5555.8 & 0 & 0 \\
\hline
\end{tabular}


Table 2. HPLC raw sample data results for figure 8 from Peak Simple Version 4.0.

\begin{tabular}{|c|c|c|c|c|c|c|c|}
\hline \multicolumn{8}{|c|}{ 11-Aug } \\
\hline Bottle 1 & & & & Bottle 2 & & & \\
\hline Component & Retention & Area & Height & Component & Retention & Area & Height \\
\hline Unbound & 4.84 & 10.7512 & 0.227 & Unbound & 4.84 & $\quad 17.16$ & 0.785 \\
\hline Oxylate & 6.073 & 4.89 & 0.089 & Oxylate & 0 & 0 & 0 \\
\hline Citrate & 7.066 & 1.954 & 0.053 & Citrate & 0 & 0 & 0 \\
\hline Tartrate & 0 & 0 & 0 & Tartrate & 0 & 0 & 0 \\
\hline Pyruvate & 0 & 0 & 0 & Pyruvate & 0 & 0 & 0 \\
\hline Succinate 1 & 0 & 0 & 0 & Succinate 1 & 10.87 & 1.3188 & 0.009 \\
\hline Lactate & 0 & 0 & 0 & Lactate & 0 & 0 & 0 \\
\hline Acetate & 13.016 & 3.2622 & 0.058 & Acetate & 12.9 & 7.8692 & 0.342 \\
\hline Butyric Acid & 0 & 0 & 0 & Butyric Acid & 0 & 0 & 0 \\
\hline Isovaleric Acid 1 & 22.976 & 1.0936 & 0.031 & Isovaleric Acid 1 & 0 & 0 & 0 \\
\hline Valeric Acid & 0 & 0 & 0 & Valeric Acid & 0 & 0 & 0 \\
\hline \multicolumn{8}{|c|}{ 17-Aug } \\
\hline Bottle 1 & & & & Bottle 2 & & & \\
\hline Component & Retention & Area & Height & Component & Retention & Area & Height \\
\hline Unbound & 4.873 & 30.2874 & 1.032 & Unbound & 4.92 & 5.806 & 0.166 \\
\hline Oxylate & 6.203 & 13.9462 & 0.242 & Oxylate & 0 & 0 & 0 \\
\hline Citrate & 0 & 0 & 0 & Citrate & 0 & 0 & 0 \\
\hline Tartrate & 7.596 & 1.5361 & 0.062 & Tartrate & 7.21 & 1.4093 & 0.047 \\
\hline Pyruvate & 8.043 & 1.2372 & 0.051 & Pyruvate & 0 & 0 & 0 \\
\hline Succinate 1 & 0 & 0 & 0 & Succinate 1 & 0 & 0 & 0 \\
\hline Lactate & 0 & 0 & 0 & Lactate & 11.133 & 37.2099 & 0.529 \\
\hline Acetate & 13.54 & 1.804 & 0.048 & Acetate & 12.976 & 37.5238 & 0.544 \\
\hline Butyric Acid & 0 & 0 & 0 & Butyric Acid & 19.463 & 22.1535 & 0.33 \\
\hline Isovaleric Acid 1 & 22.993 & 5.6684 & 0.147 & Isovaleric Acid 1 & 22.513 & 16.9264 & 0.243 \\
\hline Valeric Acid & 28.29 & 2.1964 & 0.048 & Valeric Acid & 28.3 & 1.8212 & 0.033 \\
\hline \multicolumn{8}{|l|}{ 25-Aug } \\
\hline Bottle 1 & & & & Bottle 2 & & & \\
\hline Component & Retention & Area & Height & Component & Retention & Area & Height \\
\hline Unbound & 4.796 & 23.7675 & 1.29 & Unbound & 4.683 & 1.0692 & 0.127 \\
\hline Oxylate & 6.13 & 5.4231 & 0.173 & Unbound & 5.073 & 2.9438 & 0.112 \\
\hline Citrate & 0 & 0 & 0 & Oxylate & 6 & 7.8392 & 0.265 \\
\hline Tartrate & 0 & 0 & 0 & Citrate & 0 & 0 & 0 \\
\hline Pyruvate & 0 & 0 & 0 & Tartrate & 0 & 0 & 0 \\
\hline Succinate 1 & 0 & 0 & 0 & Pyruvate & 7.81 & 1.493 & 0.074 \\
\hline Lactate & 0 & 0 & 0 & Succinate 1 & 0 & 0 & 0 \\
\hline Acetate & 13.59 & 2.2768 & 0.061 & Lactate & 11.866 & 21.0072 & 0.89 \\
\hline Butyric Acid & 0 & 0 & 0 & Acetate & 13.626 & 2.5527 & 0.049 \\
\hline Isovaleric Acid 1 & 0 & 0 & 0 & Butyric Acid & 0 & 0 & 0 \\
\hline \multirow[t]{2}{*}{ Valeric Acid } & 0 & 0 & 0 & Isovaleric Acid 1 & 0 & 0 & 0 \\
\hline & & & & Valeric Acid & 0 & 0 & 0 \\
\hline \multicolumn{8}{|c|}{ 30-Aug } \\
\hline Bottle 1 & & & & Botle 2 & & & \\
\hline Component & Retention & Area & Height & Component & Retention & Area & Height \\
\hline Unbound & 4.646 & 5.665 & 0.609 & Unbound & 4.58 & 3.1476 & 0.281 \\
\hline Unbound & 5 & 4.3968 & 0.114 & Unbound & 4.81 & 11.0146 & 0.243 \\
\hline Oxylate & 5.893 & 3.768 & 0.098 & Oxylate & 5.93 & 7.382 & 0.175 \\
\hline Citrate & 0 & 0 & 0 & Citrate & 6.933 & 2.5164 & 0.167 \\
\hline Tartrate & 7.446 & 1.8336 & 0.069 & Citrate & 7.166 & 2.6406 & 0.163 \\
\hline Pyruvate & 0 & 0 & 0 & Tartrate & 7.406 & 1.9704 & 0.163 \\
\hline Succinate 1 & 10.483 & 1.752 & 0.053 & Pyruvate & 8.05 & 3.8618 & 0.171 \\
\hline Lactate & 11.81 & 1.7455 & 0.049 & Succinate 1 & 10.563 & 1.2604 & 0.158 \\
\hline Acetate & 0 & 0 & 0 & Lactate & 11.793 & 3.6688 & 0.152 \\
\hline Butyric Acid & 0 & 0 & 0 & Acetate & 13.51 & 11.4564 & 0.199 \\
\hline Isovaleric Acid 1 & 0 & 0 & 0 & Butyric Acid & 19.356 & 7.3172 & 0.148 \\
\hline \multirow[t]{2}{*}{ Valeric Acid } & 0 & 0 & 0 & Isovaleric Acid 1 & 22.173 & 9.3974 & 0.139 \\
\hline & & & & Valeric Acid & 27.863 & 1.136 & 0.04 \\
\hline
\end{tabular}


Table 3.GC raw sample data results for figure 9 from Peak Simple Version 4.0.

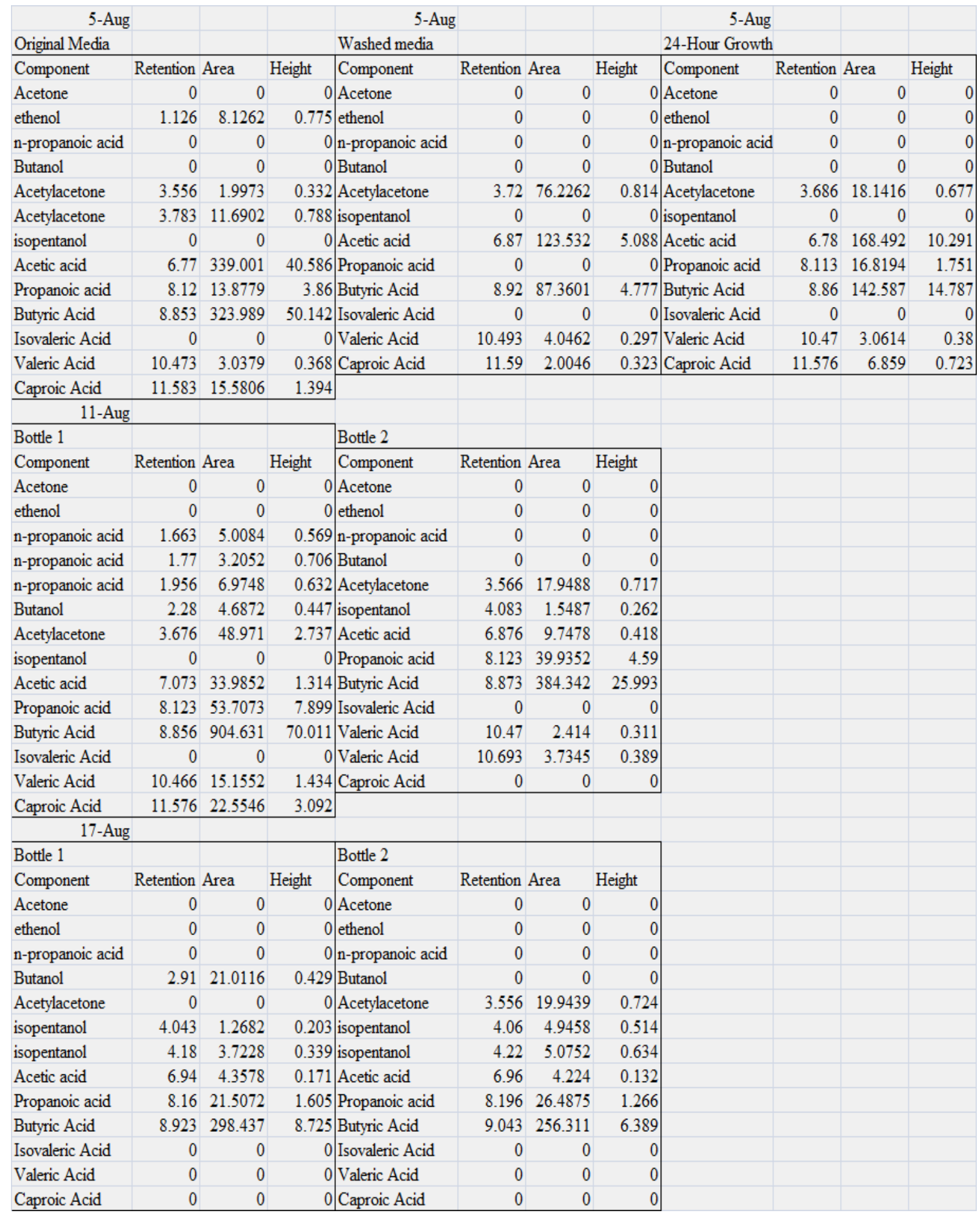


Table 3 con't

\begin{tabular}{|c|c|c|c|c|c|c|c|}
\hline \multicolumn{8}{|l|}{ 18-Aug } \\
\hline Bottle 1 & & & & Bottle 2 & & & \\
\hline Component & Retention & Area & Height & Component & Retention & Area & Height \\
\hline Acetone & 0 & 0 & 0 & Acetone & 0 & 0 & 0 \\
\hline ethenol & 0 & 0 & 0 & ethenol & 0 & 0 & 0 \\
\hline n-propanoic acid & 0 & 0 & 0 & n-propanoic acid & 0 & 0 & 0 \\
\hline Butanol & 2.576 & 8.4322 & 0.382 & Butanol & 2.31 & 1.6096 & 0.143 \\
\hline Butanol & 2.896 & 3.6386 & 0.312 & Butanol & 2.563 & 3.4456 & 0.325 \\
\hline Acetylacetone & 0 & 0 & 0 & Butanol & 2.896 & 5.9538 & 0.35 \\
\hline isopentanol & 0 & 0 & 0 & Acetylacetone & 0 & 0 & 0 \\
\hline Acetic acid & 0 & 0 & 0 & isopentanol & 0 & 0 & 0 \\
\hline Propanoic acid & 0 & 0 & 0 & Acetic acid & 7.076 & 4.9944 & 0.205 \\
\hline Butyric Acid & 9.19 & 28.6304 & 0.824 & Propanoic acid & 7.95 & 5.3434 & 0.441 \\
\hline Isovaleric Acid & 0 & 0 & 0 & Butyric Acid & 9.05 & 63.4566 & 2.31 \\
\hline Valeric Acid & 0 & 0 & 0 & Isovaleric Acid & 0 & 0 & 0 \\
\hline \multirow[t]{2}{*}{ Caproic Acid } & 0 & 0 & 0 & Valeric Acid & 0 & 0 & 0 \\
\hline & & & & Caproic Acid & 0 & 0 & 0 \\
\hline \multicolumn{8}{|l|}{ 25-Aug } \\
\hline Bottle 1 & & & & Bottle 2 & & & \\
\hline Component & Retention & Area & Height & Component & Retention & Area & Height \\
\hline Acetone & 0 & 0 & 0 & Acetone & 0 & 0 & 0 \\
\hline ethenol & 0 & 0 & 0 & ethenol & 0 & 0 & 0 \\
\hline n-propanoic acid & 0 & 0 & 0 & n-propanoic acid & 0 & 0 & 0 \\
\hline Butanol & 2.223 & 1.017 & 0.116 & Butanol & 2.166 & 39.4574 & 0.309 \\
\hline Butanol & 2.913 & 13.5255 & 0.669 & Acetylacetone & 0 & 0 & 0 \\
\hline Acetylacetone & 0 & 0 & 0 & isopentanol & 0 & 0 & 0 \\
\hline isopentanol & 3.91 & 3.1002 & 0.253 & Acetic acid & 0 & 0 & 0 \\
\hline isopentanol & 4.04 & 2.084 & 0.261 & Propanoic acid & 0 & 0 & 0 \\
\hline isopentanol & 4.176 & 5.2654 & 0.243 & Butyric Acid & 0 & 0 & 0 \\
\hline Acetic acid & 0 & 0 & 0 & Isovaleric Acid & 9.466 & 1.1498 & 0.124 \\
\hline Propanoic acid & 0 & 0 & 0 & Valeric Acid & 0 & 0 & 0 \\
\hline Butyric Acid & 0 & 0 & 0 & Caproic Acid & 0 & 0 & 0 \\
\hline Isovaleric Acid & 0 & 0 & 0 & & & & \\
\hline Valeric Acid & 0 & 0 & 0 & & & & \\
\hline Caproic Acid & 11.586 & 2.7049 & 0.204 & & & & \\
\hline \multicolumn{8}{|l|}{ 30-Aug } \\
\hline Bottle 1 & & & & Bottle 2 & & & \\
\hline Component & Retention & Area & Height & Component & Retention & Area & Height \\
\hline Acetone & 0 & 0 & 0 & Acetone & 0 & 0 & 0 \\
\hline ethenol & 0 & 0 & 0 & ethenol & 0 & 0 & 0 \\
\hline n-propanoic acid & 0 & 0 & 0 & n-propanoic acid & 0 & 0 & 0 \\
\hline Butanol & 2.346 & 57.8514 & 0.457 & Butanol & 2.52 & 6.1005 & 0.316 \\
\hline Acetylacetone & 0 & 0 & 0 & Butanol & 2.893 & 4.5072 & 0.299 \\
\hline isopentanol & 0 & 0 & 0 & Acetylacetone & 0 & 0 & 0 \\
\hline Acetic acid & 0 & 0 & 0 & isopentanol & 0 & 0 & 0 \\
\hline Propanoic acid & 0 & 0 & 0 & Acetic acid & 0 & 0 & 0 \\
\hline Butyric Acid & 0 & 0 & 0 & Propanoic acid & 0 & 0 & 0 \\
\hline Isovaleric Acid & 9.513 & 8.8971 & 0.196 & Butyric Acid & 0 & 0 & 0 \\
\hline Valeric Acid & 0 & 0 & 0 & Isovaleric Acid & 0 & 0 & 0 \\
\hline \multirow[t]{3}{*}{ Caproic Acid } & 0 & 0 & 0 & Valeric Acid & 10.546 & 2.5879 & 0.153 \\
\hline & & & & Valeric Acid & 10.713 & 3.7673 & 0.114 \\
\hline & & & & Caproic Acid & 0 & 0 & 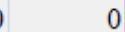 \\
\hline
\end{tabular}


Table 4. GC raw sample data results for figure 10 from Peak Simple Version 4.0.

\begin{tabular}{|c|c|c|c|c|c|c|c|c|c|c|c|}
\hline \multicolumn{12}{|c|}{ 10-Nov Cultures without antibiotics } \\
\hline Bottle 1 & & & & Bottle 2 & & & & Bottle 3 & & & \\
\hline Component & Retention & Area & Height & Component & Retention & Area & Height & Component & Retention & Area & Height \\
\hline Acetone & 0 & 0 & 0 & Acetone & 0 & 0 & 0 & Acetone & 0 & 0 & 0 \\
\hline ethenol & 0 & 0 & 0 & ethenol & 0 & 0 & 0 & ethenol & 0 & 0 & 0 \\
\hline n-propanoic acid & 0 & 0 & 0 & n-propanoic acid & 1.893 & 2.7109 & 0.392 & n-propanoic acid & 0 & 0 & 0 \\
\hline Butanol & 2.29 & 2.2769 & 0.506 & Butanol & 2.263 & 3.7324 & 0.463 & Butanol & 2.25 & 1.0973 & 0.147 \\
\hline Acetic acid & 6.986 & 4.6698 & 0.244 & Acetic acid & 0 & 0 & 0 & Acetic acid & 6.74 & 1.2 & 0.093 \\
\hline Propanoic acid & 8.18 & 12.2692 & 1.219 & Propanoic acid & 0 & 0 & 0 & Propanoic acid & 0 & 0 & 0 \\
\hline Butyric Acid & 8.943 & 156.996 & 5.841 & Butyric Acid & 0 & 0 & 0 & Butyric Acid & 0 & 0 & 0 \\
\hline Isovaleric Acid & 0 & 0 & 0 & Isovaleric Acid & 0 & 0 & 0 & Isovaleric Acid & 0 & 0 & 0 \\
\hline Valeric Acid & 0 & 0 & 0 & Valeric Acid & 0 & 0 & 0 & Valeric Acid & 0 & 0 & 0 \\
\hline
\end{tabular}

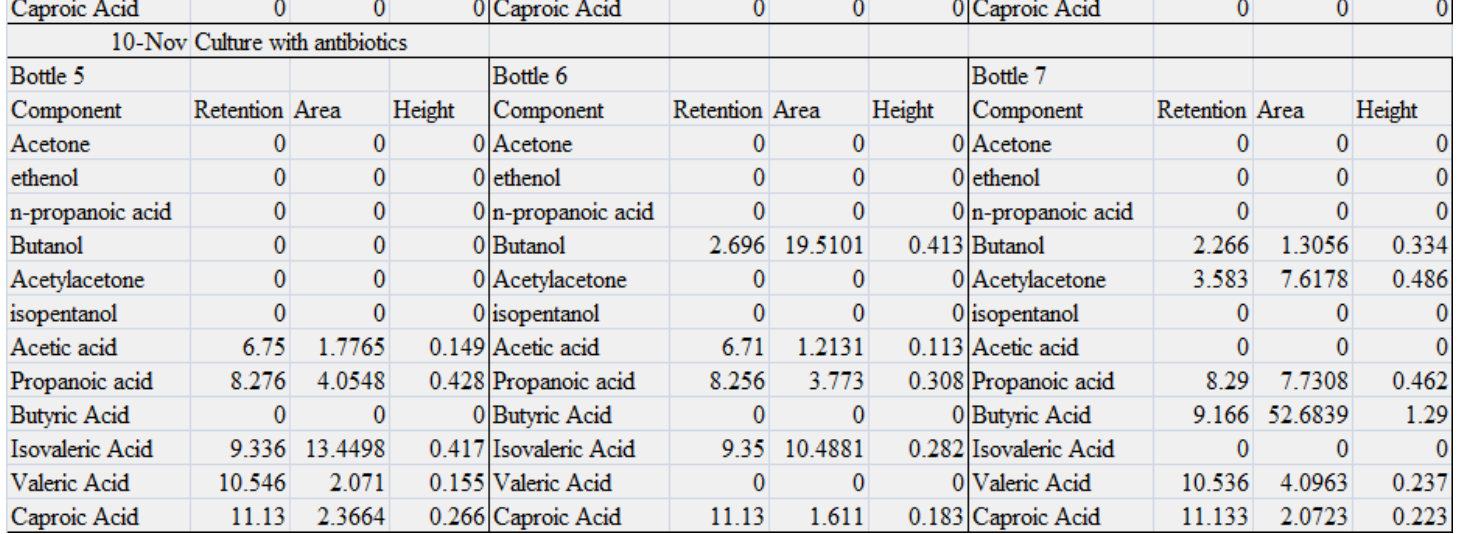


Figure 1. Example of data analysis from Peaksimple 4.0. Red line is the standards of known concentration which were measured in two separate runs at the start of each day. The data from the standards was merged using PeakSimple and the area of the peaks used to calculate the equation for deterining the concentrations from the samples. The peaks are designated in red text above the bars that indicate where the peaks lie. The black line is the sample run, green circles and labels showing the established component are inserted by PeakSimple. The area of thepeaks in the sample runs were then used to claculate the concentration of the components in the sample. See table 1 as an example.

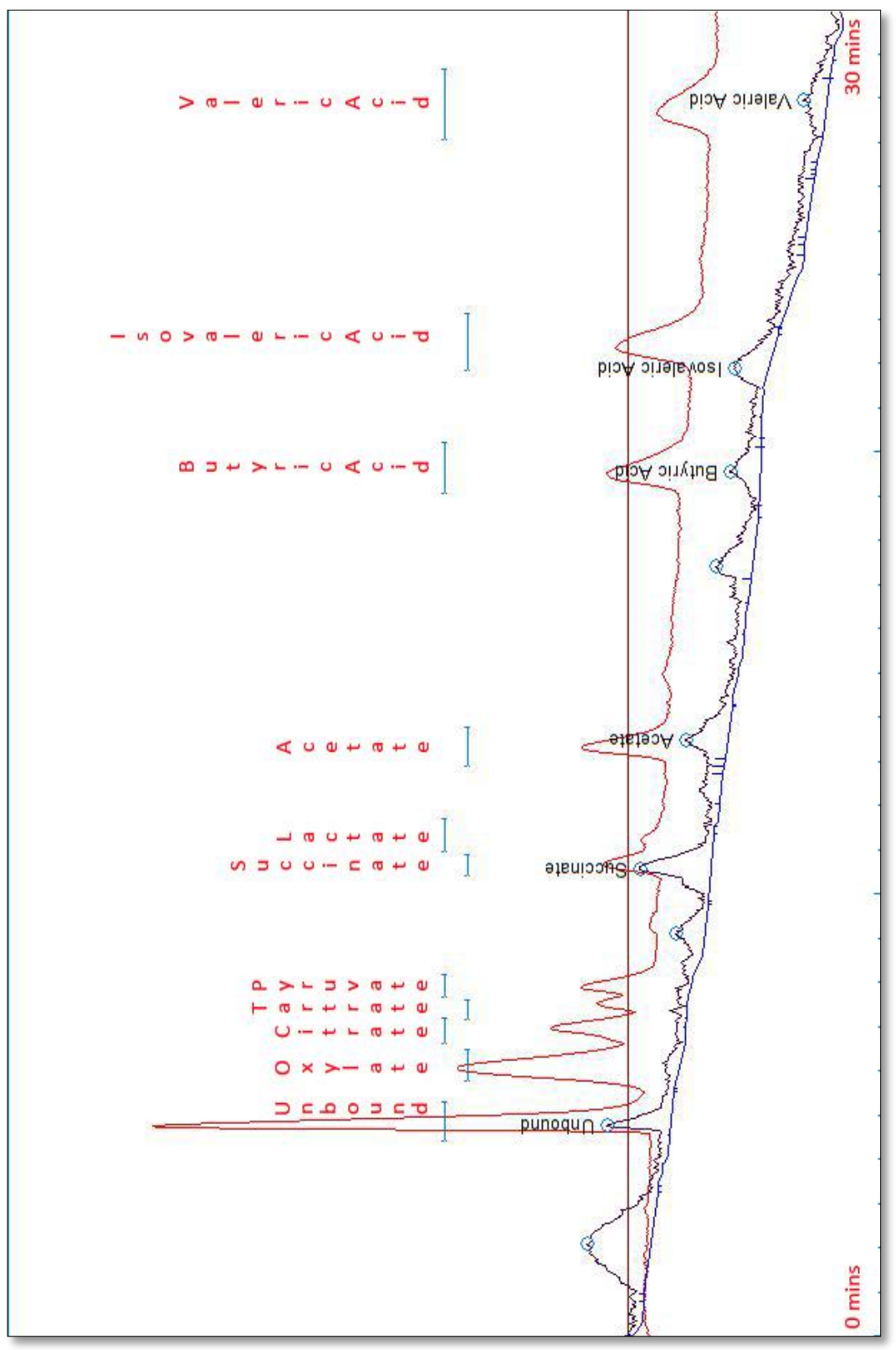




\section{Appendix D \\ Phospholipid Phosphate Spectrophotometer Data}

Readings of phospholipid phosphate in Ver01 growth with $\mathrm{Fe}(\mathrm{II})$ or $\mathrm{Fe}(\mathrm{III})$ in minimal nutrient acidic liquid media

Table 1. Readings from triplicate inorganic phosphate standards analyzed on the BioTek Spectrophotometer.

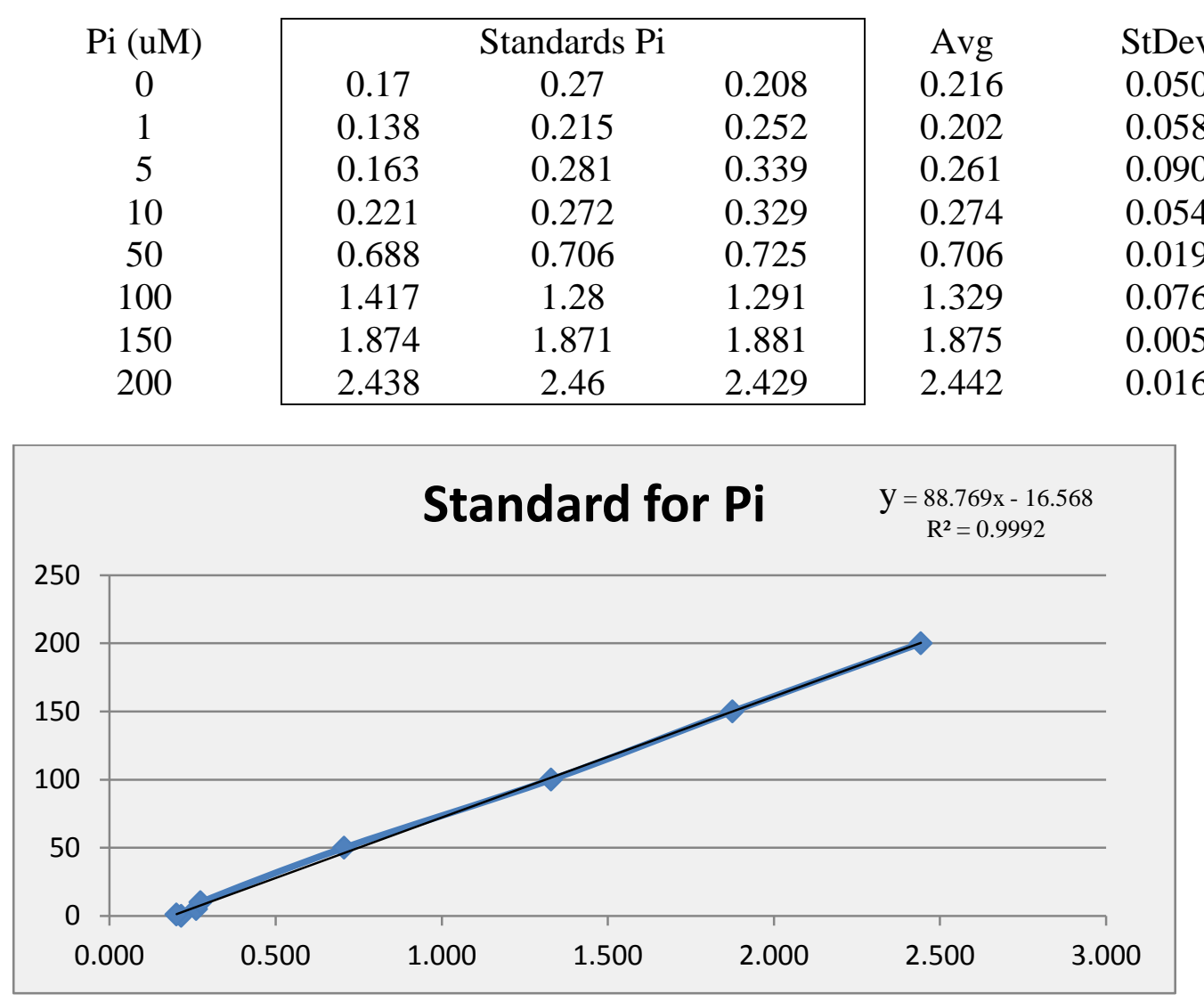

Figure 1. Graph of averages from table 1. The equation of the line $y=88.769 x-16.568$ was used to calculate the concentration of phospholipid phosphate present in the samples analyzed in table 2 . 


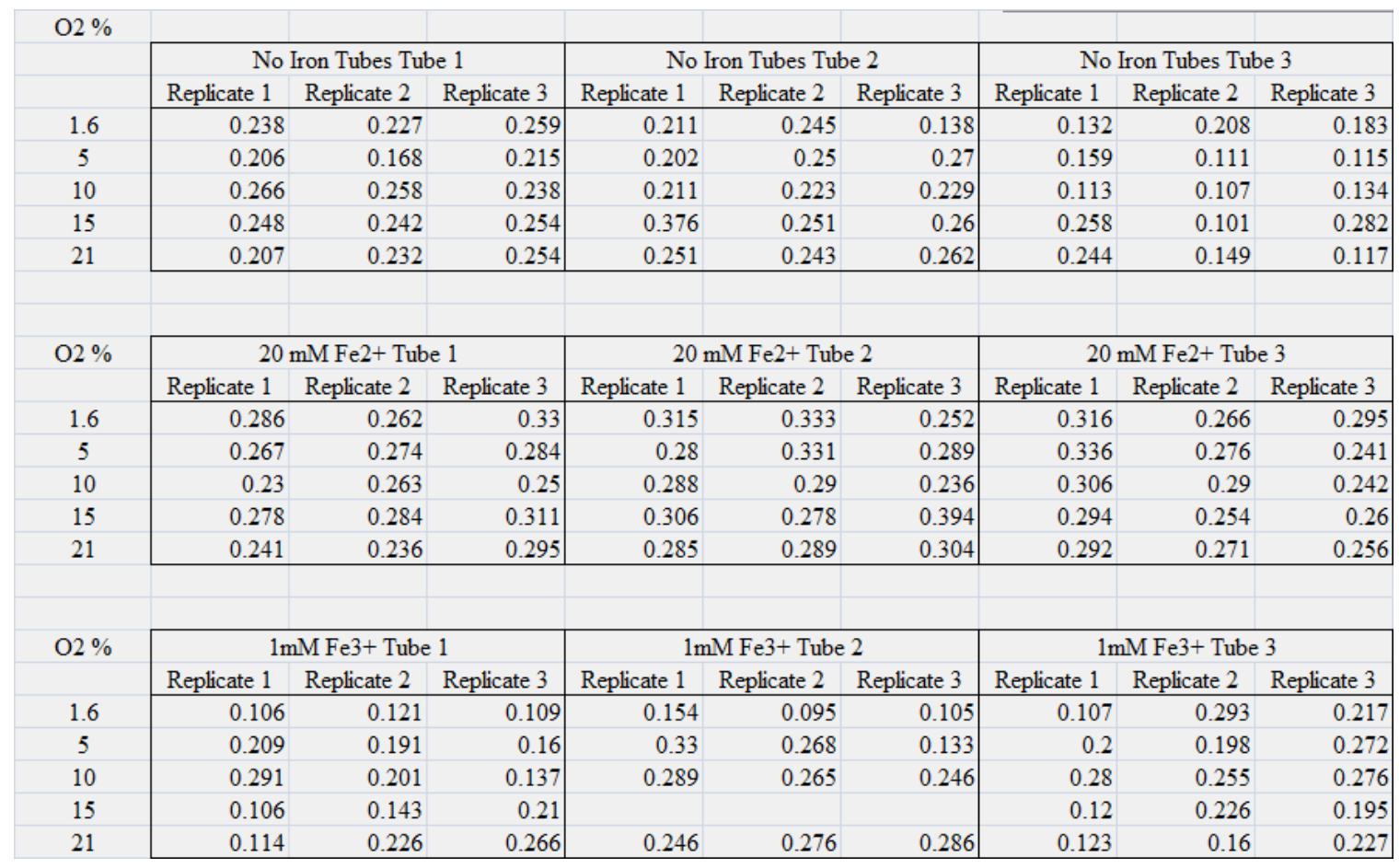

Table 2. Readings from phospholipid phosphate analyses. Each series had three tubes which were analyzed in triplicate. $15 \% \mathrm{O}_{2} \mathrm{Fe} 3+$ series tube 2 was not read due to spillage during sample preparation.

To calculate the amount of inorganic phosphate in each sample the equation from the standard line was applied to each reading. Readings that calculated to be below a zero value were assigned a zero value and the readings averaged between replicates and tubes. Standard deviations were calculated both by replicate set as well as between tube sets. The larger standard deviation (tube sets) was used for graphing. 